Illinois State University

ISU ReD: Research and eData

Theses and Dissertations

3-1-2016

\title{
Trio-Eligible Students And Study Abroad: Influential Factors, Barriers, And Benefits
}

Michael R. Minton

Illinois State University, mrminto@ilstu.edu

Follow this and additional works at: https://ir.library.illinoisstate.edu/etd

Part of the Higher Education Administration Commons

\section{Recommended Citation}

Minton, Michael R., "Trio-Eligible Students And Study Abroad: Influential Factors, Barriers, And Benefits" (2016). Theses and Dissertations. 531.

https://ir.library.illinoisstate.edu/etd/531

This Dissertation is brought to you for free and open access by ISU ReD: Research and eData. It has been accepted for inclusion in Theses and Dissertations by an authorized administrator of ISU ReD: Research and eData. For more information, please contact ISUReD@ilstu.edu. 


\title{
TRIO-ELIGIBLE STUDENTS AND STUDY ABROAD: INFLUENTIAL
}

FACTORS, BARRIERS, AND BENEFITS

\author{
Michael R. Minton
}

\section{Pages}

Despite the fact that only $1.8 \%$ of U.S. undergraduate students choose to participate in a study abroad program, the popularity of study abroad has grown significantly in recent years (Open Doors, 2013). Participation in study abroad programs has grown by over 97\% since 2000, and has increased every year since 2008-09 (Open Doors, 2013). Many institutions recognize the importance of this educational activity in preparing their students to be productive citizens in an ever-growing global economy and society.

While the number of U.S. undergraduate students participating in study abroad has continued to increase overall, it is important to note that these data trends do not remain the same when disaggregated. For instance, the number of underrepresented students, especially first-generation and low income, participating in study abroad programs has remained low.

While attention has been drawn to this population, especially by offering U.S. Department of State Benjamin A. Gilman International Scholarship Program scholarships and travel stipends to Pell Grant recipients who desire to study abroad, more research is 
required. Since the annual Open Doors Survey, the main instrument used to gather data on study abroad programs, does not allow for differentiation of socioeconomic or firstgeneration status of individuals participating in study abroad, a better sense of the trends in study abroad program involvement among underrepresented students needs to be obtained. In addition, no data are gathered on the benefits or barriers that influence study abroad decision making among underrepresented groups.

For these reasons, a transformative, mixed-methods approach was used to identify the influential factors, barriers, and benefits that influenced first-generation and lowincome students to participate in study abroad programs. This study focused on TRiOeligible students who chose to study abroad and were enrolled at a Midwestern institution in the United States. To be eligible for a federal TRiO program, a student can qualify as first-generation, low-income, or disabled (as defined by the American Disabilities Act); however, for the purposes of this study, only first-generation and low-income students were included. The disability status of an individual was intentionally excluded to minimize potential violations of the strict regulations of confidentiality that accompany the recording of disability status of an individual.

This study built upon three previous studies that examined the decision of individuals to decide to participate in study abroad programs: Booker's (2001) DecisionMaking Process for Applying or Not Applying to Study Abroad Model, Peterson's (2003) Decision to Study Abroad Model, and Kasravi’s (2009) Adapted Model of Decision to Study Abroad for students of color in study abroad programs. The framework and survey instrument utilized for this study were based upon these models to determine the personal, social, and institutional factors influencing TRiO-eligible 
students who decided to study abroad, the barriers students faced in making their decision to study abroad, and how they benefited from their participation in a study abroad program.

The findings gleaned from analyzing 208 complete surveys, one focus group interview, and four individual interviews, suggest that all three factors (personal, social, institutional) played a role. Institutional factors were most influential when it came to the decision of TRiO-eligible students to participate in study abroad. These findings demonstrate that institutional investment into factors such as funding, awareness, and support for first-generation students and Pell Grant recipients are effective in influencing these students to study abroad, answering the Institute for International Education's call to diversify the study abroad population through the Generation Study Abroad initiative. The study provides practical implications for improving data collection of demographic variables, such as socioeconomic status and generational status in college, in order to gauge the participation level of TRiO-eligible students in study abroad at the institutional level, as well as recommendations for future research.

KEY WORDS: First-Generation, Low-Income, Pell Grant, Study Abroad, TRiO-Eligible Students, TRiO Programs 
TRIO-ELIGIBLE STUDENTS AND STUDY ABROAD: INFLUENTIAL

FACTORS, BARRIERS, AND BENEFITS

MICHAEL R. MINTON

A Dissertation Submitted in Partial

Fulfillment of the Requirements

for the Degree of

DOCTOR OF PHILOSOPHY

Department of Educational Administration and Foundations

ILLINOIS STATE UNIVERSITY

2016 
Copyright 2016 Michael R. Minton 


\section{TRIO-ELIGIBLE STUDENTS AND STUDY ABROAD: INFLUENTIAL}

FACTORS, BARRIERS, AND BENEFITS

MICHAEL R. MINTON

COMMITTEE MEMBERS:

Mohamed Nur-Awaleh, Chair

Lydia Kyei-Blankson

Phyllis McCluskey-Titus

Dianne Renn 


\section{ACKNOWLEDGMENTS}

First and foremost, I want to thank my wife Brittney, who encouraged me to enroll in the doctoral program, believed in me, and supported me along the way. To our children Caty, Aubrey, and Reid who all wanted daddy to finish. I will never forget the times that each of you wanted to help me type during those early morning sessions. I would like to thank my parents for all their encouragement and support to complete this program.

I would like to thank my committee chair Dr. Mohamed Nur-Awaleh for his belief in me, my topic, and his encouragement to keep building on it during my time in the program. I would like to acknowledge Dr. Lydia Kyei-Blankson as the best methodologist a doctoral student could ask for. Thank you for your suggestions, timely feedback, and encouragement through this entire process. I would like to thank my committee members Dr. Phyllis McCluskey-Titus and Dr. Dianne Renn for their support and validation that this was a meaningful study. I would also like to acknowledge Dr. Wendy Troxel for her coaching and guidance early in my program. I would like to thank Dr. Amelia Noel-Elkins and Dr. Dan Elkins for their mentoring, guidance, and support through this entire process.

I would like to thank my doctoral classmates and colleagues. Our cohort was an experiment, and I know I truly benefited from the format and from the support of my classmates. A very special thank you is deserved to Rosa and Brian. Thank you both for helping me make this study a reality. I cannot thank you two enough for your support of 
this study. To the many work colleagues from the University of Southern Indiana and Illinois State University who encouraged me along the way, I am grateful. Thank you to the many TRiO students and alums who have been such a privilege to work with and who were the inspiration for this study.

M. R. M. 


\section{CONTENTS}

\section{Page}

ACKNOWLEDGMENTS

CONTENTS

iii

TABLES

vii

\section{CHAPTER}

I. INTRODUCTION TO THE STUDY 1

Overview and Statement of the Problem 1

Purpose and Scope of the Study 6

Research Questions $\quad 8$

Theoretical Framework $\quad 11$

Significance of the Study $\quad 12$

Definitions $\quad 13$

Organization of the Study $\quad 15$

Summary 16

II. LITERATURE REVIEW 17

$\begin{array}{ll}\text { Introduction and Organization } & 17\end{array}$

Historical Overview of Study Abroad $\quad 18$

Ancient Beginnings $\quad 19$

Early European Influences $\quad 20$

Colonial and Early America $\quad 21$

$19^{\text {th }}$ Century America $\quad 22$

Early $20^{\text {th }}$ Century America and the First U.S.

Study Abroad Program 24

Impact of WWII on Study Abroad 26

Role of the Federal Government, 1948-Present 27

The 1960's federal involvement in study abroad 31

Federal role in study abroad since the 1990s 32 
Critics of U.S. Study Abroad Through Historical and

Contemporary Anti-Neoliberal Lenses

Current Relevance of Study Abroad Programs

Overview of the Lincoln Commission

Growth of Study Abroad Examined Through a

Review of Open Doors Data

Characteristics of Study Abroad Programs

Curriculum Integration

Outcomes and Benefits of Study Abroad

Academic Value of Study Abroad

Students' Decision Process to Study Abroad 46

Barriers to Study Abroad 49

Overview of Students Underrepresented in U.S. Study Abroad 50

Males

Students of Color

Students with Disabilities

TRiO-Eligible: First-Generation and Low-Income Students

Summary

\section{METHODOLOGY AND PROCEDURES}

Research Design

Participants and Study Setting

Instrumentation

Pilot Testing

Qualitative Methods

Study Procedures

Quantitative Phase 
$\begin{array}{ll}\text { Participant Descriptions } & 75\end{array}$

$\begin{array}{ll}\text { Quantitative Phase } & 75\end{array}$

Individual Interview and Focus Group Participants' Profiles 80

Presentation of Findings by Research Question $\quad 82$

Research Question $1 \quad 82$

$\begin{array}{ll}\text { Social factors } & 83\end{array}$

Peer social factors $\quad 85$

Family social influence $\quad 86$

Social influence of professors and campus staff $\quad 87$

Institutional factors $\quad 89$

Personal factors $\quad 95$

$\begin{array}{ll}\text { Perceived outcomes } & 98\end{array}$

$\begin{array}{ll}\text { Research Question } 2 & 101\end{array}$

A comparison of institutional, personal, and social factors

Benefits obtained from participating in study abroad programs

Adaptability and flexibility $\quad 110$

Cultural knowledge and competence 111

Problem solving 113

Independence 114

Learning about self and their comfort zone $\quad 115$

An experience of a lifetime $\quad 116$

$\begin{array}{ll}\text { Course content } & 117\end{array}$

$\begin{array}{ll}\text { Summary of Findings } & 118\end{array}$

V. SUMMARY, CONCLUSION, IMPLICATIONS, AND RECOMMENDATIONS

$\begin{array}{ll}\text { Summary } & 120\end{array}$

Quantitative Findings $\quad 120$

Qualitative Findings $\quad 124$ 
Importance of Institutional Factors in the Decision of TRiO-Eligible Students to Study Abroad

Discussion of the Findings

Limitations

Implications for Future Practice 


\section{TABLES}

Table

Page

1. Distribution of Online Survey Participants by Pell Grant Status and Demographics

2. Citizenship and Experiences Outside the United States

3. Focus Group Participant Profiles 81

4. Individual Interviews Participant Profiles 81

5. First Consideration of Study Abroad 83

6. Social Factor: Sources of Information First Heard About the Specific Study Abroad Program 84

7. Social Factor: Recommendations of Influential People 84

8. Institutional Factor: Institutional Support Programs for TRiO-eligible Students

9. Institutional Factors in the Study Abroad Decision

10. Personal Factors: Importance of Specific Program Characteristics by Percent

11. Personal Factor: The Influence of Perceived Outcomes on the Decision to Study Abroad

12. Personal Factor: Obstacles to Study Abroad

13. A Comparison of Mean Scores by Social, Institutional, and Personal Factors 


\section{CHAPTER I}

\section{INTRODUCTION TO THE STUDY}

\section{Overview and Statement of the Problem}

As the United States moves to a global economy, undergraduate students must gain experience learning about and navigating other cultures. During the 2012-13 academic year, 289,408 U.S. college students went abroad to learn and experience other cultures through study abroad programs, a $2 \%$ increase from the previous year (Open Doors, 2013). While this may seem like a large number of students, data presented by Open Doors (2013) suggest that this number represents less than $10 \%$ of students graduating with associates or baccalaureate degrees each year and only $1.4 \%$ of the overall number of U.S. students enrolled in higher education. In the previous decade, the percentage of U.S. students participating in study abroad was even lower, which influenced legislators involved in the Commission on the Abraham Lincoln Study Abroad Fellowship Program (Lincoln Commission), during the 2005 legislative session, to set a goal of sending one million U.S. undergraduates to study abroad by 2017 (Lincoln Commission, 2005). The momentum and attention for study abroad as generated by the Lincoln Commission has recently been adopted by the Institute of International Educators (IIE) Generation Study Abroad initiative.

Generation Study Abroad is a collaboration between governments, employers, associations, and institutions that aims to double the U.S. study abroad population to 600,000 participants by 2019 (Institute of International Education, 2015). While the U.S. 
is a long way from reaching the 600,000 mark, let alone the one million mark, the momentum of college students studying abroad has been positive, with an increase in participation by nearly $76 \%$ over the past 10 years, and a steady increase for every year since 2009 (Open Doors, 2013).

Research shows that while the benefits of participation in study abroad programs have been well-documented (Goucher College, 2015; Kuh, 2008; Twombly et. al, 2012; Woodruff, 2009), participation rates among certain demographics of college students remain minimal. For instance, participation is lower among males (Shirley, 2006) and racial minority students (Carter, 1991; Burkhart, Hexter, \& Thompson, 2001). No national data currently exist to determine the true participation rates of first-generation students and economically disadvantaged students in study abroad. These trends have been observed by Martinez, Ranjeet, and Marx (2009), but not much is known about the factors that influence these students' decision to participate (or not) in the study abroad experience. Of the little research that has been conducted on this group, no information exists for first-generation and economically disadvantaged students, who usually receive support through campus programs such as TRiO.

Information regarding students in these groups is relevant to international student advisors, faculty advisors, and administrators, so they can understand how best to encourage the students to engage in study abroad programs and how to make the programs more accessible to all students. Additionally, Generation Study Abroad's goal of doubling the number of students studying abroad to 600,000 can only be achieved by also increasing participation among first-generation and economically underserved students, making this dissertation a useful study. 
It is important to note that many factors will play a role in ensuring that the Lincoln Commission's goal of one million or Generation Study Abroad's goal of 600,000 students studying abroad is met. For instance, to accomplish this goal, legislators, policy makers, and education administrators will have to identify barriers to student participation in study abroad and find solutions to break down those barriers. In addition, advocates of study abroad programs agree that higher education professionals should be concerned with increasing the participation of all undergraduates in study abroad programs, because all students need to be globally competent, and administrators need to be aware of the unique needs for various populations of students (Booker, 2001; Brustein, 2007; Kasravi, 2009). Attention must be paid particularly to underrepresented student populations and their experiences in order to diversify the study abroad population and to help both the Lincoln Commission and Generation Study Abroad reach their respective goals of increasing study abroad populations. For instance, of the 2012-2013 population of study abroad participants, only $34.7 \%$ were males, and only $23.7 \%$ were identified as being from a racial/ethnic minority background (Open Doors, 2013). These numbers are nowhere near the representation of males and students of color in the overall population of degree-granting institutions within the United States, with males representing $43.5 \%$ and students of color representing $40.7 \%$ of the total enrollment in degree-granting postsecondary institutions (NCES, 2013). Of even more concern is that the main instrument for gathering study abroad data, Open Doors, does not allow for further disaggregation by important demographics, such as first-generation or income status of students. As such, there is very limited information regarding the participation of these groups of underrepresented students in study abroad programs. 
First-generation and low-income students face many challenges to accessing a college education, including lower levels of academic preparation, lower educational aspirations, less encouragement and support from family to attend college, and less knowledge about the college application process (Engle, Bermeo, \& O’Brien, 2006). Other factors include financial and cultural barriers that keep these students from pursuing a college education (Carter, 1991; Burkhart, Hexter, \& Thompson, 2001). During the college experience, first-generation students are more likely to live off campus and work while in college, which has a negative effect on social and academic outcomes of college (Saenz et al., 2007). The same challenges may also be true for their participation in study abroad programs, an important educational activity that prepares students to be competitive in an increasingly global society.

First-generation and low-income students who beat the odds and make it to college, and who are bold enough to desire to study abroad, deserve more attention focused on what influences them to go abroad. As Martinez, Ranjeet, and Marx (2009) posited,

The void in the literature regarding study abroad policies, practices, and program models that meet the needs of first-generation college students presents a tremendous challenge for faculty and higher education administrators who are interested in developing study abroad initiatives for this population. (p. 529)

Exploring the barriers that almost kept them from participating, as well as the benefits and outcomes these students identify from this important educational activity, can also add to the understanding of the decision-making process.

Many of these undergraduate students are provided opportunities to enroll in two federal TRiO programs on a variety of campuses throughout the United States. Student 
Support Services (SSS) is one of the TRiO programs that aims to increase the college retention and graduation rates of first-generation, low-income, and disabled undergraduate students who participate. The other, the Ronald E. McNair Post Baccalaureate Achievement Program, strives to improve the attainment of $\mathrm{PhD}$ degrees by students from underrepresented populations. During the 2012-2013 fiscal year, 158 McNair Programs provided services to 4,482 students, while 1,028 Student Support Services Programs provided support to 202,750 students (Office of Postsecondary Education, U.S. Department of Education, 2015a). As these programs focus on educational attainment of underrepresented students, attention also needs to be paid to the ultimate challenge of encouraging participation in study abroad programs to a level that mirrors their representation in the overall population of undergraduate students.

As previously mentioned, not much is known about underrepresented students' (such as those enrolled in or eligible for TRiO programs) participation in study abroad programs, and limited research focuses on the factors influencing their decision to study abroad. In fact, only one source, Burkart, Hexter, and Thompson (2001), looked specifically at low-income students, while a handful of sources focused on minority students who were underrepresented in study abroad (Booker, 2001; Carter, 1991; Kasravi, 2009; Norfles, 2006). The Open Doors data make it clear that the number of ethnic minority students studying abroad does not mirror their representation in the overall population in higher education, something that deserves considerable attention from a critical research perspective. According to Open Doors (2013), during the 201213 academic year, the proportion of Asian, Hispanic, and African American students increased slightly from previous years, yet only constituted $23.7 \%$ of U.S. students 
abroad. Data from the U.S. National Center for Educational Statistics (NCES) for the 2012-13 academic year reveal that $40.7 \%$ of students enrolled in postsecondary education identify as Asian, Native Hawaiian or Other Pacific Islander, American Indian or Alaska Native, Hispanic, African American, or multiracial (NCES, 2013). On the flip side, $76.3 \%$ of the study abroad population was Caucasian, which is an overrepresentation, considering only 59.3\% of the U.S. higher education enrollment in 2012-13 consisted of Caucasian students (NCES, 2013; Open Doors, 2013).

Burkart, Hexter, and Thompson (2001) highlighted the underrepresentation of low-income students and students of color among students who participate in study abroad. The authors cited costs and cultural factors, such as family attitudes toward the value of the study abroad experience, that act as barriers to participation. Burkart, Hexter and Thompson (2001) called upon TRiO directors and staff to play an important role in facilitating such opportunities for TRiO students. While this focus on TRiO staff is certainly valid, this study is relevant to American higher education in an ever-growing global society, as evidenced by the words of Illinois U.S. Senator Dick Durbin when he wrote,

It is the responsibility of the American educational system to engage students in a global education. We owe it to the future of our country-we owe it to our students. Study abroad should be an integral part of the education of all students. (Durbin, 2006, p. 6)

\section{Purpose and Scope of the Study}

Senator Durbin and other members of the Lincoln Commission recognized the importance of diversifying the population of U.S. students studying abroad and dedicated extra federal funding for programs that provide financial resources for low-income and 
students of color to go abroad. Such funds include the Gilman Scholarship, National Security Education Program, and institutional diversity scholarships for study abroad. IIE's Generation Study Abroad also addresses and emphasizes the need to diversify the study abroad population and has included "expand student diversity" among its top five partner actions (IIE, 2015). Additionally, IIE is intentional in promoting many financial resources and initiatives that assist in increasing diversity of students who participate in study abroad.

As Kasravi (2009) pointed out, the IIE established a full-time staff position in 2008 focused solely on promoting study abroad for diverse groups of students. Both IIE and NAFSA: Association of International Educators sponsor The Diversity Network's Diversity Abroad Conference, which is focused on developing effective partnerships to increase access and student success for diverse and underrepresented student populations in international programming.

Despite these efforts, the participation rate among males, students of color, firstgeneration, and low-income students remains low. Most of the research efforts on diversity of study abroad have relied too heavily on discussing barriers faced by minority students, why students do not study abroad, or the experiences students have while abroad. Little to no attention is paid to what influences students to actually go abroad. In addition, research on first-generation and low-income students has taken a backseat to research focused mostly on the minority status of students (Martinez, Ranjeet, \& Marx, 2009). The problem is that the most widely used and respected data instrument in the field of study abroad, the Open Doors Survey, does not collect data on the number of low-income or first-generation students participating in study abroad programs. The 
instrument even collects data on the disability status of students going abroad, but for whatever reason ignores the generation or income status of these students.

An ideal methodology would consist of surveying all TRiO-eligible students who participate in study abroad nationally on the factors that influenced their decision to participate in study abroad; however, this information is not available. Since the Open Doors survey does not collect data on first-generation or Pell Grant status, it is simply not known what the current study abroad participation rate is for TRiO-eligible students. Further, since first-generation or Pell Grant status is not collected by the Open Doors survey, most study abroad offices do not collect or track this information at the institutional level.

Another ideal and alternative method would be to survey all TRiO/Student Support Services Program participants who participate in study abroad. The challenge is that there is no national database or collection method for TRiO/Student Support Services participants who participate in study abroad programs. Further, since study abroad participation is not a required field in the Student Support Services Annual Performance Report, which is required by the U.S. Department of Education, most TRiO/SSS programs do not accurately collect study abroad information among its participants. Therefore, the goal of this study was to gauge the current TRiO-eligible participation rate within one institution's study abroad population. It was possible to accomplish this at the institutional level, but not on a national level.

\section{Research Questions}

The purpose of this mixed-methods study was to explore the factors that influence the decision of first-generation and low-income students at a Midwestern institution to 
participate in a study abroad program and the barriers/challenges/obstacles and benefits of study abroad participation for these students. The research questions this study addressed were:

1. What factors influence TRiO-eligible students' decision to participate in study abroad programs at this Midwestern institution?

2. What are the barriers and benefits to these TRiO-eligible students who make the decision to participate in study abroad programs?

One way to reach this subgroup was through $\mathrm{TRiO}$ programs that are geared toward first-generation/low-income students. This study explored the factors that influence TRiO-eligible students' decision to participate in a study abroad program at this Midwestern institution. In addition, the study examined the challenges the students faced and the benefits they obtained from participating in study abroad programs. This study consisted of two parts: (a) a quantitative phase based on the administration of an online survey similar to the ones used by Booker (2001), Peterson (2003), and Kasravi (2009); and (b) a qualitative second phase consisting of a focus group and in-depth, one-on-one interviews with TRiO-eligible students who had all participated in study abroad.

The online survey was based on Fishbein and Ajzen's (1970) Theory of Reasoned Action, Booker's (2001) Decision-Making Process for Applying or Not Applying to Study Abroad Model, Peterson's (2003) Decision to Study Abroad Model, and Kasravi’s (2009) Adapted Model of the Decision to Study Abroad for students of color. The online survey instrument was adapted for use with TRiO-eligible students and focused on exploring the personal, social, and institutional factors that influenced their decision to study abroad. In addition to the online survey, focus group and individual interviews 
were conducted to gain a deeper understanding of the factors that influenced TRiOeligible students' decision to study abroad, what barriers these students faced in making their decision, and how they benefited from their participation in study abroad. The online survey was administered to a purposeful sample of $757 \mathrm{TRiO}$-eligible students who participated in a study abroad program at the Midwestern institution.

This Midwestern institution was chosen for this study because it ranks in the top 40 nationally among doctorate-granting universities for the total number of study abroad participants, boasting over 1,300 annually. This large, public institution also has a sizeable TRiO-eligible population, with $24 \%$ of the almost 30,000 undergraduates receiving a federal Pell Grant during the 2011-12 academic year. Furthermore, the institution has the data collection capability and an interest in identifying a TRiO-eligible population among its study abroad participants. Aggregate reporting revealed that of the 3,421 former study abroad participants still enrolled at the institution during the 2013-14 academic year, 1,030 (or 30\%) of the study abroad population was TRiO-eligible (B. Harley, personal communication, 2014). This TRiO-eligible participation rate of $30 \%$ in study abroad mirrored the representation of TRiO-eligible at the institution during the 2013-14 academic year, according to the institutional research office at the research site. The institution has a TRiO/SSS Program that sponsors annual study trips, and other support programs exist on campus for first-generation and economically underserved students.

In this study, factors that influenced the decision, as well as challenges/ barriers/obstacles that played a role in TRiO-eligible students' interest and decisions to study abroad were explored. In essence, the study examined TRiO-eligible student 
participation and ultimately identified how best they might be supported as they made the decision to study abroad.

\section{Theoretical Framework}

The theoretical framework utilized for this study was influenced by study abroad models developed by Booker (2001) and Peterson (2003), which were both based upon Fishbein and Ajzen's (1975) Theory of Reasoned Action and implemented in the design of Kasravi's (2009) Adapted Model of the Decision to Study Abroad for students of color.

The foundation of Fishbein and Ajzen's (1975) Theory of Reasoned Action is that "a person's beliefs serve as the informational base that ultimately determines his attitudes, intentions, and behaviors" (p. 14). The theory assumes individuals are rational organisms that use the information available to them to make judgments, form evaluations by considering the possible consequences or outcomes of an action, and ultimately arrive at a decision on the action in question. Attitudes toward the behavior in question are composed of behavioral beliefs and an evaluation of the consequences of the behavior. The behavioral beliefs are comprised of an individual's personal beliefs about the behavior or action in question, while the evaluation of consequences are what the individual expects to be the outcomes of engaging in the behavior or action in question. In addition, normative beliefs, what an individual believes others will think of their behavior or action, influence their intention to engage in the behavior or action. Additionally, a person's subjective norm "is viewed as a major determinant of his intention to perform the behavior. Thus a person's behavioral intention is viewed as a function of two factors: his attitude toward the behavior and his subjective norm" 
(Fishbein \& Ajzen, 1975, p. 16).

The theory also assumes that "specific behavior is viewed as determined by the person's intention to perform that behavior" and that this assumption "raises the question of the factors that influence the formation of behavioral intentions" (Fishbein \& Ajzen, 1975, p. 16). It is for these reasons that this theoretical framework was appropriate for this study examining the factors that influence TRiO-eligible participants in their decision to study abroad. According to Kasravi's (2009) Adapted Model of the Decision to Study Abroad for students of color, a variety of factors - personal, social, and institutionalinfluence students to make the "intention" to study abroad, which is a necessary step in the decision-making process for students to decide to study abroad. Therefore, it is fitting to examine these personal, social, and institutional factors in order to identify which factors are influential in the decision are making process for TRiO-eligible students.

In addition, this theoretical framework is relevant because it accounts for the information available as influencing the decision of individuals to engage or not engage in an action. The literature clearly highlights that students of color and low-income students do not necessarily have all the information available to them in regard to study abroad programs, and this lack of information influences these individuals not to study abroad (Burkhart, Hexter, \& Thompson, 2001; Carter, 1991; Kasravi, 2009; Norfles, 2006). This study, therefore, examined the information available to students to gauge its effect on the decision to study abroad for TRiO-eligible students.

\section{Significance of the Study}

The researcher sought to learn what factors influence TRiO-eligible students to study abroad, and what barriers students face in their decision to go abroad. This study 
also identified the benefits and outcomes these individuals received from participating in study abroad programs and highlighted the implications of identifying the factors that influence TRiO-eligible students to study abroad. Since there is limited information about study abroad focusing primarily on first-generation and low-income students, this study helps fill the deficiency in the literature. The results may be particularly useful to higher education administrators, TRiO professionals, international educators, and other individuals interested in promoting study abroad participation among American undergraduate students. Participants' focus group and individual interviews in this study benefited by processing and reflecting upon the factors that influenced them to study abroad, the barriers that almost prevented their participation, and what they gained from the study abroad experience. Participants may have also felt a sense of value in assisting future TRiO-eligible students who wish to study abroad by sharing their narrative.

\section{Definitions}

Several key terms were used in this study, mostly relating to study abroad and the criteria to qualify as a TRiO-eligible student. To be eligible for a federal TRiO program, a student can qualify as first-generation, low-income, or on disability status as defined by the American Disabilities Act of 2008. For the purposes of this study, TRiO-eligible students were defined as students who were first-generation college students, low-income according to federal guidelines, or both first-generation and low-income. The disability status of an individual was intentionally excluded from this study to emphasize the focus on the first-generation and income status of an individual, and to minimize risk of violating the strict regulations of confidentiality that accompany the recording of disability status of an individual. 
First-generation: For TRiO qualifications, a first-generation college student means: (a) a student neither of whose natural or adoptive parents received a baccalaureate degree; (b) a student who, prior to the age of 18, regularly resided with and received support from only one parent and whose supporting parent did not receive a baccalaureate degree; or (c) an individual who, prior to the age of 18 , did not regularly reside with or receive support from a natural or an adoptive parent. (TRiO Legislation and Regulations, 2011)

Low-income: According to the Office of Postsecondary Education, a "low-income individual" means an individual whose family's taxable income for the preceding year did not exceed $150 \%$ of the poverty level (Office of Postsecondary Education, U.S. Department of Education, 2015b). For the purposes of this study, individuals were considered low-income if they had received a Federal Pell Grant to finance their undergraduate education.

Pell Grant: The maximum Pell Grant award for the 2015-16 award year (July 1, 2015 to June 30, 2016) was $\$ 5,775$. According to the U.S. Department of Education, the amount awarded is determined by the financial need of the student, cost of college attendance, status as a full-time or part-time student, and plans to attend school for a full academic year or less (Federal Student Aid, 2015).

Study Abroad Population: This study used the Open Doors Survey definition for study abroad: "U.S. citizens and permanent residents, enrolled for a degree at an accredited higher education institution in the U.S., who received academic credit from their home institution for study abroad upon their return to campus" (Open Doors, 2013, p. 109). 
TRiO eligible: This term refers to a student who met the criteria for participation in a federally funded Student Support Services Program, which included students who were first-generation, low-income, or had a documented disability recognized by the American Disabilities Act. For the purposes of this study, the disability qualifier was excluded because of the highly sensitive nature of the information; therefore the term TRiO-eligible referred to just first-generation, low-income, or both first-generation/lowincome students. As stated previously, low-income students in this study were considered those students who utilized a federal Pell Grant during the academic year they studied abroad.

\section{Organization of the Study}

Chapter I provided an overview of study abroad and a statement of the problem, with particular emphasis on the lack of participation of TRiO-eligible students, purpose and scope of the study, research questions, theoretical framework, significance of the study, definition of terms for the reader, and assumptions and limitations. Chapter II provides a review of the literature, which offers context for this study, including research on the history of study abroad, the role of the federal government in study abroad, current trends in student demographics in study abroad, underrepresented student groups in study abroad, and a proposed theoretical framework for the study. Chapter III describes the mixed method research design, instruments, data collection, and data analysis strategies that were utilized in this study. Chapter IV provides a description of the study's results and, in Chapter V, the study's analysis, summary, conclusions, implications, and recommendations for future practice and further research are presented. 


\section{Summary}

This study, exploring the factors influencing the decision of TRiO-eligible students to study abroad, was a worthy undertaking given the underrepresentation of TRiO-eligible students who participate in study abroad. TRiO-eligible students face several barriers to completing their undergraduate education and choosing to study abroad is a brave decision on the part of the TRiO-eligible students. Although many resources exist on study abroad, including research focusing on minority students, little is known about the experiences of first-generation and low-income students in their decision to study abroad and their experiences while studying abroad. The introduction confirms that study abroad is a relevant topic in higher education research, and more attention needs to be paid to investigate which factors are influencing TRiO-eligible students who are overcoming the barriers and deciding to study abroad. 


\section{CHAPTER II \\ LITERATURE REVIEW \\ Introduction and Organization}

It would be misleading for this study to begin with the modern concept of study abroad without exploring its early beginning in higher education, since the focus of this study was to examine the factors that influence TRiO-eligible students to decide to study abroad. As a result, a historical overview of study abroad is presented in the literature to not only explore the structure of how study abroad existed during different points in time, but also to examine societal factors that influence individuals to leave their homeland to study in another country. Critical voices of study abroad were included in the review through historical and contemporary anti-neoliberal lenses. The review also highlights the current state of study abroad and the relevance of this educational activity as it exists in American higher education today. Next, this review explores the benefits and outcomes of the study abroad experience on students who engage in this activity. The review moves on to address the student's decision process to study abroad, with a particular focus on the theoretical frameworks used for this study, along with barriers encountered by these underrepresented student groups. The review narrows to focus on the problem at hand by providing an overview of underrepresented students in study abroad, concluding with a focus on TRiO-eligible students. 


\section{Historical Overview of Study Abroad}

Study abroad, as it exists today in the United States, has grown in both popularity and in the number of undergraduate students engaging in this educational activity in recent years. A significant part of this recent growth in popularity has to do with the way study abroad has evolved over the past 230 years alongside the American system of higher education. The concept of study abroad is not uniquely American, however; it has deep historical roots in ancient times, as does the U.S. concept of higher education.

The way U.S. study abroad exists today is shaped heavily by several historical movements that also affected U.S. higher education. This historical analysis of the literature will focus on the following sections: the origins of study abroad in ancient times, European influences, colonial America, $19^{\text {th }}$ century America, and early $20^{\text {th }}$ century America. As with ancient times, one of the hardest factors individuals must overcome to participate in pursuing an education outside of their homeland is first considering that the world extends beyond their periphery and that something can be learned from people of different nations. Especially in the United States, isolationist attitudes affected the growth of study abroad and are still a factor preventing many Americans from choosing to study abroad or even from traveling abroad (Hoffa, 2007). Through this discussion, historical events and movements will demonstrate the momentum gained for study abroad in the United States.

In his 2007 work, A History of U.S. Study Abroad: Beginnings to 1965, William Hoffa attributed the growth of study abroad in the U.S. to the structure of the American college education that included: a liberal and unique curriculum, a residential campus, a modular course-credit system, the focus on whole student development to produce 
enlightened citizens to take on a modern democratic republic, and the emergence of the U.S. on the world stage after World War I. Without these complex characteristics, "U.S. study abroad is unlikely to have evolved" (p. 21). This section of the literature will focus on the historical development of study abroad from ancient times through $20^{\text {th }}$ century America, the role of the federal government in the development of study abroad programs, and conclude with characteristics of study abroad programs as they exist today.

\section{Ancient Beginnings}

As with the development of higher education, study abroad has roots in the early universities of ancient times. According to Hoffa (2007), the beginnings of study abroad can be traced to the learning centers of India, Greece, Rome, the Middle East, and Asia. While these places of learning do not technically meet today's definition of a university, since they did not confer degrees, they certainly influenced the creation of educational institutions and encouraged individuals from various backgrounds to gather for the sake of learning traditional and accepted knowledge. Brickman (1961) attributed the ancient beginnings of study abroad to the University of Takshasila, located in modern day Pakistan. The institution received wandering scholars from $600 \mathrm{BC}$ to AD 250, including Alexander the Great (as cited in Hoffa, 2007, p. 3). The learning taking place at Takshasila, the Library of Alexandria, and other educational centers focused on learning from elders, mostly through rote memorization, and then taking this knowledge to pass on to others. In his observations of Greek student mobility, Hoffa (2007) noted "the truism that all one needed to know was not available at home spawned generations of student mobility" (p. 3). The desire to seek knowledge beyond one's native land would also influence future generations of scholars in Europe. 


\section{Early European Influences}

The Middle Ages in Western Europe limited the expansion of learning and of scholars traveling for the sake of knowledge. Much of the knowledge that existed from early texts and scholars within Europe lay hidden away in private collections for fear of persecution from Church officials or within the collections of the Roman Catholic Church (Hoffa, 2007). It was not until the Early Modern Period that a reemergence of learning in the knowledge of the ancient world occurred, making it more welcoming to student mobility and promoting the creation of learning centers within Western Europe. Some of the earliest European universities were located in Paris, Montpellier, Oxford, Bologna, and Salerno (Hoffa, 2007, p. 11). Students traveled Europe widely, away from their homelands, to attend these institutions.

In addition to the creation of new learning centers, the customs and traditions of the European aristocratic class contributed to the foundations of study abroad. According to Hoffa (2007), it became popular and fashionable from the Renaissance onward to "have a few foreign feathers in one's cap" (p. 13). Outside of attending formal education, one way individuals pursued knowledge and experience outside of their homeland was the wanderjahr. The concept of the wanderjahr "involved traveling widely, fending for oneself in new places, meeting people, having adventures, sowing one's wild seeds, growing up" (Hoffa, 2007, p. 18). The wanderjahr was not limited to only affluent classes; many were artists, craftsmen, and writers (Hoffa, 2007). This was not an intellectual quest, however, and parents of sons on the wanderjahr hoped their offspring "would return safely with a new sense of maturity and confidence and ready to settle into their preordained social, civic, and familial roles" (Hoffa, 2007, p. 18). The concept of 
the wanderjah created a cultural acceptance of traveling beyond one's border and certainly influenced some Americans in their decision to leave colonial America to learn from Old Europe.

\section{Colonial and Early America}

One of the most significant challenges presented by the concept of study abroad during the early Colonial period in America was the hardship that life presented. Life was not easy for early colonists, where most attention was paid to survival. As Hoffa (2007) observed of colonial America, "most students were born on this side of the ocean, had not been abroad, and never would be, given the dangers and expense. Education abroad was not a practical option for most youth. Nor were they encouraged to think much beyond America's vast borders" (p. 24). In addition, there was a movement to create institutions of higher learning in the American colonies to satisfy the needs of the wealthy elite and to prepare the next generation of clergy. As Thelin (2004) posited, the purpose of colonial colleges "was to identify a colonial elite" and was "a conservative institution that was essential to transmitting a relatively fixed social order" (p. 25). The idea of the colonial colleges influenced the break from the traditions of Europe to bring education to the colonies, making the idea of pursuing an education outside of the colonies unnecessary and mostly out of reach.

However, as economic conditions improved in the colonies and trade between the colonies and Europe expanded, "the temptation remained (or re-emerged) among both wealthy colonists and early nationals to send their sons to the Old World for at least some of their education" and was even viewed as proper training for American gentlemen (Hoffa, 2007, p. 25). Even with this reemergence, isolationist attitudes further 
discouraged Americans from going abroad as the American colonies began to break away and challenge British authority. According to Thelin (2004), the colonial colleges played a central role in the American campaign for independence, with classrooms hosting patriotic oratory and dormitories pressed into service as hospitals and barracks for troops during the Revolutionary War (p. 1). American higher education in the late $18^{\text {th }}$ and $19^{\text {th }}$ centuries entered into a "new national period," a period that included "extreme innovation and consumerism" (Thelin, 2004, p. 41). During this period, the focus remained to break further from European traditions and to create institutions that would serve the regional needs of America and reflect a new American identity. American isolationist attitudes were encouraged further by prominent American leaders: "George Washington warned against entanglements in European affairs as well as overseas study by American youth" (Hoffa, 2007, p. 7). Hoffa (2007) argued that in addition to Washington, Noah Webster also opposed overseas study, implying that enough Americans were studying outside of the country to garner attention from such prominent individuals.

\section{$19^{\text {th }}$ Century America}

Hoffa (2007) argued that foreign study by American college students during the $19^{\text {th }}$ century "generally took one of three forms, each with a European precedent: a grand Tour or wanderjahr, a year of unmatriculated study at a German or British university, or a postgraduate degree" (p. 30). In his work The American College in the Nineteenth Century, Roger Geiger (2000) highlighted the impact of American study abroad activity in Germany, under the German Research Model during the $19^{\text {th }}$ century on the development of the Graduate School within American higher education. In tracing the 
history and influence of this model, Geiger's work revealed that American study abroad activity within Germany during the $19^{\text {th }}$ century was quite staggering. According to Geiger (2000), “significant scholarly pilgrimages to Germany began immediately after the War of 1812, when men like George Ticknor and Edward Everett studied in Germany and then returned to apply their foreign learning" (p. 337). Geiger (2000) estimated that some 9,000-10,000 Americans studied in Germany between the outbreak of the Napoleonic Wars and the outbreak of World War I, with most individuals only studying for one term. Geiger (2000) posited that the adoption of the German Research Model among American institutions "was the example and personal experience of German universities that commonly inspired reformers and shaped their vision” (p. 222). This underscores the significance of study abroad during this period, as the influence of the German Research Model on American higher education was motivated by study abroad activities by Americans, and these reforms lead to the development of a globally competitive American higher education model.

The $19^{\text {th }}$ century in U.S. history of study abroad faced the same challenge of overcoming American isolationist attitudes as previous periods; however, European universities still continued to receive upper-class American students both for graduate degrees and for 1-year periods of learning (Hoffa, 2007, p. 31). Prominent Americans who went abroad during this period included Henry Wadsworth Longfellow, Nathaniel Hawthorne, and Theodore Roosevelt, for either an American version of the European Grand Tour or for study at a German or British University (Hoffa, 2007). As Comp (2015) notes, "Perhaps the most famous American to study in Germany during this period was W.E.B. Du Bois from 1882 to 1894” (p. 192). Comp (2015) further argues that it 
was during the late $19^{\text {th }}$ century that elite American institutions influenced by the German model of graduate education were founded, such as The University of Chicago, Stanford University, Cornell University, and Johns Hopkins University.

Having these prominent and influential Americans with international experience under their belts was important for advancing the idea of studying outside of the United States. However, it was not until the United States elevated its status on the world level to promote more dialogue and attention to the idea of going outside of the United States that the concept of study abroad would gain momentum.

\section{Early $20^{\text {th }}$ Century America and the}

\section{First U.S. Study Abroad Program}

Hoffa (2007) proclaimed that the awareness that the United States had a larger role to assume on the world stage grew on American campuses and that this momentum "provided the impetus for the beginning of overseas study as a component of U.S. higher education that could be pursued far beyond its national borders and count for credit toward completion of the undergraduate degree" (p. 21). It was during this time that the modern concept of study abroad as "an institutional and academic endeavor, taking place in another country and leading to credit toward a student's home institution degree, got its start in the 1920s" (p. 69). Most historians and scholars attribute professor Raymond Kirkbride and president Walter S. Hullihen of the University of Delaware and their creation of the Delaware Foreign Study Plan in 1923 as America's first study abroad program (“Our History,” 2013). Kirkbride was a World War I veteran and understood firsthand the importance of cross-cultural understanding, and he believed his program would produce better-rounded students, train future foreign language teachers, and 
provide students with the opportunity to enter into professions with international components (“Our History,” 2013).

What the University of Delaware accomplished in 1923 is what Hoffa (2007) considered an example of "an innovative and programmatic attempt on the part of a few American colleges to combine academic and experiential learning modes in a foreign study" (p.69-70). Since the University of Delaware program was the first modern conception of study abroad, future institutions would look to it as a model. As a result, three distinct program designs of study abroad emerged during the 1920s: (a) Junior Year Abroad, (b) Faculty Led Tours, and (c) Summer Study (Hoffa, 2007, p. 70). The Junior Year Abroad focused on a full year of language immersion in a selected country, and outside of the University of Delaware, most of these "attracted an overwhelming proportion of female students" (p. 83). The Junior Year Abroad legacy continues to this day, as women continue to study abroad at higher rates than men; during the 2010-11 academic year, $64.4 \%$ of U.S. study abroad students were female and $35.6 \%$ were male (Open Doors, 2013).

Faculty-led tours during the 1920s involved travel and visits to several countries while offering coursework focusing on world issues that were taught in English by a faculty member from the student's home institution. Students received academic credit from the faculty-led study tour via examination or paper. Summer study involved a discipline-specific, short-term program offered by either the student's home institution or a foreign one. Most of the coursework focused on independent research or preprofessional training (Hoffa, 2007, p. 70). 
Study abroad at the end of the 1920s received support from the Rockefeller Foundation with the establishment of the Division of Humanities in 1929. This division focused on supporting research and grants in the areas of creative writing, history, the arts, linguistics, and selected aspects of education. The division "recognized to a considerable degree the importance of intercultural understanding involving studies abroad, as well as the need to increase knowledge of foreign areas in American higher education" (Rockefeller Foundation, 2003, p. 13). While this period of study abroad saw a great increase in attention to the legitimacy of study abroad with the awarding of academic credit for time spent abroad, it would be world affairs and the growing prominence of the United States that would provide a further catalyst.

\section{Impact of WWII on Study Abroad}

In his A History of American Higher Education, John Thelin referred to the period following the close of World War II as the "Golden Age" of American higher education due to the "three P's" of prosperity, prestige, and popularity (Thelin, 2004, p. 260). Without a doubt, higher education grew significantly in the years following World War II; however, the state of study abroad during and immediately following the war saw a decline in numbers and momentum. During the war, travel overseas by students all but ceased due to the fighting and instability across the globe. In addition, as Hoffa (2007) observed, "for former students who headed back to college to resume their interrupted studies, leaving again to study overseas was the furthest thing from their minds" (p. 105). While study abroad lost momentum in the years immediately after the war, the war itself presented the U.S. with a new role in world affairs and a need for more Americans to gain international experience to better handle these challenges. More importantly, the 
federal government embraced these challenges and responded with a series of federal initiatives that would eventually lead to a greater expansion of study abroad.

\section{Role of the Federal Government, 1948-Present}

With the responsibility of the United States as a leader of the "free" world, the U.S. took a lead position in diplomatic affairs, focusing on improving foreign relations. Thelin (2004) highlighted that the cooperation between higher education and the federal government during World War II proved to be effective, and higher education was utilized in the "large-scale planning for the transition to a peacetime society, including a civilian economy" (p. 261). The most significant federal investment in higher education at the conclusion of the war was the G.I. Bill of Rights (Thelin, 2004); however, other federal initiatives helped study abroad programs gain momentum.

The pressure of the Cold War at the close of World War II motivated the United States to promote friendly relations worldwide. Through the Marshall Plan, colleges and universities provided educational and technical support to countries and nations rebuilding after the war. As Hoffa (2007) posited, "The field of international education would not have developed as it did without U.S. government initiatives and support" (p. 113). Other federal initiatives during this time that also bolstered study abroad included the Fulbright Program of 1946, which greatly increased the exchange of undergraduate students, scholars, and faculty into and out of the United States. According to the Fulbright Program website, “approximately 310,000 'Fulbrighters' have participated in the Program since its inception in 1946. Currently, the Fulbright Program operates in over 155 countries worldwide" ("Fulbright Program History," 2013). 
It was also during this period that private foundations and organizations had an influence on the expansion of study abroad in the postwar world. During the summer of 1948, civic organizations and groups invested in the field of international education met in Paris under the leadership of the Carnegie Endowment to take measure of U.S. student opportunities in Europe and to discuss possible coordination and cooperation between groups to reopen this line of travel in a postwar world (Mikhailova, 2002). This meeting led to the formation of the Executive Committee on Student Travel, later reorganized as the Council on Student Travel. This group worked directly with the U.S. government in negotiating space on military transports for U.S. students desiring to study in Europe. The Council on Student Travel, the Carnegie Foundation, and other groups were mainly concerned with the challenge of "getting American young people to Europe, helping with the reconstruction of Europe, and having an educational experience at the same time" (Mikhailova, 2002, p. 3). While the Carnegie Foundation was integral in reopening study abroad activity after World War II, it was not the only private foundation invested in international education efforts during this period.

The Rockefeller Foundation expanded 10 fellowships to the research director of Peru's Institute of Andean Biology Alberto Hurtado, not to be confused with the Chilean Jesuit of the same name. Hurtado's staff's study abroad opportunities, combined with other foundational initiatives, made the Institute of Andean Biology a "global leader in physiology studies. Extended throughout Latin America, the fellowships of the Rockefeller Foundation, and similar fellowships offered by the John Simon Guggenheim Foundation, helped to reorient Latin American science from Europe to North America" (Heilbron, 2003, p. 312). While not solely a study abroad program for American 
students, Hurtado's fellowship program demonstrated the significant impact of international education exchange, and how instrumental private foundations were to this expansion.

In 1957, the Soviet Union launched the satellite Sputnik, motivating federal officials to create and pass the National Defense Education Act of 1958, which "injected unprecedented new resources into advanced scientific research" (Thelin, 2004, p. 280). Also included in this legislation were provisions for learning Eastern European languages, other modern languages, and a variety of area studies focused on specific geographic regions (Hoffa, 2007). The federal government provided these resources with the idea of "winning the hearts and minds of people in Third World countries" in order to compete with the Soviets for the allegiance of peoples in the Third World (Hoffa, 2007, p. 118). In 1959, the Bureau of Educational and Cultural Affairs of the U.S. State Department offered federal financial assistance to several universities to create and administer programs in Latin America (Hoffa, 2007). The goal of this initiative was to use federal subsidies to compete with the Soviet Union for influence in Latin America and to help the United States build a more positive image in that region. Hoffa (2007) highlighted the significance of this particular federal initiative in that it was the first and last time that the federal government offered direct federal financial assistance to set up study abroad programs for a specific purpose. Federal funds could be used for the purpose of study abroad, but not as intentionally or directly as the Latin America campaign.

During this time, the real motives behind the role of the federal government in the development of study abroad began to be questioned, specifically in Latin America. In 
her work on institutional history, Mary Ann Wynkoop (2002) highlighted an Indiana University research project called Project Themis, funded by the U.S. Department of Defense, that established study abroad opportunities in Latin America. The project came under suspicion for providing cover for CIA involvement in that region. The purpose of the project was to investigate

...the use of languages and language behavior as indications of potential sources of international conflicts. Suspicions of shadowy connections with national intelligence agencies were common on most state university campuses in the 1960s, and the information that SDS researchers discovered confirmed many of them. (Wynkoop, 2002, p. 75)

Anti-government concerns were common on U.S. college campuses during this time period, however, and Hoffa (2007) noted that it is unclear if espionage was a clear motive behind these federal initiatives for study abroad at this period in time.

It is important to note during this period of history of study abroad, many outside for-profit and not-for-profit agencies offered travel opportunities to college students in the form of cultural enrichment trips or study tours in the late 1950s, causing a lot of problems for study abroad administrators. These changes threatened the legitimacy that existing study abroad programs had fought so hard for, because the "line between serious study abroad (for credit) and extracurricular tourism (not for credit) was becoming blurred" (Hoffa, 2007, p. 237). While not a federal initiative, national leaders of the Council on Student Travel, the Association of American Colleges, the Institute of International Education, and the Experiment in International Living convened twice in 1960 at the Mount Holyoke Conference and the National Conference on Undergraduate Study Abroad to address the perceived threat the reputation of study abroad faced at the hands of these new outside organizations. The main focus of these meetings called for 
national standards to ensure program quality of study abroad programs (Hoffa, 2007, p. 249).

The 1960's federal involvement in study abroad. During the years of 19451975, American higher education saw sweeping change unprecedented from any other time period in American history, from a student growth rate of $500 \%$ to the creation of a variety of institutions (Cohen, 1998, p. 196). A great catalyst to the modifications taking place in American higher education during this period was the federal government's intervention with the enactment of the Higher Education Act of 1965. The act drastically changed the way study abroad had been funded, allowing for the first time discretionary authority to colleges and universities to use federal financial aid in support of students studying abroad (Mukherjee, 2012). This impact was positive; however, the proposed International Education Act failed to pass in 1966, slowing the momentum and attention study abroad had received earlier in the decade from the Peace Corps and other initiatives aimed at improving U.S. relations abroad (Keller \& Frain, 2010). It is important to note that credible third-party organizations, such as the Council on International Education Exchange (CIEE), previously known as the Council on Student Travel, did see an increase in use from universities to set up programs abroad. The International Student Exchange Programs (ISEP) is an organization dedicated to help students overcome the academic and financial barriers to study abroad (ISEP, 2015). ISEP was established in 1979 as a non-profit organization under the authority of the Fulbright-Hays Act, and was supported by a grant from the United States Information Agency until 1997 when it became incorporated as an independent organization (ISEP, 2015). It would not be until the 1980 s that U.S. study abroad would see another swing in momentum, with the 
inclusion of Title VI with the 1980s Higher Education Act, called the International and Foreign Language Studies (Keller \& Frain, p. 31, 2010).

Federal role in study abroad since the 1990s. The 1990s saw an end to the Cold War and changing geopolitical interests for the United States. The National Security Education Program, sponsored by Senator Boren, was established by the National Security Education Act of 1991 under the auspices of increasing international education exchange and attention to areas vital to U.S. foreign policy (Kasravi, 2009). Many higher education institutions initiated study abroad efforts on their campuses, either through an institutionally based program or from a program provider, such as the CIE or International Student Exchange Programs (ISEP). These newer programs emphasized destinations outside of Western Europe and expanded beyond traditional programs types to also include internships and service-learning (Kasravi, 2009).

\section{Critics of U.S. Study Abroad Through Historical and}

\section{Contemporary Anti-Neoliberal Lenses}

The interplay between the U.S. federal government and organizations dedicated to the expansion of international education has been a long one, filled with both challenging and positive outcomes. Historically, these challenging occurrences have influenced the critical voices of study abroad, which continually question the true intentions behind U.S. study abroad efforts. This is a small cross-section of the literature on study abroad, but one that warrants mention. Contemporary neoliberal arguments used in the promotion of study abroad receive further skepticism from study abroad critics. This section of the literature review features critical voices of study abroad through historical and antineoliberal arguments. 
Due to the questionable intentions behind U.S. governmental agencies' sponsorship of study abroad programs in the 1960s, critics have emerged over time to provide discourse in the overall purpose of U.S. study abroad activity. As Twombly, Salisbury, Turnanut, and Klute (2012) highlighted, "rarely do faculty, policymakers, study abroad directors, or advocates question study abroad, its purposes, or its benefits" (p. 95). While the critical voices of study abroad are often overshadowed by the positive literature on study abroad, this body of research does deserve attention. Liping Bu's (1999) work investigated the promotion and expansion of American cultural values and political idealism abroad through religious, social, political, and governmental agencies during the Cold War.

$\mathrm{Bu}$ (1999) asserted that U.S. educational exchanges played into these overarching schemes of cultural imperialism, particularly during the Cold War. "It mobilized the American society for the achievement of 'total diplomacy' with political rhetoric, legislative measures, and financial support” (p. 393). According to Bu (1999), exporting American culture, values, and technology were emphasized in these cultural "exchange" efforts, a term that could be more accurately described as "mutual understanding." Hence, educational exchange or study abroad efforts during this period were influenced heavily by the U.S. government's principal interest "to achieve short-term political objectives, whereas educators were more interested in the long-term educational goals" (Bu, 1999, p. 408). Educators and policy officials differed not just in their interests, but also in how to and who should fund such activities. This difference still exists to this day, as discussed in the section concerning the Lincoln Commission. 
The Lincoln Commission and the efforts of the IIE's Generation Study Abroad campaign rely on neoliberal arguments to justify the existence of study abroad and the money needed to fund such activities. Harvey (2007) noted that neoliberalism "proposes that human well-being can best be advanced by liberating individual entrepreneurial freedoms and skills within an institutional framework characterized by strong private property rights, free markets, and free trade" (p. 2). The Lincoln Commission utilized neoliberal arguments when emphasizing the need to prepare individuals to work and live in a global socioeconomic and political context. Additionally, the commission stressed how study abroad could be used as a tool for the U.S. to address both its economic and security interests. This type of neoliberal argument is challenged by some education scholars within the context of higher education, who argue that the true value of education is jeopardized.

Giroux (2002) argued that,

As society is defined through the culture and values of neoliberalism, the relationship between a critical education, public morality, and civic responsibility as conditions for creating thoughtful and engaged citizens are sacrificed all too willingly to the interest of financial capital and the logic of profit-making. ( $\mathrm{p}$. 427)

Giroux's argument was further discussed by Twombly et al. (2012), who claimed that study abroad is an example of both an instrument of commercialism and the consumer mentality consistent with all of higher education. An example of such commercial instruments includes New York University's effort to create a facility in Ghana to promote study abroad to its students.

New York University's property in Ghana features air-conditioning, guaranteed power, 24-hour security, wireless Internet, an Americanized dining hall, on-site nurses, 
and shuttle buses for students studying at the University of Ghana in Legon (Pappano, 2007). While NYU's goal is to make U.S. students abroad feel comfortable, many criticize the university for disrupting a long-understood value of study abroad as an opportunity for authentic cultural immersion and for exporting a version of American imperialism and commercialization. In her contribution to the Harvard Crimson, Lin (2007) warned against such efforts in educational exchange as it represents cultural imperialism, and that "our education must be sensitive to the changing realities of the international situation" (par. 9). These consumerist tendencies within study abroad extend beyond travel and amenities of students while abroad, but also in the message behind why study abroad is promoted.

As highlighted by Twomby et al. (2012), this consumer identity mentality meshes with the need 'to consume others' cultures for the instrumental purpose of helping U.S. students get jobs. In fact, the rationale for study abroad frequently emphasizes its role in promoting individual and national success in a global economy" (p. 97). As a result, many individuals within higher education and society question the integrity and academic value behind study abroad as the lines can become blurred between commercialism, imperialism, and tourism.

The anti-neoliberal argument should be considered and realized by institutions and organizations that aim to increase study abroad participation in how they structure programs and how they tailor their messages in promoting study abroad. Without quality collaboration and encouragement from faculty and colleagues working in higher education, who can be a critical group by nature, neither the Lincoln Commission's nor Generation Study Abroad's goals will be realized. For the most part, IIE has been 
intentional in balancing the way the Generation Study Abroad's materials represent critical education/civic responsibility and neoliberal messages.

For example, in their Top Ten GREAT Reasons to Study Abroad pamphlet, only "enhance your career opportunities" and "strengthen communication team-building \& adaptability skills" can be viewed as neoliberal reasons for study abroad (IIE, 2015). The eight remaining reasons, "expand your worldview, learn another language, experience another culture first-hand, make new friends from around the world, gain invaluable experience, discover new things about your own culture, boost your confidence and independence, and travel," represent more traditional and democratic ideals of education (IIE, 2015). However, despite all the criticisms concerning the motives behind U.S. study abroad or how study abroad is being promoted through neoliberal messages, few would argue that the alternative of keeping students in the U.S. is better, especially when so few American students participate in study abroad. Further, most can understand that the neoliberal message in the promotion of study abroad is just a necessary tactic, even for underrepresented populations. As Twombly et al. (2012) argue, "sincere efforts to promote study abroad among the underrepresented populations needs to respond to some of the other concerns expressed, such as what is the payoff, is study abroad worth the investment, and so on" (p. 107).

\section{Current Relevance of Study Abroad Programs}

Study abroad has gained considerable attention in recent years. The section that follows highlights some of the major initiatives that have heightened the awareness and relevance of study abroad within higher education. 


\section{Overview of the Lincoln Commission}

The events of 9/11 strongly shaped the conversation for the need to increase the prominence and priority of study abroad among American undergraduates. It also highlighted the disproportionate rate at which international students were coming into the U.S. versus the number of American students going abroad. In the academic year following the events of 9/11, 586,323 international students studied in the U.S., while only 174,629 American undergraduates studied abroad, comprising just $1 \%$ of the overall undergraduate population (Open Doors, 2012). This did not go unnoticed by federal policy makers: "What nations don't know can hurt them. The stakes involved in study abroad are that simple, that straightforward, and that important. For their own future and that of the nation, college graduates today must be internationally competent" (Lincoln Commission, 2005, p. 4). A bi-partisan effort through the Lincoln Commission concluded that it was in the United States' national interests to encourage students to study abroad to prepare them to work and live in a global socioeconomic and political context for use in meeting the economic and security interests of the United States. The Commission called for one million undergraduate students to participate in a study abroad program by 2017 (Lincoln Commission, 2005)

Much of the recent growth and attention to U.S. study abroad, as seen through IIE's Generation Study Abroad initiative, is attributed to the federal initiatives born out of the Lincoln Commission. The chair of the Commission, M. Peter McPherson, added, "Study abroad is not a frill. Greater engagement of American undergraduates with the world around them is vital to our nation's national security, economic competitiveness, and public diplomacy" (College News, 2005, par. 2). The Commission called for five 
main objectives:

1. Increase student diversity in study abroad programs, ensuring that the demographics of U.S. students studying abroad is similar to those of the undergraduate population.

2. Increase the number of students going abroad to study in non-traditional countries outside of Europe, North America, and Australia.

3. Increase the number of study abroad students enrolled in minority servinginstitutions, community colleges, and institutions serving large numbers of low-income and first-generation students.

4. Require Lincoln Fellows, a program established to provide monetary assistant to encourage students to participate in study abroad, to participate in academic credit bearing programs of high quality.

5. Address issues related to student security, safety, and health. (College News, 2005, par. 11)

Overall, three of the five main objectives speak directly to addressing the diversity of the study abroad population. Specifically, the objectives of the Lincoln Commission addressed the need to provide awareness and support for first-generation and low-income individuals who seek to study abroad.

While the momentum to attain this goal has been slowed considerably by the economic recession of 2008 , the fact that study abroad received so much attention at the national level reflects that it is a legitimate educational activity that is valued by many in higher education institutions, the federal government, and society at large. The IIE picked up where the Lincoln Commission left off with the creation of Generation Study Abroad, with a goal to double the study abroad population to 600,000 U.S. students studying abroad by 2019 , to coincide with the centennial anniversary of the organization. The following section provides an overview of data on study abroad. 


\section{Growth of Study Abroad Examined Through}

\section{a Review of Open Doors Data}

The increase in the number of students choosing to study abroad today is quite staggering, given the obstacles faced by U.S. study abroad program administrators through the years. The IIE has tracked the number of U.S. students participating in study abroad programs through the administration of the Open Doors Study Abroad Survey since 1957, reporting that a total of 9,887 American students studied abroad during the 1955-56 academic year out of the three million U.S. students enrolled in higher education (Open Doors, 1957).

The format of the Open Doors Study Abroad Survey has existed in its current format since 1985-86. Data reported from the survey usually lag one year after collection to allow for the time it takes to transfer academic credit from a student's institution abroad to their home campus. The Open Doors Survey on Study Abroad defines the U.S. study abroad population as "U.S. citizens and permanent residents, enrolled for a degree at an accredited higher education institution in the U.S., who received academic credit from their home institution for study upon their return to campus" (Open Doors, 2012, p. 109). Students who do not receive academic credit are not included in the figures represented for study abroad, offering a conservative picture of U.S. study abroad activity (Open Doors, 2012). In 2009, the survey was made available online.

The 2012 Open Doors Study Abroad Survey was distributed to 1,697 institutions and received 908 responses, a 54\% response rate. During the 2010-11 academic year, a record 273,996 U.S. students studied abroad for academic credit, marking a 285\% increase since 1991-92, a 77.7\% increase over the past decade (2000-01), and a $22.6 \%$ 
increase from just 5 years prior (2005-06; Open Doors, 2012, p. 18). The study abroad population continues to grow, not just in size, but also in the destinations where students choose to travel.

In 2010-11, European countries accounted for the destination of $54.6 \%$ of study abroad students; however, this is a significant decrease from the $76.7 \%$ of students who studied there in 1989-90. The most popular European countries chosen as a destination for study abroad include the United Kingdom, Italy, Spain, and France. The second most popular region for study is Latin America, which hosted $14.6 \%$ of U.S. study abroad students, followed by Asia with 11.7\% (Open Doors, 2012, p. 19). Behind the four European countries listed above, China ranks fifth as a country of destination, hosting 14,596 students or $5.3 \%$ of the U.S. study abroad population in 2010-11 (Open Doors, 2012, p. 19). Of the students going abroad, $58.1 \%$ participated in short-term summer programs for 8 weeks or less, $38 \%$ in mid-length (defined as one or two quarters or one semester), and 3.9\% for a long-term program lasting for an academic or calendar year (Open Doors, 2012, p. 42).

\section{Characteristics of Study Abroad Programs}

Today, study abroad programs exist in many variations and contain several focuses; however, they all still require students to gain academic credit from the experience abroad to "count" as a study abroad experience, according to the Open Doors Survey. The Forum on Education Abroad provides a glossary of important items and topics within the field of education abroad. In relation to study abroad, the Forum provides five "study abroad program types" based on the student experience as it relates 
to pedagogy and program format. The five main types of study abroad programs according to the Forum (2011) are:

1. Field Study Program: experiential study outside the classroom setting. Examples include field research programs, internship programs, and service-learning programs.

2. Integrated University Study: the predominant study format is participation in regular courses alongside degree-seeking students from the host university. May be either through direct enrollment or enrollment facilitated by a study abroad provider organization. Examples of such providers include International Student Exchange Programs (ISEP) and the Council on International Education Exchange (CIEE)

3. Overseas Branch Campus: A separate campus of a college or university whose main campus is in a different country.

4. Study Abroad Center: the predominant study consists of classroom-based courses designed for non-host country students.

5. Travel Seminar: (preferable term to the roughly synonymous Study Tour or Study Travel Program) a program in which students travel to many different cities or countries and receive instruction in each location, often regarding a designated unifying topic. Examples include shipboard education programs or European cultural studies tours. (Forum on Education Abroad, 2011, pp. 13-14)

While these program types provide clarity to the common characteristics of study abroad programs, it is important to highlight that this glossary also offers 24 "sub-types" of the study abroad experience. For higher education administrators charged with planning study abroad programs, it is important to highlight that outside of the branch campus option, these opportunities exist usually in one of three ways. The first kind includes institutionally created programs where their own faculty lead short-term programs. The second form includes an agreement between a U.S. institution and one outside of the United States, established through a Memorandum of Understanding (MOU). The third kind includes a partnership either between two U.S. institutions or with an outside provider to send students and faculty overseas. Overall, the defining characteristic of distinguishing the U.S. study abroad experience from other 
internationally focused forms of education is that students gain academic credit toward the completion of their degree at their home institution.

\section{Curriculum Integration}

Integration of study abroad into the curriculum is happening, and many higher education professionals expect study abroad to become part of the mainstream offerings of most institutions (Niser, 2010). For example, the University of Minnesota made integrating study abroad programs a high priority on its campuses, including it in the strategic plan of the university in the late 1990 s, setting a goal to have $50 \%$ of its student body participate in a study abroad program. Today, the University of Minnesota has moved close to achieving its goal, boasting that $30 \%$ of its undergraduate students from all five campuses participated in travel overseas during the 2008-09 academic year (Fisher, 2010).

Indiana University Bloomington offers 22 major programs that have incorporated study abroad into the curriculum and offers their students the opportunity to gain not only general education but also major credit while going abroad (Indiana University, 2011). Five institutions received the 2011 Senator Paul Simon Award for Internationalization: Beloit College (Wisconsin), Indiana University-Purdue University Indianapolis (Indiana), Kennesaw State University (Georgia), Macalester College (Minnesota), and New York University (New York). They received this award because they integrated study abroad into the curriculum, as evidenced in their practices, structures, philosophies, and policies (NAFSA, 2011). The growth in the inclusion of study abroad into the university curriculum is due to the perceived benefits this educational activity affords participants, as evidenced in the next section. 


\section{Outcomes and Benefits of Study Abroad}

This section of the literature discusses the outcomes and benefits of study abroad for individuals who engage in it. Many working in higher education espouse the value of study abroad, as evidenced in literature cited thus far. While the value of study abroad is important to the discussion of the perception of study abroad, benefits and outcomes for study abroad are identified below. These outcomes and benefits are presented in two main sections: academic and individual.

\section{Academic Value of Study Abroad}

In his 2008 work dedicated to the investigation of 10 "high-impact educational practices," George Kuh answered the question, why are some educational activities unusually effective? Kuh (2008) provided three reasons: (a) these educational practices require students to devote considerable time and effort to a purposeful task that in turn deepens a students' investment in the activity and their commitment to their academics and college; (b) the nature of these activities creates circumstances that command students to interact with peers and faculty "about substantive matters typically over extended periods of time"; and (c) participating in "these activities increases the likelihood that students will experience diversity through contact with people who are different from themselves" (Kuh, 2008, p. 24-25). It is not a surprise that study abroad is included as one of these 10 high-impact educational activities.

Kuh (2008) concluded that

Similar patterns of benefits are reported by students who study abroad, in that they engage more frequently in educationally purposeful activities upon returning to their home campuses and report gaining more from college compared with their peers who do not study abroad. (Kuh, 2008, p. 24) 
When these students engage in this way, they have a tendency to increase their performance across several educational outcome measures, such as persistence, retention, and even graduation rates. For example, Woodruff (2009) highlighted an analysis of time to graduation data at the University of Minnesota that revealed students who participated in a study abroad program graduated in a timelier manner than undergraduate students who did not study abroad. For underrepresented students, high-impact educational activities are very influential on their success, as underrepresented students engaged in these high-impact activities demonstrate higher levels of engagement and improved academic performance (Kuh, 2008).

Twombly et al. (2012) concurred that study abroad encourages graduation in a timely manner. The authors identified additional benefits for students who participate in study abroad including language gains, ability to understand themselves and what it means to be American, open-mindedness and global-mindedness, and greater inclination to engage in diverse experiences. In summary, several academic benefits exist for students who participate in study abroad programs. Many institutions have come to realize this and the need to provide more study abroad opportunities, and one way of doing that is through integrating study abroad into the university curriculum.

\section{Personal Benefits}

Kuh (2008) attributed the study abroad experience with deepening learning and challenging students to reflect on their values and beliefs, which in turn helps students better understand themselves in relation to others within the context of the larger world. Intercultural communication and global understanding has become an attractive economic commodity in the global market place, which can be gained from the study 
abroad experience (Stroud, 2010). Intercultural competence allows individuals to recognize their own differences and the differences of others and how to navigate these in facilitating communication toward common goals (Anderson \& Lawton, 2011; Deardorff, 2006; Woodruff, 2009). Intercultural competence is a central tenant of the study abroad experience, and many study abroad professionals in recent years have sought ways to document the development of students in this area through many assessments now available.

In her 2005 qualitative study, Lindsey investigated the impact of the study abroad experience on undergraduate social work students from the U.S. and Scotland. This study revealed themes that included opening a student mind's to new ways of thinking, awareness of values and beliefs, social awareness, appreciation of difference, cultural sensitivity, social justice, and professional identity development (Lindsey, 2005). Lindsey (2005) concluded that study abroad has an important role in affirming social work values and the commitment of these students to the profession of social work.

Campbell and Drexler (2006), utilizing Chickering and Reisser's (1993) Theory of Student Development, attempted to identify competency areas to measure the development of global awareness and overall student development among community college students who participated in a study abroad experience. The results of the survey demonstrated that the study abroad experience had an impact on the perceived development of research participants within Chickering and Reisser's (1993) vectors of Developing Competence and Developing Mature Interpersonal Relationships, and Overall Student Development. Particularly, research participants "perceived a developmental change in academic, athletic, and interpersonal competence, as well as the 
ability to respect and communicate with persons of different cultural backgrounds as a result of studying abroad" (Campbell \& Drexler, 2006, p. 616). This suggests that study abroad programs are offering the experiences needed for a student to develop the competencies necessary in the current global economy. Campbell and Drexler (2006) further argued that this development increases the professional skills of students, improving the employability of students to be competitive in a globally based economy.

In summary, many benefits stem from student participation in a study abroad program, including helping students connect better with the campus, earn better grades, and graduate in a timely fashion. Students also benefit personally from study abroad, and from study abroad programs that include service-learning and internships, as these offer students the opportunity to further develop professional skills within a global context (Lindsey, 2005). These skills help students feel more marketable as they transition from undergraduate study into the workforce. Institutions also benefit from these positive student outcomes, and many institutions are intentional in integrating study abroad into the central component of the undergraduate student life, the curriculum. For example, since 2006, Goucher College has established a requirement that every student is required to participate in study abroad (Goucher College, 2015).

\section{Students' Decision Process to Study Abroad}

In their survey of college freshmen and the intent to study abroad Rust, Dhanatya, Furuto, and Khlitash (2008) showed that 53.8\% of students surveyed already had some interest in study abroad, and they charge study abroad offices to sustain this intent by making study abroad as "attainable" as possible for all students (Rust et al., 2008, p. 11). Their finding is somewhat significant, since it was a widely accepted stance that students 
chose not to study abroad simply because they did not know about the opportunity. This section of the literature review will focus on factors that influence students to participate in a study abroad program and to examine potential barriers that inhibit participation.

Results from a 2010 study on student intent to participate in a study abroad program revealed "that being female, attending school more than 100 miles from home, and expressing an interest in improving one's understanding of other cultures and countries have a positive influence on American students' intent to study abroad" (Stroud, 2010, p. 491). A study conducted by Booker (2001), surveying the general student population at the University of Missouri, identified nine factors that directly influenced the decision of students to study abroad. In order of preference, the factors include: influence of faculty and advisers, perception that study abroad would delay graduation, finances, influence of family and friends, need for a travel break during college, learning about the world and oneself, GPA and foreign language requirements, helping future career prospects, and academic constraints.

Booker (2001) developed a theoretical framework to explain the decision-making process for applying or not applying to study abroad, utilizing both Ajzen's (1985, 1991) theory of planned behavior, which itself was an expansion of Fishbein's $(1967,1980)$ theory of reasoned action. Booker (2001) proposed that participation in study abroad is a "planned behavior that is based upon a rational decision to voluntarily engage in study abroad, which is influenced by the perceived or expected outcomes or consequences of study abroad, perceived social pressures, and perceived obstacles" (Booker, 2001, p. 6). This theory heavily influenced Kasravi's (2009) study of students of color in their decision to participate in study abroad. 
In a 2009 study, Salisbury, Umbach, Paulsen, and Pascarella applied an integrated model of college choice to better describe students who do and do not intend to study abroad, and to explore the impact of financial, human, social, and cultural capital on students' intent to participate in study abroad. After reviewing literature on the benefits and barriers of study abroad, Salisbury et al. (2009) explored financial constraints and a lack of awareness of study abroad as prominent barriers for minority students in participating in study abroad. They argued that these barriers presented in the literature did not demonstrate that such conclusions "were evidence of an active barrier to participation or a retroactive justification for the decision not to participate" (p. 121). They further argued that little hard data exists that explores what motivates students to go abroad, and they positioned this argument within the context of the importance of understanding the factors that influence the decision of students to pursue study abroad in order to accomplish the Lincoln Commissions' goal. Their conclusion is consistent with the purpose of this study to help close this gap.

Salisbury, Umbach, Paulsen, and Pascarella (2009) wrote that their study had three general purposes. The first was to argue that the "student-choice" construct of Paulsen and St. John, (2002) and St. John and Asker, (2001) and "college choice theory" (Hossler et al., 1989; Paulsen, 1990) could be applied and used to explain the decision of students to participate in educationally valued experiences during their time in college. Second, Salisbury et al. (2009) applied Laura Perna's (2006) integrated model of college choice to examine the factors that shape students' intentions to study abroad among college freshmen from the Wabash National Study on Liberal Arts Education. The hypothesis from the Wabash study was that "intent to study abroad is substantially 
influenced by a combination of pre-college socioeconomic status and the social and cultural capital accumulated before entering and during college" (p. 122). Third, the study provided an analysis and discussion of the implications of their finding for individuals and policy makers interested in increasing the study abroad population and for future research on student decision-making regarding participation in study abroad and other educationally valued experiences during college.

In regard to TRiO-eligible participants, Salisbury et al. (2009) discovered that students coming from lower-income households are 11 percentage points less likely intent on studying abroad than students from higher income families who do not qualify for federal financial aid. Additionally, they discovered that parent's education level is also positively related to the probability of a student planning to study abroad:

With every standard deviation increase in average parental education, the likelihood of planning to study abroad increases approximately 5 percentage points. In combination, both of these elements of socioeconomic status - as formative, class-based indicators of early home habitus - can discourage even the development of aspirations or intentions to participate in study abroad programs. (Salisbury et al., 2009, p. 133, par. 3)

As noted earlier, students cannot make a decision about whether to study abroad or not if they do not first have the intention to study abroad. The findings of Salisbury et al. (2009) is concerning for TRiO-eligible students and their likelihood to study abroad, giving credence to the value of the proposed study investigating the factors that influence the TRiO-eligible students in their decision to study abroad.

\section{Barriers to Study Abroad}

Barriers for the overall study abroad population include student concerns over credit transfer, lack of faculty/campus support, lack of foreign language knowledge, and 
cost (Kasravi, 2009; Stroud, 2010; Rust et al., 2008). In a 2010 study conducted by April Stroud, additional barriers were identified, including students living with family while attending school, planning to pursue a master's degree or higher, and “majoring in engineering and professional areas such as architecture and medicine negatively affect U.S. student intent to study abroad" (Stroud, 2010, p. 491). Rust et al. (2008) identified family obligations, cost, and interference with academic progress as factors that may hinder likelihood for an individual to study abroad (Rust et al., 2008, p. 11). For underrepresented students in study abroad, additional factors exist that limit their participation in study abroad programs below their level of participation within the overall system of higher education.

\section{Overview of Students Underrepresented in U.S. Study Abroad}

Only $1 \%$ of the U.S. undergraduate population studies abroad; however, for students of color, the study abroad numbers are even smaller, according to the IIE. Only $6.3 \%$ of the Americans studying abroad in 2004-05 were Asian, 5.6\% Hispanic or Latino(a), 3.5\% African-American, 1.2\% multiracial, and 0.4\% American Indian (Stuart, 2007). These numbers do not reflect the representation of these students within the overall population in higher education. The students who choose to study abroad are “predominantly female, white, and from four-year colleges and universities. Representation from minority, male, and less affluent students-as well as community colleges--lags behind" (College News, 2005, par. 9). The following section of the literature review focuses on some of the populations underrepresented in U.S. study abroad participation. 


\section{Males}

Outside of the University of Delaware's Foreign Study Plan Program, male participation has historically been lower than female participation since the 1920 s. One reason for this could be the inability of the field of international education to move beyond the model provided by the Junior Year Abroad, which focused mainly on academic subjects predominantly studied by women (Hoffa, 2007). During the 2010-11 academic year, women outnumbered men in study abroad programs, at $64.4 \%$ to $35.6 \%$ (Open Doors, 2012). Shirley's (2006) study examined differences in how males and females perceive studying abroad in order to potentially find ways of encouraging more males to study internationally. Shirley's (2006) study revealed three significant differences existed between genders: (a) females stated parents and other relatives were a greater positive influence in their decision to study abroad than for males; (b) females felt interference with an internship or job, as well as the overall cost of studying abroad, represented greater obstacles than did males; and (c) males more strongly felt studying abroad delayed their potential graduation date more than did females.

\section{Students of Color}

A survey conducted by the National Association for Equal Opportunity in Higher Education of 53 historically Black colleges and universities (HBCUs) revealed that only 844 students from these institutions had studied abroad during the 2003-04 academic year, and only one-fourth of the HBCU institutions surveyed had full-time study abroad coordinators (Walker, Bukenya, \& Thomas, 2010). Students of color have been underrepresented among study abroad participants for decades (Lincoln Commission 2005; Walker, Bukenya, \& Thomas, 2010). The participation of students of color in study 
abroad programming does not mirror their level of representation in the overall population in higher education.

Kasravi (2009) categorized obstacles faced by students of color during the decision-making process of choosing to study abroad into situational, dispositional, and institutional barriers. Situational barriers include lack of language competency, lack of family support, and finances. Dispositional barriers include lack of knowledge about study abroad programs, lack of interest in going overseas, and fear of potential racism. Institutional barriers include lack of information about study abroad programs provided by the institutions and academic fit within the institution.

Utilizing the models developed by Booker (2001) and Peterson (2003), Kasravi (2009) utilized survey instruments to explore the factors influencing students of color's decision to study abroad who had recently studied abroad at the University of California San Diego and students of color who did not study abroad. Kasravi’s (2009) study summarized the following findings:

1. Personal and social factors were discovered to be the primary factor for influencing a student's decision to apply.

2. Finances and academics were the main barriers faced by both students of color who studied abroad and those who did not.

3. Students of color who chose to participate in study abroad did so by seeking information, using external messengers, being personally determined, and possessing internal drive in deciding to participate in study abroad.

Kasravi's study on students of color provides a great framework for investigating what influences TRiO-eligible students to study abroad. Much of the discussion and literature 
available about TRiO-eligible students focuses on the barriers to study abroad, and Kasravi's approach is one that has promise for semi-replication with a TRiO-eligible student population.

\section{Students with Disabilities}

The Open Doors Survey has collected information relating to the disability status of study abroad participants since the 2006-07 academic year in the following categories of disability: learning, mental, physical, sensory, and other. In the 5 years of data available, students with disabilities composed $2.6 \%$ of the study abroad population in $2006-07,3 \%$ in $2007-08,3.6 \%$ in $2008-09,4 \%$ in $2009-10$, and $4.1 \%$ in $2010-11$ (Open Doors, 2012). The positive trend of students with disabilities in study abroad is encouraging and could also be attributed to better reporting among professionals in the field. It would be helpful if the IIE would also include first-generation status and income status of students who participate in study abroad programs. Especially with federal initiatives such as the Gilman Scholarship for Pell Grant recipients, it would be important to have this data to make better informed policy decisions.

\section{TRiO-Eligible: First-Generation and Low-Income Students}

According to the National Survey for Student Engagement( NSSE, 2007), "firstgeneration and transfer students were much less likely than other students to participate in a high-impact activity such as a learning community, research projects with a faculty member, study abroad, or culminating senior experience" (p. 17). Also referenced from NSSE (2007), students who participated in study abroad were more engaged in educationally purposeful activities when they returned to campus and reported gaining more from the college experience than students who did not participate in study abroad. 
It is for these reasons that study abroad should be encouraged to a wide audience of students, with special attention paid to TRiO-eligible students, who are less likely to study abroad than their peers.

As Martinez, Ranjeet, and Marx (2009) posited,

Of particular concern to those who seek to increase the numbers of students involved in study abroad are the disproportionately low participation rates of firstgeneration college students, many of whom are from low-income families and from historically underrepresented minority groups. Study abroad opportunities can no longer be a luxury reserved for more affluent U.S. college students whose family backgrounds predispose them to seek out such experiences and whose income levels allow them to take advantage of such opportunities. (p. 528)

Further, Pascarella , Pierson, Wolniak, and Terenzini (2004) argued that colleges and universities must make it a priority that all students have access to "the full range of college experiences and to the personal, social, and economic benefits to which those experiences and degree completions lead" (p. 281).

Few studies or reports exist that demonstrate the actual level of participation of first-generation or Pell Grant recipients in study abroad. One of the few institutions that does is the University of Texas at Austin. According to Open Doors (2013), the University of Texas at Austin ranks second among doctoral-granting institutions, sending over 2,500 students abroad during the 2011-12 academic year. According to Syed and Tolan (2013), of students participating in study abroad from the University of Texas at Austin, only $9 \%$ were first-generation college students.

While these numbers seem discouraging, the University of Texas should be applauded for thinking to include first-generation students in their reporting and for being willing to share their data. More research needs to be made available about institutions that report participation rates of first-generation students in study abroad and those that 
are doing a good job of making study abroad a priority and reality for TRiO-eligible participants.

TRiO students face many barriers when they seek to study abroad, with financial barriers being the most significant, according to a study conducted by the Pell Institute (Burkart, Hexter, \& Thompson, 2001). Citing Carter (1991), the Pell Institute revealed barriers such as language requirements, admissions requirements, marketing, program costs, campus culture, family attitudes toward international experience, and lack of faculty or departmental support for study abroad in some cases contributed to low participation among TRiO-eligible students in study abroad programs (Burkhart, Hexter, \& Thompson, 2001).

A study conducted by the Council for Opportunity in Education to identify additional barriers faced specifically by $\mathrm{TRiO}$ participants concluded that $\mathrm{TRiO}$ programs thought that study abroad was not a high priority for participants because graduation from college was regarded as the main priority (Norfles, 2006). In their investigation of the choice process behind the intent of students to study abroad, Salisbury, Umbach, Paulsen, and Pascarella (2009) found that socioeconomic status of a student's family is positively related to the intent to study abroad. They further highlighted that lower income students are less likely to plan to study abroad than their higher income peers, and lower income students are 11 percentage points less likely to intend on studying abroad than students whose families do not qualify for federal financial aid (Salisbury et al., 2009). Few studies have focused on the experience of TRiO-eligible students in study abroad programs, as most focus on other underrepresented groups in study abroad. Therefore, utilizing Kasravi’s (2009) framework for students of color is appropriate for analysis with 
this group, due to the lack of attention in the literature and data available on TRiOeligible students.

\section{Summary}

The attention to and relevance of study abroad has developed greatly in recent years, and some argue that study abroad should be an integral part of the undergraduate curriculum. After reviewing the history from a critical lens, both critical of the motivations behind study abroad and of the population of American students who are actually participating, it is clear that more attention needs to be paid to underrepresented student groups. Limited research and data exists that specifically addresses how TRiOeligible students engage in making a decision whether or not to participate in a study abroad program. The limited literature that does address this group makes it clear that TRiO-eligible students are significantly less likely to even intend to study abroad than their more well-to-do peers. Therefore, it is important to investigate the personal, social, and institutional factors that influence their decision. Since limited literature exists that specifically addresses this group, utilizing a framework for another underrepresented student group, students of color, is an appropriate step in advancing the literature in this area. 


\section{CHAPTER III}

\section{METHODOLOGY AND PROCEDURES}

This study investigated what factors influenced TRiO-eligible students' decision to participate in study abroad programs. Benefits as well as barriers, challenges, and obstacles that play a role in students' interest and decisions to study abroad were explored. In this chapter, the methodology applied in this study is detailed. Information related to the research design, participants, data collection and data analysis is presented.

\section{Research Design}

Using a mixed methods approach, this study explored the factors that influence TRiO-eligible students in their decision to study abroad, drawing from survey results and narratives from these students. A mixed methods research design involves a combination of qualitative and quantitative approaches in data collection and analysis. Creswell (2009) describes qualitative research "as a means for exploring and understanding the meaning individuals or groups ascribe to a social or human program" and quantitative research as "a means for testing objective theories by examining the relationship among variables" (p. 4). Creswell further argues that mixed methods research involves more than combining both qualitative and quantitative approaches; rather, it involves philosophical assumptions, the mixing of both approaches in tandem so the overall strength of the study is greater than either qualitative or quantitative research methods alone (Creswell, 2009). 
Creswell goes further to distinguish mixed methods as using sequential, concurrent, or transformative approaches. A sequential mixed methods approach involves a researcher expanding upon the findings of one method at a time. Sequential mixed methods could begin with a qualitative interview to explore a topic and inform the design and administration of a quantitative survey, or begin with a quantitative method to test a concept or theory and follow that by a qualitative process to explore the details of the topic at an individual level. Concurrent mixed methods, on the other hand, is where an investigator collects both forms of data at the same time and then integrates the information in the analysis and interpretation of the results. Lastly, a transformative mixed method design, as defined by Creswell (2009), is used where there is a need to create an understanding of an issue as it pertains to a marginalized group and developing the needed changes for the group. For the purposes of this study, a transformative mixed methods approach was applied to explore the factors that influence study abroad participation among TRiO-eligible students at a Midwestern institution well-known for its study abroad population and emphasis of study abroad.

The frameworks used for this study—Fishbein and Ajzen's (1970) Theory of Reasoned Action, Booker's (2001) Decision Making Process for Applying or Not Applying to Study Abroad Model, Peterson's (2003) Decision to Study Abroad Model, and Kasravi's (2009) Adapted Model of Decision to Study Abroad for students of color in study abroad programs - provided the guide to the quantitative approach. Overall, this study built upon the works of Booker (2001), Peterson (2003), and Kasravi (2009) to address factors influencing TRiO-eligible students in their decision to participate in study abroad. Kasravi's (2009) framework and survey instruments for her study on students of 
color and study abroad, based upon Booker (2001) and Peterson (2003), were utilized and applied to TRiO-eligible students in this study. Further, Kasravi's frameworks and survey instruments, focused on students of color and grounded in Fishbein and Ajzen's (1970) Theory of Reasoned Action, were utilized to create the quantitative survey (Attachment A) utilized in this study with TRiO-eligible students.

In addition to the quantitative surveys, the qualitative phases of this study were employed to assist the researcher in understanding the meaning the TRiO-eligible students constructed from their experiences (Merriam, 2009). This study explored how TRiO-eligible students interpreted their decision to study abroad through identifying influences and barriers to their participation, along with how they made meaning of the study abroad experience. This study valued the participants' interpretation of their decision-making process to study abroad and their experience while abroad, by drawing upon narratives from focus groups and from semi-structured individual interviews.

The research questions this study addressed were:

1. What factors influence TRiO-eligible students' decision to participate in study abroad programs at this Midwestern institution?

2. What are the barriers and benefits to these TRiO-eligible students who make the decision to participate in study abroad programs?

\section{Participants and Study Setting}

A purposeful sampling technique, as suggested by Creswell (2009), was used to select the research setting as well as the participants of this study. According to Creswell, the idea behind using a purposeful sample is "to purposefully select participant or sites (or documents or visual material) that will best help the research understand the 
problem and the research question" (p. 178). According to Vogt (2007), purposive sampling is commonly used by researchers utilizing surveys, where a sample is gathered deliberately, not randomly, with a purpose in mind. It is for these reasons that a purposeful sampling technique was used in this study. This study focused on a purposefully sampled Midwestern institution and its population of 757 TRiO-eligible students who had studied abroad previous to the start of the fall 2015 semester at the research site. The researcher worked with the Associate Dean of International Programs, study abroad office, the TRiO/Student Support Services program, and the institutional research office at the research site to distribute an online survey to the TRiO-eligible participants who had studied abroad.

The Midwestern institution is a large public research institution comprising an enrollment of over 40,000 students, with 30,000 of those being undergraduate students. According to the National Center of Education Statistics (2012), 94\% of the undergraduate population attended full-time and were 24 years of age or under. In regard to gender, $58 \%$ were male and $42 \%$ were female. Of the undergraduate population, $55 \%$ were in-state, $28 \%$ were out-of-state, and $15 \%$ were international students.

The research site is a predominately white campus with $68 \%$ identifying as white, 5\% as Asian, 3\% as Black or African American, 4\% as Hispanic/Latino, 2\% as two or more races, $16 \%$ as non-resident alien, and $2 \%$ who did not identify race/ethnicity. Twenty-four percent of the undergraduate population on this campus received a federal Pell Grant in 2011-2012. In addition, this institution had a study abroad population totaling over 1,300 during the 2011-2012 academic year (Open Doors, 2013). 
The research site's institutional research office reported that 1,800 students participated in study abroad during the 2013-2014 academic year. The research site also provided a study abroad opportunity specifically for TRiO/Student Support Services participants and had done so every academic year since the 2011-2012 academic year. In collaboration with the study abroad office, and the TRiO/Student Support Services program, the institutional research office identified 3,421 students who had previously studied abroad and who were still enrolled at the research site during the 2013-2014 academic year. Disaggregation of those 3,421 student records revealed 443 students had received a federal Pell Grant, 281 students were first-generation college students, and 306 were both first-generation college students and had received a federal Pell Grant. In total, a TRiO-eligible study abroad population of 1,030 was identified during the 2013-2014 academic year. Considering that $30 \%$ of the research site's study abroad population was TRiO-eligible, this Midwestern institution contained a promising sample for this study. Overall, this Midwestern institution was chosen for this study because it ranks in the top 40 nationally among doctoral-granting universities for the total number of study abroad participants, hosts a sizeable TRiO-eligible population in its student body, and further, the institution has the data collection capability and interest to identify a TRiOeligible population among its study abroad participants. Since there is a lack of national data available on the study abroad participation rate among TRiO-eligible students, most study abroad offices do not collect first-generation and income criteria, and since TRiO programs do not accurately track study abroad participation, it was fitting to use one institution to gauge the participation rate of TRiO-eligible students as it related to their representation within the university. 


\section{Instrumentation}

This study was conducted using two approaches: quantitative and qualitative research. In the quantitative approach, a survey instrument, modeled after the questionnaires utilized first by Booker (2001), Peterson (2003), and Kasravi (2009) that focused on "the influence of the potential outcomes or consequences of study abroad, social influences on the study abroad decision, influence on the potential obstacles to study abroad, and institutional support for international education" (Kasravi, p. 55), was adapted. The survey (Appendix A) was administered online through the Select Survey system. Select Survey is software that allows for online and mobile kiosk surveys; however, only online surveys were used for this study. The software allows for filters and grouping of survey items to assist in data analysis. Once research subjects complete the online surveys, the software provides statistical tools to help identify patterns and trends in the survey responses. The Select Survey data files can be easily converted to Microsoft Excel and SPSS data files for further analysis.

This survey (see Appendix A) contained 31 questions, with seven of those questions containing several items that require the participant to rate, for a total of 71 survey items. The survey questions and items were divided into the following sections: background information of participants (questions 1-21), first consideration of study abroad (question 22), social influences (question 23), influencing sources of information (question 24), institutional factors (questions 25-26), personal factor characteristics in choosing a particular study abroad program (question 27), personal factor of the perceived outcomes of the study abroad experience (question 28), and the personal factor of obstacles to study abroad (question 30). The last question of the survey asked 
participants if they wanted to enter a drawing for a chance to win a gift card as compensation for participating in the survey.

Overall, the survey contained questions that were represented in all three previous studies. Of the 31 questions, 20 questions were similarly represented in Booker's (2001) instrument, 18 in Peterson's (2003) instrument, and 27 in Kasravi's (2009) survey for students of color. Of the five main questions requiring participants to rate 58 items, 47 items were represented similarly in Booker's (2001) survey, 33 in Peterson's (2003) survey, and 57 items in Kasravi's (2009) survey. The researcher obtained permission from Kasravi (2009) to adapt her survey for the purpose outlined above. While a high percentage of questions and survey items were similarly represented in Kasravi's (2009) survey, great effort was made to add and customize questions to address the specific needs of TRiO-eligible students. An overview of the efforts to tailor the survey is highlighted below; however, it is important to trace the origins of Kasravi's survey to provide context.

Kasravi (2009) modeled her survey after Booker's (2001) survey instruments that explored the factors influencing the decision to study abroad between applicants and nonapplicants. Booker's (2001) survey contained ordinal and nominal items within six parts:

(1) demographic information, (2) study abroad preferences, (3) influence of the potential outcomes or consequences of study abroad, (4) social influences on study abroad decision, (5) influence on the potential obstacles to study abroad, and (6) institutional support for international education. (Kasravi, 2009, p. 55)

Booker (2001) conducted a pilot test of his survey with a convenience sample of 21 individuals at a university close to his home. He made minor changes to his survey after conducting the pilot study. 
After adapting Booker's instruments, Kasravi (2009) administered a pilot test of her survey to a convenience sample of 30 participants at the University of Minnesota to address issues of validity and reliability. Items of the survey were grouped according to social, personal, and institutional factors to compute the internal consistency of the scale. Survey items were tested for reliability and revealed the following Cronbach alpha levels: 0.68 for the social factors subscale, 0.61 for institutional subscales, 0.59 for anticipated outcomes, and 0.71 for main barriers (Kasravi, 2009).

In an effort to make the survey more authentic for a TRiO-eligible population, questions were added to the online survey utilized in this study that were not represented in Kasravi's (2009) survey. The first two questions of the survey asked participants to identify their Pell Grant recipient and first-generation status. This was a crucial step to identifying a purposeful sample of TRiO-eligible participants necessary for this study. Additional items such as "state aid" and "working while going to school" were added as choices to the demographic section of the survey to address the needs of TRiO-eligible participants as was represented in the literature.

Great effort was made to tailor the items that addressed institutional factors, present in Kasravi's survey, to the actual research site used for this study. As a result, a new question was added asking participants to indicate their participation level in programs present at the research site that are geared specifically to first-generation students and Pell Grant recipients. Additionally, the survey was reviewed by both the director of TRiO/Student Support Services and the Associate Dean of International Programs/Director of Study Abroad at the research site. Both individuals reviewed the institutional specific survey items for fit, uniqueness, and authenticity with the 
institutional resources present at the research site.

\section{Pilot Testing}

Pilot tests of the online survey were conducted to test the validity and reliability of the survey at a midsized comprehensive institution and a small regional state institution with IRB approval. The online survey was tailored to each institution following the same process used for the research site as outlined above to make the institutional specific items on the survey authentic for each institution. The online survey at the midsized comprehensive institution followed the same sampling procedures as for the full study. The researcher worked with the institutional research office at each institution during the pilot survey to create a purposeful sample of TRiO-eligible students who had participated in study abroad. The institutional research offices utilized the Financial Aid data tables to identify Pell Grant and first-generation status, Study Abroad Data Tables to identify participants who had gone abroad, and Registrar Data Tables to identify email addresses and enrollment status of individuals meeting the previous criteria to create this purposeful sample of participants.

As of the spring 2015 term, 138 students at the midsized institution had already participated in study abroad. Of those students, 46 or $33 \%$ of that population met the sampling criteria of being TRiO-eligible. Of these 46 TRiO-eligible students who had participated in study abroad, only 20 students had agreed to be contacted for research purposes as stated by institutional policy. As a result, the survey was distributed to the 20 students who had opted-in to receive invitations to participate in research studies through institutional email. The survey was also distributed to a convenience sample of 4 former TRiO/Student Support Services participants from the midsized institution who had all 
participated in study abroad through social media. Between the two groups from the midsized institution, the 20 who received the invitation to participate through institutional email and the 4 who received the invitation through social media, only 10 research subjects began the survey. In total, the survey results revealed only 7 fully completed responses from participants to the online survey, resulting in a $29 \%$ response rate for the online survey from the midsized institution.

The online survey for the small regional state institution was administered to a convenience sample of 11 former TRiO/Student Support Services participants who had participated in study abroad, as the institutional research office at the small regional state institution was not able to identify a purposeful sample at the time of the request. The online survey that had been tailored to the small regional state institution was sent via Facebook to these former SSS participants. Of these participants, 8 responded to the survey with fully completed results, yielding a $72 \%$ response rate from the 11 former TRiO/Student Support Services participants who had participated in study abroad.

The online survey items for both institutions had a combined total of 15 fully completed survey responses. The items from both surveys were grouped according to the social, personal, and institutional factors to compute the internal consistency of the scale. Analyses for survey agree/disagree items for questions 26, 29, and 30 yielded a reliability index of 0.911. According to Green \& Salkind, a reliability index, or Cronbach alpha score above 0.81 is good, meaning the "scale scores are reasonably reliable for respondents like those in the study" (Green \& Salkind, 2008, p. 331). Vogt (2007) acknowledges that an alpha score of .70 or higher is considered to be satisfactory for most purposes; therefore the results of the pilot survey test demonstrated that survey is a 
reliable and valid instrument.

\section{Qualitative Methods}

For the qualitative phase of the study, participants were recruited to participate in the focus group and/or individual interviews through an email invitation sent to those research participants who completed and registered for the chance to win a gift card at the end of the online survey. The purpose of the focus group and individual interviews was to allow the researcher an opportunity to dig deeper into how TRiO-eligible students make meaning of the factors influencing them to study abroad and their experience from their participation. The focus group and individual interviews were conducted using a semi-structured protocol modeled after Kasravi’s (2009) study. The factors presented within the literature review of this study and within the theoretical framework served as the foundation in the creation of the interview protocol for the focus groups. Preliminary results of the survey data also informed the focus group protocol. According to Creswell (2009), qualitative researchers engage in an "emergent design" where "the initial plan for research cannot be tightly prescribed, and all phases of the process may change or shift after the researcher enters the field and begins to collect data" (pp. 175-176). An emergent design was utilized for the interview protocol, allowing the researcher to explore further any topics, issues, or factors that arose during qualitative data collection from the focus group meeting.

The focus group questions were semi-structured and were modeled after the personal, social, and institutional factors sections of the online survey. The focus group interview began by assigning everyone in the room a pseudonym and asking participants to say where they studied abroad and for how long. As discussed by Merriam (2009), 
focus groups should include a purposeful sample in order to find individuals who know the most about a topic. In addition, Merriam (2009) states that while no formal rules exist for the number of participants, "most writers suggest somewhere between six and ten participants, preferably people who are strangers to each other" (p. 94). The desired focus group size for this study was 10 students, all of whom were TRiO-eligible and had studied abroad. While eight participants responded to the email invitation to participate in a focus group, only two participants showed up to the actual focus group. The protocol for the focus group was aimed at exploring reasons participants chose to study abroad, institutional factors influencing the decision, and barriers faced by students during the decision to study abroad. The protocol also explored benefits and outcomes participants gained from the study abroad experience. The interview protocol for the focus groups is included within this study (see Appendix B).

The individual interview protocol consisted of conducting individual interviews with TRiO-eligible participants who had participated in a study abroad program. These individuals were recruited from the gift card registration at the end of the online survey. Individuals provided their email to register for the gift card, and individuals received an email to participate in a focus group and/or an individual interview. By following the emergent research design, the goal was to dig deeper into the issues that arose from the survey results. The individual interviews lasted between 45-60 minutes, and consisted of no more than 12 questions with the researcher asking probing questions to dig deeper into issues that arose from the focus groups and from the survey results.

Merriam (2009) highlights that the key to obtaining quality data from interviewing is to ask good questions, that asking good questions takes practice, and that 
pilot interviews are integral to testing the quality of a researcher's questions. It is for these reasons that the individual interview questions for this mixed method study were informed after a 2011 qualitative study conducted by the researcher that explored factors that influenced TRiO-eligible students to study abroad, in addition to the influence of Kasravi's (2009) study with students of color. The intended individual interview protocol and questions are found within the materials of this dissertation (see Appendix C). The individual interviews took between 45-60 minutes to conduct and explored the influential factors, barriers, and benefits of the decision of the student to participate in study abroad. The researcher employed a digital recorder and a note pad to assist with accuracy of data collection and to improve the ability of coding and categorizing the data for analysis.

\section{Study Procedures}

This mixed methods study was conducted in two phases, first a quantitative phase and then a qualitative phase. Both quantitative and qualitative phases followed the research procedures outlined below.

\section{Quantitative Phase}

Once the research site had been identified, the researcher worked directly with the directors of study abroad and TRiO/Student Support Services at the research site to identify email distribution lists for the quantitative survey in compliance with the policies of the Registrar's Office. The survey was distributed to only the 757 TRiO-eligible students at the research site who had all participated in a study abroad program prior to the start of the fall 2015 semester. Recipients of the survey were asked personal identifying items to determine if their self-reported first-generation and Pell Grant status were consistent with what the institutional research office had identified. 


\section{Qualitative Phase}

According to Merriam (2009), the goal of critical inquiry "is to critique and challenge, to transform and empower" (p. 10). Further, this type of research must go beyond trying to just understand a phenomenon; rather, it must challenge and analyze in terms of conflict and oppression to eventually bring about change (Crotty, 1998, as cited in Merriam, 2009). Research must pay attention to "whose interests are being served by the way the educational system is organized, who really has access to particular programs, who has the power to make changes, and what are the outcomes of the way in which education is structured" (Merriam, 2009, p. 35). A critical perspective focuses on marginalized groups within a privileged society, and this study utilized this critical perspective to examine the effects of the educational system on TRiO-eligible students.

In addition, Merriam (2009) notes, "often qualitative researchers undertake a qualitative study because there is a lack of theory or an existing theory fails to adequately explain a phenomenon" (p. 15). Due to the lack of existing theory specifically for TRiOeligible students, a qualitative technique was employed by the researcher in the form of focus groups and individual interviews, as little evidence or theory exists that explains the underrepresentation of TRiO-eligible students in study abroad programs. The focus group and individual interview techniques were utilized as a data collection methodology to understand how TRiO-eligible participants process factors in their decision to study abroad. In addition, focus groups and individual interviews are useful when participants cannot be directly observed, and for allowing the research to have control over the line of questioning (Creswell, 2009). 
Utilizing features in Select Survey, an invitation to participate in a focus group and/or an individual interview was sent to participants who registered for the drawing to win compensation at the end of the online survey. The researcher worked with the directors of TRiO/Student Support Services and study abroad at the research site to identify a campus meeting room with a capacity of 20 participants and time to host a focus group. The original goal was to have a space large enough to comfortably accommodate 8 to 10 participants in the focus group, and schedule a backup focus group in the event there was low turnout. Therefore, one focus group was scheduled for a Thursday evening, and the backup focus group was scheduled for the next day. The original plan was to also recruit individuals from the focus groups to participate in the individual interviews. Eight research participants responded to the recruitment email confirming their participation for the Thursday focus group, while no students expressed interest in the backup focus group to take place on Friday.

During the Thursday focus group interview Kasravi's (2009) focus group protocol (see Appendix B) was followed by the researcher in the interaction with the two students who participated. Due to the low turnout for the Thursday focus group, and in consultation with the dissertation chair and methodologist, the researcher again contacted students who did not show up to the Thursday focus group. Those who registered for the gift card were invited to participate in an individual interview. An email invitation to participate in an individual interview was also sent to those research participants who expressed interest in the focus group but were unable to attend the Thursday or Friday focus group. The focus group and individual interviews each lasted 45-60 minutes. 
As Merriam (2009) articulates, qualitative researchers "are interested in understanding how people interpret their experiences, how they construct their worlds, and what meaning they attribute to their experiences" (p. 5). All three of these reasons motivated the researcher to follow up with participants from the online survey to conduct an in-depth interview modeled off of Kasravi’s (2009) and Minton's (2011) interview questions and protocol (Appendix C). Utilizing a digital recorder, notepads, and wellcrafted interview questions, the researcher set out to collect rich narratives from the participants. As Merriam (2009) highlights, "stories are how we make sense of our experiences, how we communicate with others, and through which we understand the world around us" (p. 32). The researcher attempted to make sense of the study abroad experience as evidenced through the TRiO-eligible participants, specifically the influential factors, barriers, and benefits of the students these students who chose to study abroad.

Merriam (2009) proposes that issues of rigor and trustworthiness in qualitative research should be discussed in traditional terminology of reliability and validity. Merriam (2009) further posits, "Ensuring validity and reliability in qualitative research involves conducting the investigation in an ethical manner" (p. 209). Therefore to ensure validity and reliability during the qualitative phase of the study, the researcher utilized several strategies. One strategy was to follow well established protocols for both the focus groups and individual interviews. As Yin (2003) suggests, qualitative researchers should document as many steps and procedures as possible to improve consistency and reliability. A second strategy was to submit interview protocols for review by the dissertation committee and to a collection of peers engaged in qualitative research within 
the field of education. This was done to determine the relevance of the questions and protocols to the overall study. Third, the researcher provided individual-interview participants with a copy of the transcripts from the focus group and individual interviews, to check for accuracy, as suggested by Creswell (2009).

\section{Data Analysis}

As Vogt (2007) describes, descriptive statistics focus on helping researchers summarize and describe the data collected. Four different types of descriptive statistics exist: measure of central tendency, measures of dispersion, measures of elative position, and measures of association (Vogt, 2007). To answer the research questions posited by the researcher, descriptive statistics such as measures of central tendency (means scores from survey items) were utilized, specifically to describe student responses to the items on the survey as they related to the personal, social, and institutional factors. In addition, student responses across the factors were compared by displaying mean scores for each survey item and factor. The findings from the data analysis are presented in Chapter IV.

The qualitative data captured on digital recorders and gathered from the focus group and individual interviews were transcribed verbatim. The data were reviewed several times by the researcher to look for commonalities between the different transcripts, and a coding scheme developed. As Merriam (2009) notes,

Coding is nothing more than assigning some sort of shorthand designation to various aspects of your data so that you can easily retrieve specific pieces of the data. The designation can be single words, letters, numbers, phrases, colors, or combinations of these. (p. 173)

An inductive process was used to develop a color coding scheme to review the transcripts utilizing the highlight text feature within Microsoft Word. 
Vogt, Vogt, Gardner, and Haeffele (2014) suggest that the computer spreadsheet program Excel can be a useful tool to assist qualitative researchers with keeping track of notes and organizing coding decisions. For this reason, the color coded data from the transcripts were moved into an Excel spreadsheet and divided into the following columns: pseudonym of the human subject, factor, the format of qualitative data capture, transcript line number, and the direct quote from the transcript for further analysis. As suggested by Merriam (2009), "Devising categories is largely an intuitive process, but is also systematic and informed by the study's purpose, the investigator's orientation and knowledge, and the meanings made explicit by the participants themselves" (p. 184). For these reasons, a column was added to the Excel spreadsheet to identify further themes as evidenced in the data to reflect the influence of the personal, social, and institutional factors on the decision to study abroad, as well as the barriers and benefits to participation.

\section{Summary}

A mixed method approach was used to explore the factors that influence firstgeneration and low-income students (TRiO-eligible) in their decision to study abroad, with barriers participants identified as inhibitive, and benefits of studying abroad also being explored. The data were collected in two phases using an online survey and interview protocol in focus group and individual interviews. The data were analyzed using both quantitative and qualitative techniques, such as descriptive analysis relying on measures of central tendency, and an inductive reasoning method to create codes and themes for the qualitative that was in line with the research questions posed in the study. 


\section{CHAPTER IV}

\section{RESULTS}

The purpose of this mixed methods study was to explore the factors that influence TRiO-eligible students' decision to participate in a study abroad program. In addition, the study sought to examine the challenges the students faced and the benefits they obtained from participating in study abroad programs. This study consisted of two parts: a quantitative phase based on the administration of an online survey, and a qualitative phase, which existed in the form of focus groups and in-depth, one-on-one interviews. In this chapter, study results are presented in two sections: first, the participants' demographics and profiles from both quantitative and qualitative phases, and second, a discussion of the findings in line with the central research questions posed in the study.

\section{Participant Descriptions}

The following section provides a description of the participants in both the quantitative and qualitative phases of the study. Tables are provided that include the demographic information of the participants in both phases of the study.

\section{Quantitative Phase}

The study abroad office and the institutional research office at the research site queried the respective campus databases to determine that 2,651 students (either enrolled or registered for Summer 2015 or Fall 2015 classes) had participated in a study abroad experience. Disaggregation of the query included data by first-generation and Pell grant status to provide further insight into the TRiO-eligible study abroad population. First- 
generation data utilized in the query came from an admissions attribute code applied to student admissions applications from students who indicated that their parents never attended college. Financial aid data used for the query included all study abroad participants who were eligible to receive a federal Pell grant through information from the Free Application for Federal Student Aid (FAFSA) at the research site. In total, the query revealed 746 students, or $28 \%$ of the study abroad population, had participated in a study abroad experience prior to the Fall 2015 term, were enrolled in either the Summer 2015 or Fall 2015 terms at the research site, and met the sampling criteria of being a firstgeneration college student, a Pell Grant recipient, and/or TRiO-eligible. The TRiOeligible participation rate in study abroad of $28 \%$ based on the institutional query almost mirrored the representation of first-generation and Pell Grant recipients enrolled on campus at the research site during the 2014-2015 academic year, which was $30 \%$.

In addition, the TRiO program at the research site queried the program data base to identify all 77 students who participated in the study abroad programs administered by their office since their inaugural study abroad trip in 2012. Of those 77 students, 66 were still enrolled at the research site and were included in the 746 names returned by the institutional query, leaving 11 individuals who had graduated from the research site that were not included on the list generated from the institutional query. In total, the online survey was administered to a purposeful sample of 757 TRiO-eligible participants who had participated in a study abroad program through the research site.

A total of 246 individuals responded to the survey; however, 38 individuals had several incomplete survey items or indicated they were no longer TRiO-eligible and therefore their responses were eliminated, leaving 208 TRiO-eligible survey responses. 
In total, the online survey yielded a $27.4 \%$ response rate from the TRiO-eligible population at the research site. Visser, Krosnick, Marquette, and Curtin (1996) investigated the accuracy of statewide mail surveys conducted by the Columbus Dispatch to determine election results. The researchers concluded the surveys, which received a response rate ranging from $21 \%-28 \%$ and averaging $25 \%$, were surprisingly much more accurate than other methods. Their findings challenged conventional wisdom that the larger the response rate, the more likely an instrument is to be accurate in generalizing results for a population. Therefore, the response rate of over $27 \%$ was within the acceptable range to yield accurate results. Tables 1 and 2 provide information on the online survey participants' demographics.

According to Table 1, the majority of individuals who participated in the online survey $(76 \%)$ had received a federal Pell grant to finance their education at the research site, while (63\%) identified as a first-generation college student. Additionally, 52.9\% came from households with an annual income below $\$ 50,000$. Similar to the overall population of study abroad students, survey respondents identified as being predominately female $(76.0 \%)$ and white $(84.6 \%)$. It is important to note that a limitation of this study was that only male and female were options on the survey for gender, not addressing the needs of transgender students. Only $11.1 \%$ identified their ethnicity as Hispanic or Latino, 5.8\% as Black or African American, 5.8\% identified as Asian, and $2.9 \%$ indicated they were bi-racial or multi-racial. 
Table 1

Distribution of Online Survey Participants by Pell Grant Status and Demographics

\begin{tabular}{|c|c|c|}
\hline Demographics & $\mathrm{N}$ & $\%$ \\
\hline \multicolumn{3}{|l|}{ Pell Grant Status } \\
\hline No & 50 & 24.0 \\
\hline Yes & 158 & 76.0 \\
\hline Total & 208 & 100.0 \\
\hline \multicolumn{3}{|l|}{ Annual Family Income } \\
\hline$\$ 25,000$ or less & 37 & 17.8 \\
\hline$\$ 25,001-\$ 50,000$ & 73 & 35.1 \\
\hline$\$ 50,001-\$ 75,000$ & 56 & 26.9 \\
\hline$\$ 75,001-\$ 100,000$ & 19 & 9.1 \\
\hline$\$ 100,001$ or more & 16 & 7.7 \\
\hline No Response & 7 & 3.4 \\
\hline Total & 208 & 100.0 \\
\hline \multicolumn{3}{|l|}{ First-Generation Status } \\
\hline Not First Generation & 77 & 37.0 \\
\hline First Generation & 131 & 63.0 \\
\hline Total & 208 & 100.0 \\
\hline \multicolumn{3}{|l|}{ Gender } \\
\hline Male & 50 & 24.0 \\
\hline Female & 158 & 76.0 \\
\hline Total & 208 & 100.0 \\
\hline \multicolumn{3}{|l|}{ Ethnicity } \\
\hline Hispanic or Latino & 23 & 11.1 \\
\hline Not Hispanic or Latino & 185 & 88.9 \\
\hline Total & 208 & 100.0 \\
\hline \multicolumn{3}{|l|}{ Race } \\
\hline No Response & 2 & 1.0 \\
\hline Two or More Races & 6 & 2.9 \\
\hline Asian & 12 & 5.8 \\
\hline Black or African American & 12 & 5.8 \\
\hline White & 176 & 84.6 \\
\hline Total & 208 & 100.0 \\
\hline \multicolumn{3}{|l|}{ Age } \\
\hline $18-24$ & 205 & 98.6 \\
\hline 25 or Older & 3 & 1.4 \\
\hline Total & 208 & 100.0 \\
\hline \multicolumn{3}{|l|}{ Year in College } \\
\hline Freshmen & 1 & .5 \\
\hline Sophomore & 30 & 14.4 \\
\hline Junior & 62 & 29.8 \\
\hline Senior & 110 & 52.9 \\
\hline Recent Graduate of Site & 5 & 2.4 \\
\hline Total & 208 & 100.0 \\
\hline
\end{tabular}


Respondents predominately associated with the traditional college student age range of 18-24 (98.6\%), with (52.9\%) identifying their current class standing as seniors and $(29.5 \%)$ as juniors. A wide range of academic colleges out of the 13 at the research site were represented, with the most (26.4\%) from the College of Health and Human Sciences, followed by the College of Agriculture (19.7\%). Survey respondents reported a minimum GPA of 2.20 out of a max of 4.00, mode of 3.00, and mean GPA of 3.30.

Table 2

Citizenship and Experiences Outside the United States

\begin{tabular}{lrr}
\hline Item & $\mathrm{N}$ & \multicolumn{1}{c}{$\%$} \\
\hline Citizenship Status & & \\
U.S. citizen & 205 & 98.6 \\
Naturalized U.S. citizen & 1 & 0.5 \\
Permanent resident & 2 & 1.0 \\
Total & 208 & 100.0 \\
Previous Travel Outside the U.S. & & \\
Yes & 120 & 57.6 \\
No & 88 & 42.3 \\
Total & 208 & 100.0 \\
Lived Outside the U.S. & & \\
Yes & 12 & 5.8 \\
No & 196 & 94.2 \\
Total & 208 & 100.0 \\
Length of Study Abroad & & \\
4 Weeks & 55 & 26.4 \\
5 Weeks & 2 & 1.0 \\
6 Weeks & 21 & 10.1 \\
7 Weeks & 5 & 2.4 \\
8 Weeks & 8 & 3.8 \\
1 Semester & 30 & 14.4 \\
1 Academic Year & 4 & 1.9 \\
Other & 83 & 39.9 \\
Total & 208 & 100.0 \\
\hline
\end{tabular}

Additional demographic information, listed in Table 2, provides insight into the citizenship status of survey respondents and previous activity of the individual outside the 
United States. As demonstrated below, 98.6\% identified as U.S. citizens, and only 5.8\% reported having lived outside the United State prior to participating in study abroad. It appears that travel outside the United States before participating in study abroad was common among respondents, with $57.2 \%$ reporting having traveled outside the U.S. A total of $60 \%$ of the study respondents participated in study abroad for 4 weeks or longer.

\section{Individual Interview and Focus Group Participants' Profiles}

The qualitative phase of the study consisted of one focus group and four semistructured individual interviews. The following tables display a summary of participant backgrounds for both the focus group (Table 3) and the individual interviews (Table 4). Pseudonyms, provided by the research participants, were utilized to minimize risk and to ensure participant confidentiality. Great effort was made to recruit students for the focus group interview that took place at the research site. The researcher requested the TRiO/Student Support Services Program and the Study Abroad Offices at the research site to post messages on a variety of social media platforms to raise awareness of the study, particularly the focus group. Several students responded to the recruitment e-mail to secure a spot in the focus group, and received email reminders from the researcher only to either cancel or not attend the focus group. This resulted in having only two participants for the focus group.

As illustrated, the two individuals who participated in the focus group majored in agriculture, and even went on the same study abroad program sponsored through their college. One participant had studied abroad more than once. Both graduated in May from the research site with a pre-professional major and were current graduate students. Both were female and identified as white. 
Table 3

Focus Group Participant Profiles

\begin{tabular}{lllll}
\hline $\begin{array}{l}\text { Participant Name } \\
\text { (pseudonym) }\end{array}$ & TRiO-Eligibility & $\begin{array}{l}\text { Major and Year } \\
\text { in School }\end{array}$ & Race/Ethnicity & $\begin{array}{c}\text { Study Abroad } \\
\text { Location }\end{array}$ \\
\hline Alex & First-Generation & $\begin{array}{l}\text { Animal Science } \\
\text { Current Graduate } \\
\text { Student }\end{array}$ & White & $\begin{array}{l}\text { Romania } \\
4 \text { weeks }\end{array}$ \\
& Pell Grant & $\begin{array}{l}\text { Pre-veterinary } \\
\text { Science senior }\end{array}$ & White & $\begin{array}{l}\text { Romania } \\
4 \text { weeks \& } \\
\text { Leigh }\end{array}$ \\
& Recipient & Ireland \\
& & & 3 weeks \\
\hline
\end{tabular}

The individual interview participants studied a range of academic programs, and represented study abroad participation on three continents. All participants in the individual interviews were female, but represented a variety of TRiO-eligibility and race/ethnicity (see Table 4).

Table 4

Individual Interviews Participant Profiles

\begin{tabular}{|c|c|c|c|c|}
\hline $\begin{array}{l}\text { Participant } \\
\text { Name } \\
\text { (pseudonym) }\end{array}$ & TRiO-Eligibility & $\begin{array}{l}\text { Major and Year } \\
\text { in School }\end{array}$ & Race/Ethnicity & $\begin{array}{c}\text { Study Abroad } \\
\text { Location }\end{array}$ \\
\hline Kendall & First Generation & $\begin{array}{l}\text { Pre-Physical } \\
\text { Therapy/Senior }\end{array}$ & White & $\begin{array}{l}\text { Queensland, } \\
\text { Australia }\end{array}$ \\
\hline Azalea & $\begin{array}{l}\text { First Generation } \\
\& \text { Pell Grant }\end{array}$ & $\begin{array}{l}\text { Organizational } \\
\text { Leadership/Senior }\end{array}$ & Hispanic/Latino & $\begin{array}{l}\text { Valencia, } \\
\text { Spain }\end{array}$ \\
\hline Amy & $\begin{array}{l}\text { First Generation } \\
\& \text { Pell Grant }\end{array}$ & $\begin{array}{l}\text { Agriculture/Soil } \\
\text { Science }\end{array}$ & White & $\begin{array}{l}\text { Dublin, } \\
\text { Ireland }\end{array}$ \\
\hline Jane & Pell Grant & $\begin{array}{l}\text { Finance and Mass } \\
\text { Communication }\end{array}$ & Asian & $\begin{array}{l}\text { Taipei, } \\
\text { Taiwan }\end{array}$ \\
\hline
\end{tabular}




\section{Presentation of Findings by Research Question}

\section{Research Question 1}

For the central research question (What factors influence TRiO-eligible students' decision to participate in study abroad programs?), descriptive statistics such as measures of central tendency, specifically comparing means between grouped survey items as they relate to the personal, social, and institutional factors, were utilized to analyze the data gathered from the study participants. In addition, the data gathered from the focus group and individual interviews were analyzed using thematic analysis and the results were woven together with the findings from the online survey to capture the participants' interpretation of their decision-making process to study abroad, their experiences while abroad, and the impact of the study abroad experience.

Participant perceptions with respect to the research question are highlighted in several of the tables that follow. A total of 31 questions containing 71 items were asked to ascertain what factors influence TRiO-eligible students' decision to participate in study abroad programs. Results presented in Table 5 indicate that TRiO-eligible students who decided to participate in study abroad first considered doing so early in their academic career. A total of $67.2 \%$ of survey respondents indicated they first considered participating in study abroad while in high school or during their first year of college. Fewer than $6 \%$ of survey respondents first considered study abroad after their second year in college. 
Table 5

First Consideration of Study Abroad

\begin{tabular}{lrr}
\hline Time of first consideration & \multicolumn{1}{c}{$\%$} & \multicolumn{1}{c}{$\mathrm{N}$} \\
\hline Prior to high school & 7.8 & 15 \\
During high school & 33.2 & 64 \\
First year in college & 33.7 & 65 \\
Second year in college & 20.2 & 39 \\
Third year in college & 4.1 & 8 \\
Fourth year in college & 1.0 & 2 \\
Total & $100 \%$ & 193 \\
\hline
\end{tabular}

Social factors. Consistent with the adapted model of the decision to study abroad, a social factor explored by survey results included primary sources of information about study abroad. These results provide a glimpse into the choice process for study abroad. Table 6 provides results from a multi-selection question that asked study abroad students to indicate all sources of information from which they first heard about the specific study abroad program in which they decided to participate. The results indicate that $31.7 \%$ of respondents identified the study abroad website as the most selected source of information. Professors rated as the next highest at $25.0 \%$, while study abroad information fairs resulted in $23.6 \%$.

Results presented in Table 7 explore social factors, such as the experiences and recommendations of influential people, and perceived social pressures. In looking at the survey items addressing these specific social factors, respondents were asked how influential academic advisors, professors, study abroad advisors, friend/significant others, former study abroad participants, parent(s), and sibling(s) were in the decision to study abroad. Survey results indicated that peer influences were connected most often to the decision for TRiO-eligible students to participate in study abroad programs. 
Table 6

Social Factor: Sources of Information First Heard

About the Specific Study Abroad Program

\begin{tabular}{lcc}
\hline Source of Information & $\mathrm{N}$ & $\%$ \\
\hline Academic Advisor & 37 & 17.8 \\
Support Program for First- & 36 & 17.3 \\
Generation and Pell Grant & & \\
Recipients & 33 & 15.9 \\
Study Abroad Advisor & 52 & 25.0 \\
Professor & 49 & 23.6 \\
Study Abroad Fair & 34 & 16.3 \\
Former students who went abroad & 2 & 1.0 \\
Family member & 35 & 16.8 \\
E-mail & 36 & 17.3 \\
Printed poster or flier & 66 & 31.7 \\
Study Abroad website & 15 & 7.2 \\
Study abroad information table & 34 & 16.3 \\
Classroom presentation & 22 & 10.6 \\
Friend/Significant other &
\end{tabular}

Table 7

Social Factor: Recommendations of Influential People

\begin{tabular}{lcccccc}
\hline Influential People & $\mathrm{N}$ & Mean & $\begin{array}{c}\text { Not } \\
\text { Influential } \\
\%\end{array}$ & $\begin{array}{c}\text { Somewhat } \\
\text { Influential } \\
\%\end{array}$ & $\begin{array}{c}\text { Very } \\
\text { Influential } \\
\%\end{array}$ & $\begin{array}{c}\text { Influential } \\
\%\end{array}$ \\
\hline Academic Advisor & 206 & 1.85 & 46.6 & 29.6 & 16.0 & 7.8 \\
Professor & 203 & 2.27 & 35.5 & 19.7 & 27.1 & 17.7 \\
Study Abroad Advisor & 205 & 2.06 & 42.0 & 25.4 & 17.6 & 15.1 \\
Friend/Significant Other & 206 & 2.52 & 19.9 & 27.2 & 33.5 & 19.4 \\
Former Study Abroad & 205 & 2.39 & 27.8 & 23.4 & 31.2 & 17.6 \\
Participant & & & & & & \\
Parent(s) & 206 & 2.37 & 27.7 & 24.8 & 30.6 & 17.0 \\
Sibling(s) & 205 & 1.88 & 52.2 & 19.0 & 17.6 & 11.2 \\
\hline
\end{tabular}

Of the respondents, $52.9 \%$ indicated that friends/significant others and $48.8 \%$

indicated that former study abroad participants were influential or very influential in the decision process of choosing to study abroad. Surprisingly, parents were the third highest influential social factor, with $47.6 \%$ indicating parents were influential or very influential 
in the decision process of choosing to study abroad, followed by $44.8 \%$ indicating a professor. The three items with the lowest degree of being influential or very influential to the decision of study abroad were study abroad advisor $32.7 \%$, sibling(s) $28.8 \%$, and academic advisor $23.8 \%$.

Peer social factors. Research participants in the focus group and those who participated in individual interviews provided further insight into the influence that the experiences and recommendations of others had on the decision to study abroad. Of particular importance were peer social factors, such as friends and former study abroad participants, on the decision to study abroad. The qualitative data below provides further insight into this social factor.

Kendall, a pre-physical therapy major and interview participant, described the influence of a former study abroad participant who presented in her general seminar course focused on academic and career exploration.

They brought in, like, the study abroad advisor, but then also students who had studied abroad. And you could just tell on their faces like when they were telling stories how much that they loved it. And they showed pictures, and it was such a unique experience and they talked about how independent they became and just like all of these things and they just got to do so many awesome things. And, and I don't know. That was the moment that I was just like "yup!", first semester freshman year I was like, I am going to go study abroad!

Alex, a first-year graduate student in animal science, reflected on the influence of a former study abroad participant who went on the same study abroad program to Romania that she eventually chose. She met the former study abroad participant at an ice cream social sponsored by the College of Agriculture while she was an undergraduate.

He was just trying to, like, tell people about, like, the great experience that he had and just kind of, like, let everyone know that it is very do-able, and it's, like, you can fit it into your schedule, it's affordable; like, that kind of thing. 
Jane, a finance and mass communication major, participated in a study abroad program her freshman year, sponsored through the research site. She discussed the social influence of a former study abroad participant:

They were like "Yeah I did it for spring break and it is really nice so you should definitely try it!" And yeah. I'm in a business fraternity in [the College of Business], and it's just like an older brother who had gone through the program.

Jane further attributed her finding out about the program to this fraternity brother and said she most likely would not have gone her freshman year without his influence.

Another research participant, Amy, an agriculture and soil science major, discussed the importance of peer influence on the decision to study abroad. She attributed her actual completion of the study abroad application to a sorority sister who had been accepted to a study abroad program in Ireland.

She kept talking about it and just how excited she was about it. And she told me that I should apply. Because she knew I wanted to go there, I just hadn't made that actual push and step to go. She told me "you need to apply, you need to go."

Amy additionally added that the great support she received from her sorority sister and from her boyfriend were helpful. Interestingly, Amy had the opportunity to meet with current exchange students on her campus who were from the university in Ireland she was considering. She remarked, "Getting to see students from the college I was about to go to was really motivating as well." While peer influences were clearly articulated, research participants also mentioned the importance of family in the decision process.

Family social influence. Out of the social factors measured by the survey, $47.6 \%$ of respondents acknowledged that parent(s) were influential or very influential in the decision to study abroad. Research participants revealed some parents were not supportive and needed convincing, while others spoke powerfully about the advocacy of 
parents in both the decision and process to study abroad. Azalea, an organizational leadership major who identifief as Latina, spoke highly of the positive influence she received from her family. She described the support from her mother.

So was my mom, because she is the one that helped pay for it mostly. And she knew that it was such a good opportunity for me, knowing that since we don't really have a lot of money to really spend on going abroad, especially going overseas. She knew this was a once in a lifetime opportunity for me to like do it. She was like "do it!"

Unlike Azalea, both Kendall and Amy came from families that were divided on the idea of having their daughters participate in study abroad. It was the mother in both cases that served as the influencer and advocate for the students. Kendall described her mom as the only person who was semi-encouraging in her family and said, "She dropped me off at the airport and cried and stuff, but she is a really big advocate of 'do things while you are young, do things that will better yourself.", Amy shared a similar experience and described her mother as, "Really supportive. She said that she wishes that she had went to college and been able to do something [study abroad] like that."

In addition to the family influences that contributed to the decision to study abroad, research participants also shared that professors and other campus staff influenced their decision.

Social influence of professors and campus staff. While only $44.8 \%$ of survey respondents reported professors as influential or very influential to the decision to study abroad, two research subjects in the focus group reported positive influences from faculty, while interview participants acknowledged other campus staff. Alex added the following about one of her professors. 
The specific trip that I heard about was when, uh, Dr. Russell was actually teaching one of my classes. He's one of the-one of-actually, a great professor here. And he was talking about, uh, one of the trips and stuff he was going on, and I knew I wanted to study abroad, and I just couldn't decide where I wanted to go. So he started to talk about it, and that's, like, the first time I, like, heard about the one that I went on.

Leigh, a pre-veterinary science major and participant in the focus group, also attributed

Dr. Russell, her professor and faculty advisor, with informing her about the study abroad program to Romania that she participated in. Leigh remarked, "Dr. Russell is my advisor, so I actually-it was really easy for me to just e-mail him and ask about it."

Research participants also shared that campus staff helped influence their decision to participate in study abroad. Azalea was a first-generation student and Pell Grant recipient who also identified as Hispanic. She was an active participant in the federal TRiO/Student Support Services program at the research site, and it was through this program that she participated in a summer study abroad program to Spain. She described the influence from staff that worked for the TRiO program.

The Director of [TRiO/Student Support Services], Rosa, Um. I know her very well. And she, um, was like, "this is a really good opportunity and you should think about it." Um actually, both of the staff members, Josh, they were really encouraging.

Azalea further described the social influences she received from her participation in the campus TRiO program.

And, um, the staff members, I knew them. So it was easier for me to know, like, oh, I am with this staff member who made me comfortable. I already knew them so I did not have that awkward, oh I don't know this person yet. How can I trust them? And I already knew some people who were going to apply for it, so that made it easier for me.

While the influence of these professors and campus staff was explored as a social factor, it was important to explore institutional factors that contributed to the decision making 
process of TRiO-eligible students to study abroad.

Institutional factors. Table 8 provides detailed information into the participation of survey respondents in a variety of institutional support programs geared specifically toward first-generation and low income-eligible participants. A majority, $68.3 \%$, did not participate in any institutional support program. Of the $29.3 \%$ who did participate, the most participated in the federal TRiO/Student Support Services program (16.3\%), while $12.0 \%$ participated in an institutional support program that partnered with a state-funded financial scholarship/award program that provided up to 30 credit hours of tuition at any participating institution within the state.

Table 8

Institutional Factor: Institutional Support Programs for TRiO-eligible Students

\begin{tabular}{lrr}
\hline Support Programs & $\mathrm{N}$ & \multicolumn{1}{c}{$\%$} \\
\hline TRiO/Student Support Services & 34 & 16.3 \\
Urban Leadership Program & 1 & 0.5 \\
Support Program for Underrepresented Students in Science & 1 & 0.5 \\
State \& Institutional Support Program & 25 & 12.0 \\
Do Not Participate in Any Programs & 142 & 68.3 \\
\hline
\end{tabular}

It is important to note that Table 8 is only descriptive. The table highlights the participation or lack of participation of survey responders in institutional support programs geared toward first-generation and low-income students. Further data analysis between those survey responders who received institutional support and those who did not revealed that those who received institutional support reported higher means scores for the institutional factor, "overall as a first-generation college student or Pell grant recipient, I felt that my needs and concerns were met in discussion of study abroad.” 
Those who actively participated in an institutional support program specifically for firstgeneration and low-income students reported a mean score of 3.32 compared to a 3.28 for those who did not actively participate in an institutional support program.

Of the research participants from the individual interviews and focus group, only Azalea received support from one of these institutional support programs geared toward TRiO-eligible students. Azalea described the support she received from the campus TRiO program.

Through the [TRiO] program that I went with, because like I said I am from a low-income and I am out of state, um the, cost was very affordable compared to other programs that are offered through [research site]. Some were like thousands and thousands of dollars, whereas this one, was if I remember correctly was less than $\$ 4000$ thousand for me to attend for four weeks. And that was very doable for me.

Azalea further remarked on the support from the TRiO program, "I know if I didn't have the support or the financial means to do it I would not have studied abroad." Additional institutional factors at the research site, such as advising and resources, were explored by the survey and by the narratives from individual interviews and the focus group.

Survey respondents had the opportunity to rate the degree to which a variety of institutional factors influenced their study abroad decision. Overall, the mean scores of the institutional factors in Table 9 were higher than other factor groups explored by the survey. A majority of survey respondents, $97.1 \%$, indicated that they agreed or strongly agreed that the number and type of study abroad programs offered through the institution were good. Additionally, $95.6 \%$ reported that they agreed or strongly agreed that information on study abroad programs and opportunities was readily available at the institution. Survey items addressing the unique needs of TRiO-eligible students revealed 
that $95 \%$ agreed or strongly agreed that the institution encouraged study abroad for students like themselves and that overall the institution met the needs and concerns of first-generation college students or Pell grant recipients in discussion of study abroad. When asked about the eligibility of study abroad requirements at the research site, $91.9 \%$ agreed or strongly agreed study abroad eligibility was not strict.

Additional institutional factors, such as those focused on advising and financial support, revealed that TRiO-eligible students felt comfortable and satisfied utilizing campus resources during the study abroad process. The data reveal that $90.6 \%$ indicated they agreed or strongly agreed the research site offered good sources of funding for students wanting to go abroad. Additionally, $86 \%$ of survey respondents agreed or strongly agreed that they felt comfortable speaking with a study abroad advisor about study abroad, $87.1 \%$ were comfortable speaking with an academic advisor, and $88 \%$ were comfortable speaking with their professors about study abroad. The results are shown in Table 9.

Like the survey respondents, research participants in the focus group and individual interviews all revealed the influence that these institutional factors had on their decision to participate in a study abroad program. Participants discussed the positive assistance they received from the staff of the Study Abroad Office and the efforts the office took to promote study abroad opportunities. As one of the focus group participants, Alex, shared, "Study abroad at [research site], they advertise hard!" The other focus group participant, Leigh, added that e-mails and posters from the study abroad office contributed to word being out on campus about study abroad. In addition to advertising, the study abroad office provided advising and resources to support the decision. 
Table 9

Institutional Factors in the Study Abroad Decision

\begin{tabular}{|c|c|c|c|c|c|c|}
\hline Institutional Factors & $\mathrm{N}$ & Mean & $\begin{array}{l}\text { Strongly } \\
\text { Disagree } \\
\%\end{array}$ & $\begin{array}{l}\text { Disagree } \\
\%\end{array}$ & $\begin{array}{c}\text { Agree } \\
\%\end{array}$ & $\begin{array}{l}\text { Strongly } \\
\text { Agree } \\
\%\end{array}$ \\
\hline $\begin{array}{l}\text { Study Abroad Information } \\
\text { Available }\end{array}$ & 203 & 3.35 & 0.5 & 3.9 & 55.2 & 40.4 \\
\hline $\begin{array}{l}\text { Study Abroad Types and Number } \\
\text { Good }\end{array}$ & 202 & 3.41 & 0.5 & 2.5 & 53.0 & 44.1 \\
\hline Study Abroad Eligibility Not Strict & 199 & 3.16 & 0 & 8.0 & 67.8 & 24.1 \\
\hline Good Funding Available & 202 & 3.29 & 1.0 & 8.4 & 51.0 & 39.6 \\
\hline $\begin{array}{l}\text { Study Abroad Encouraged for } \\
\text { TRiO-eligible Students }\end{array}$ & 201 & 3.46 & 0.5 & 4.5 & 43.8 & 51.2 \\
\hline $\begin{array}{l}\text { Comfortable Speaking with Study } \\
\text { Abroad Advisor about Study } \\
\text { Abroad }\end{array}$ & 201 & 3.18 & 2.0 & 11.9 & 51.7 & 34.3 \\
\hline $\begin{array}{l}\text { Comfortable Speaking with } \\
\text { Academic Advisor about Study } \\
\text { Abroad }\end{array}$ & 202 & 3.24 & 2.0 & 10.9 & 48.0 & 39.1 \\
\hline $\begin{array}{l}\text { Comfortable Speaking with } \\
\text { Professor about Study Abroad }\end{array}$ & 201 & 3.23 & 0.5 & 11.4 & 52.7 & 35.3 \\
\hline $\begin{array}{l}\text { Overall needs as a first-generation } \\
\text { college student or Pell grant } \\
\text { recipient were met }\end{array}$ & 200 & 3.30 & 1.0 & 4.0 & 59.5 & 35.5 \\
\hline
\end{tabular}

Kendall knew her first year at the research site that she desired to study abroad, but she was unsure of what to do. She described the assistance she received from study abroad office staff:

Oh, and I did meet sophomore year with the study abroad advisors, so I wasn't sure where I wanted to go but I knew I wanted to go. So I met with them, just a general meeting and they kind of helped like guide me to where would be best for me. 
Kendall eventually studied in Australia, and she added, "So the [study abroad advisor] was super helpful." It was also Kendall who mentioned first hearing about study abroad through a general studies course in which a study abroad staff member came to speak to her class. This effort too can be viewed as an institutional factor, as it promotes study abroad by the office. While the study abroad office is certainly an influencing force, other institutional factors come from academic departments in the form of academic advising and the creation of college-based study abroad programming.

The survey results were mixed as they related to academic advising, with only $17.8 \%$ of respondents identifying academic advisors as a source of information about study abroad, while $87.1 \%$ agreed or strongly agreed that they felt comfortable speaking with academic advisors about study abroad. Research participants in the interviews disclosed the impact academic advisors had on their decision. Amy, an agriculture and soil science major, described her interaction with academic advising: "The advisor, the ag advisor, she also went to UCD [Ireland], she was really motivating when she was talking to me about it." In addition to serving as an influencing factor once Amy made the decision to study abroad, she continued to find academic advising helpful. Amy reflected on her experience saying, "After talking to my advisor we found ways to, you know, take these classes at different times. Some of the classes I took at UCD, [they] counted even though it wasn't here at the [research site]." After receiving assistance about course selection and having a clear plan regarding her plan of study, Amy was able solidify her commitment and decision to study abroad.

In addition to advising, research participants felt that the college played a role in creating and advertising study abroad opportunities that were interesting and meaningful 
to students, essentially influencing the decision. Alex, one of the focus group participants, mentioned that she was in an agricultural science seminar "when I first learned about it [study abroad]." Alex followed up on learning more about the specific study abroad program that she eventually went on by attending an ice cream social sponsored by the College of Agriculture.

As referenced earlier in the discussion on social factors, it was at this ice cream social that the study abroad office had former study abroad participants speak about their experiences. The peer interaction had significant influence on Alex's decision, and this was made possible by the college. The other focus group participant, Leigh, described the college's efforts: “The College of Ag does a really good job about doing programs for us, but no matter how much money it is, in the long run it's gonna pay off." One way the colleges at the research site did a "good job" of creating study abroad opportunities for students was through providing funding, as evidenced by the descriptions of research participants below.

According to the survey, $90.6 \%$ of respondents agreed or strongly agreed that the research site offered good sources of funding for students wanting to study abroad. This sentiment is evidenced in the reactions of research participants in the interviews and focus group. Jane, a business and journalism major, attended a shot-term study abroad program studying emerging Asian markets in Taiwan sponsored through the college of business. Jane remarked, "I did get scholarships for the program, so that really helped." Kendall shared a similar opinion of the financial support she received from the institution, particularly in helping her convince her father that going to Australia was realistic from a financial perspective. Kendall described the impact of the funding. 
I ended up getting a lot of scholarships to go, which was awesome. So that really helped my dad realize like "oh, maybe that's not so bad." It ended up being cheaper than a normal semester [at research site]. Because I got a lot. There was a lot of help available, and some people do not realize that.

Leigh also voiced the importance of institutional funding for study abroad, saying "Uh, well, in terms of what made me, like, push me over the edge was definitely the scholarships offered to us." Students also felt that they had support when needing to discuss funding for study abroad from the financial aid office. Alex remarked, "They were-they e-mailed me back really quick; they were willing to answer any question that I had; they, you know, gave me a straightforward answer." Especially for first-generation students, having this type of institutional support is helpful in the decision process. Another important factor to investigate are the personal factors involved in the decision process.

Personal factors. Results from personal factors measured by the survey included personal characteristics, perceived outcomes, and obstacles. The personal characteristics, ranging from program cost to exploring one's own heritage/cultural roots, were measured by question 27 of the survey, with results presented in Table 10. Results indicated that $88.0 \%$ of respondents believed program costs were important or very important in their decision to choose the specific study abroad program they participated in. Of next importance were duration of the program $(81.7 \%)$, interest in course work available (75.6\%), and transferability of credits (74.9\%) taken while abroad. Personal factors of least importance included living in an apartment (13.0\%) and living with a host family (18.1\%). 
Table 10

Personal Factors: Importance of Specific Program Characteristics by Percent

\begin{tabular}{|c|c|c|c|c|c|c|}
\hline Personal Characteristics & $\mathrm{N}$ & Mean & $\begin{array}{c}\text { Not } \\
\text { Important } \\
\%\end{array}$ & $\begin{array}{c}\text { Slightly } \\
\text { Important } \\
\%\end{array}$ & $\begin{array}{c}\text { Important } \\
\%\end{array}$ & $\begin{array}{c}\text { Very } \\
\text { Important } \\
\%\end{array}$ \\
\hline Program costs & 199 & 3.40 & 3.5 & 8.5 & 32.2 & 55.8 \\
\hline Duration of the program & 197 & 3.10 & 4.1 & 14.2 & 49.2 & 32.5 \\
\hline Language of study & 195 & 2.75 & 15.9 & 20.5 & 35.9 & 27.7 \\
\hline Size of city/town & 199 & 1.91 & 46.7 & 26.1 & 16.1 & 11.1 \\
\hline Country of program & 199 & 2.84 & 12.6 & 16.6 & 44.7 & 26.1 \\
\hline $\begin{array}{l}\text { Parents(s)/family } \\
\text { influence }\end{array}$ & 199 & 2.29 & 28.6 & 28.1 & 28.6 & 14.6 \\
\hline Transferability of credits & 199 & 3.05 & 10.6 & 14.6 & 34.7 & 40.2 \\
\hline $\begin{array}{l}\text { Interest in course work } \\
\text { available }\end{array}$ & 197 & 3.05 & 6.1 & 18.3 & 40.1 & 35.5 \\
\hline $\begin{array}{l}\text { Exploring heritage/ } \\
\text { cultural roots }\end{array}$ & 199 & 1.74 & 57.3 & 21.1 & 12.1 & 9.5 \\
\hline $\begin{array}{l}\text { Internship/volunteer work } \\
\text { options }\end{array}$ & 199 & 2.02 & 46.2 & 18.1 & 23.6 & 12.1 \\
\hline Living with a host family & 199 & 1.61 & 63.8 & 18.1 & 11.6 & 6.5 \\
\hline Living in an apartment & 199 & 1.50 & 67.3 & 19.6 & 8.5 & 4.5 \\
\hline $\begin{array}{l}\text { Taking classes at host } \\
\text { university }\end{array}$ & 199 & 2.20 & 34.7 & 22.1 & 31.7 & 11.6 \\
\hline $\begin{array}{l}\text { Level of integration into } \\
\text { host culture }\end{array}$ & 199 & 2.87 & 12.6 & 15.6 & 44.2 & 27.6 \\
\hline
\end{tabular}

Research participants in the interviews and focus group had similar thoughts to survey respondents in regard to program costs. All participants acknowledged that program costs were important in their choice of study abroad program, and the importance that institutional factors, such as funding, played in supporting their decision was highlighted above. As Azalea reflected, "One of the big factors that influenced me was the cost." As evidenced in the institutional factor section, the TRiO program that hosted the study abroad opportunity Azalea eventually participated in strove to provide as much institutional funding as possible to help reduce program costs to students. 
In addition to cost, the duration of the study abroad program and the course work available offered through the research site played an important role in the decision process. When asked what influenced her decision, Jane described:

Um, I think this one was the length of the program. Just because yes, there are a lot of semester abroad programs. But sometimes. Like I said, I am double majoring in two different colleges so that is not often a feasible thing. Um, and also Asia is developing at a ridiculously rapid rate. And, Europe I feel will always be like how it is. And I can go back and tour anytime, but to see a country develop is, you know, it's like a specific point in time. So that is specifically why I wanted Taiwan.

Amy shared a similar degree of influence with her desire to study at the university in Ireland: "I was just really interested in their agriculture and they had a great Ag school." In addition to duration and offerings through the study abroad program, the location and overall experience were also described as influencing factors.

To Azalea, program cost was a big factor for her to participate in the study abroad program sponsored through her TRiO program; however, location was also important. As Azalea described, "And then once I heard that they were going to Spain, that was-I think that was one of the bigger factors for me because I always wanted to go to Spain." This sentiment was shared by Kendall as well, as she said, "Because like for me the overall experience was most important." In addition to location and overall experience, participants were motivated by program characteristics, such as exploring one's own heritage/cultural roots and service learning.

Amy, a first-generation college student and Pell recipient, participated in a study abroad program in Ireland. She described herself as a "townie" and "homebody" as she was from the same small city where the research site was located. For her study abroad experience, Amy chose to attend the University College of Dublin for an agricultural 
program and to explore her own cultural roots. She explained her motivation this way: "I actually, my great-grandma, she came from Belfast, Ireland, so Ireland was always a place that I was interested in going to see as far, as you know, where my ancestors come from." Other program characteristics influencing the decision of students to choose particular study abroad programs included service learning, as Leigh remarked, "I really like travel, I really wanna do this. And it was a work study, um, study abroad work service, and that was really, um, something I wanted to do.” In addition to program characteristics, the survey and interviews/focus groups explored the perceived outcomes research participants had of study abroad.

Perceived outcomes. Survey respondents rated the degree to which additional personal characteristics, including the influence of a number of perceived outcomes, had on their decision to participate in study abroad. Table 11 represents these responses, along with mean scores for comparison. Overwhelmingly, respondents desired to learn about another culture, with $91.9 \%$ indicating that this perceived outcome was influential or very influential to the decision to study abroad. The next four perceived outcomes found to be either influential or very influential were a desire to increase independence (87.0\%), helping professionally in a globalized world (82.9\%), the opportunity for individuals to learn about themselves (79.9\%), and be more marketable to future employers (77.9\%). Surprisingly, the following perceived outcomes were rated low with regard to being influential or very influential in the decision to study abroad: learning about one's own cultural roots (18.6\%), and learning/improving a foreign language (41.4\%), respectively. 
Table 11

Personal Factor: The Influence of Perceived Outcomes on the Decision to Study Abroad

\begin{tabular}{|c|c|c|c|c|c|c|}
\hline Perceived Outcomes & $\mathrm{N}$ & Mean & $\begin{array}{c}\text { Not } \\
\text { Influential } \\
\%\end{array}$ & $\begin{array}{c}\text { Somewhat } \\
\text { Influential } \\
\%\end{array}$ & $\begin{array}{c}\text { Influential } \\
\%\end{array}$ & $\begin{array}{c}\text { Very } \\
\text { Influential } \\
\%\end{array}$ \\
\hline $\begin{array}{l}\text { Fulfill elective } \\
\text { requirements }\end{array}$ & 199 & 2.48 & 24.1 & 25.6 & 28.6 & 21.6 \\
\hline Fulfill major electives & 199 & 2.52 & 31.2 & 15.6 & 23.1 & 30.2 \\
\hline $\begin{array}{l}\text { Learn/improve a foreign } \\
\text { language }\end{array}$ & 198 & 2.25 & 34.3 & 24.2 & 23.2 & 18.2 \\
\hline $\begin{array}{l}\text { Learn about my own } \\
\text { cultural roots }\end{array}$ & 199 & 1.66 & 58.8 & 22.6 & 12.1 & 6.5 \\
\hline Learn about myself & 199 & 3.22 & 6.5 & 13.6 & 31.7 & 48.2 \\
\hline $\begin{array}{l}\text { Make friends from other } \\
\text { countries }\end{array}$ & 199 & 2.81 & 13.1 & 21.6 & 36.2 & 29.1 \\
\hline $\begin{array}{l}\text { Learn about another } \\
\text { culture }\end{array}$ & 198 & 3.47 & 3.0 & 5.1 & 33.8 & 58.1 \\
\hline $\begin{array}{l}\text { Marketable to future } \\
\text { employers }\end{array}$ & 199 & 3.13 & 6.5 & 15.6 & 36.7 & 41.2 \\
\hline $\begin{array}{l}\text { Increase critical } \\
\text { thinking skills }\end{array}$ & 199 & 3.11 & 6.0 & 15.1 & 41.2 & 37.7 \\
\hline $\begin{array}{l}\text { Help professionally in a } \\
\text { globalized world }\end{array}$ & 199 & 3.27 & 3.0 & 14.1 & 36.2 & 46.7 \\
\hline Increase independence & 199 & 3.41 & 3.0 & 10.1 & 30.2 & 56.8 \\
\hline
\end{tabular}

Research participant responses to interview questions and focus group protocol revealed a range of perceived outcomes that influenced their individual decision. While learning about another culture topped the survey as a perceived outcome, only one participant shared this sentiment as an influential factor on making the decision to study abroad. Alex desired to participate in study abroad to do something different and to expand learning about other cultures. Alex described her motivations of going abroad.

But, like, my main thing was that this-that this was, like, a big, like, learning opportunity and a very, like, different, like environment, I guess, to learn about. So I think that was more of where I, like, the direction I was thinking about, like for study abroad. I love, love, love, love, like, meeting new cultures and, like, seeing what kind of things is normal to them. 
For most participants, the concept of learning about other cultures was discussed as a benefit to study abroad participation, not necessarily as an influencing factor. This type of analysis is evidenced later in this work.

Some of the more frequent responses by research participants during the interviews and focus group centered on the perceived outcome that study abroad would help students professionally. Specifically, research participants identified the perceived outcomes of growing professionally in a globalized world and of being more marketable to future employers based on the opportunities gained from the study abroad experience. As Amy described her desire to develop professionally in a globalized world, "being an Ag student myself, I thought that I could further my education. Um, you know as far as all around the world and not just [in the Midwest]." While Amy was the only one to disclose a desire to study abroad for the reason to improve global competencies, several research participants discussed this as a benefit of the experience.

Another emergent theme that was consistent with the survey was the perceived outcome that participating in study abroad would make students more marketable to future employers. Leigh articulated one of her reasons for participating in study abroad: "if you are going into a graduate program, it is one way to set yourself apart. Oh, look, I did a study abroad." In a similar way, Azalea described her desire to be more marketable as an influencing factor:

Um, for like, interview applications and stuff, that it's good to like put that you were, that you went abroad and you studied abroad, so that was another thing to make it look good on my resume. More like, make it look good on my resume and when I am interviewing for jobs. 
As with other perceived outcomes, more participants described being more marketable to future employers as a benefit or outcome to the study abroad experience, rather than as a factor influencing their decision. The last perceived outcome shared by a research participant came from Alex during the focus group. Alex expressed her desire to study abroad, "another thing was just, like, meeting new people" as a perceived outcome influencing her decision.

\section{Research Question 2}

The second research question of this study was "What are the barriers and benefits to these TRiO-eligible students who make the decision to participate in study abroad programs?"

The last personal factor explored by survey respondents indicated the degree to which they agreed or strongly agreed with the description of obstacles that they faced in the decision to study abroad. Table 12 identifies a variety of factors, from program cost to complications with preparing for graduate schools tests, as they related to obstacles that had to be overcome in the decision-making process. Program cost overwhelmingly was identified as an obstacle to be overcome, with $76.8 \%$ of respondents agreeing or strongly agreeing. The next agreed-upon obstacle was restrictions on financial aid for study abroad (43.2\%) and lack of foreign language knowledge (33.2\%). The least agreed or strongly agreed upon obstacles included complications with grad school entrance exam preparation $(7.0 \%)$, not meeting GPA requirements $(11 \%)$, and fear of racism $(12.5 \%)$. These results are consistent with the composition of this sample, comprised mainly of white students. 
Table 12

Personal Factor: Obstacles to Study Abroad

\begin{tabular}{|c|c|c|c|c|c|c|}
\hline Obstacles Faced & $\mathrm{N}$ & Mean & $\begin{array}{c}\text { Strongly } \\
\text { Disagree } \\
\%\end{array}$ & $\begin{array}{l}\text { Disagree } \\
\%\end{array}$ & $\begin{array}{c}\text { Agree } \\
\%\end{array}$ & $\begin{array}{l}\text { Strongly } \\
\text { Agree } \\
\%\end{array}$ \\
\hline Program cost & 199 & 3.00 & 5.5 & 17.6 & 48.2 & 28.6 \\
\hline Lack of family support & 199 & 1.78 & 47.2 & 33.2 & 14.1 & 5.5 \\
\hline $\begin{array}{l}\text { Study abroad courses not fitting } \\
\text { into academic program }\end{array}$ & 199 & 1.97 & 34.2 & 40.7 & 18.6 & 6.5 \\
\hline $\begin{array}{l}\text { Lack of foreign language } \\
\text { knowledge }\end{array}$ & 196 & 2.03 & 34.2 & 32.7 & 29.1 & 4.1 \\
\hline Not meeting GPA requirements & 199 & 1.52 & 61.3 & 27.6 & 8.5 & 2.5 \\
\hline Family obligations & 198 & 1.82 & 41.4 & 39.4 & 14.6 & 4.5 \\
\hline Work/internship obligations & 198 & 2.00 & 34.3 & 37.4 & 22.2 & 6.1 \\
\hline Extracurricular obligations & 198 & 1.76 & 42.4 & 41.4 & 13.6 & 2.5 \\
\hline $\begin{array}{l}\text { Study abroad delaying } \\
\text { graduation }\end{array}$ & 199 & 1.73 & 49.7 & 32.7 & 12.1 & 5.5 \\
\hline $\begin{array}{l}\text { Not wanting to be away from } \\
\text { home }\end{array}$ & 199 & 1.77 & 49.2 & 28.6 & 18.1 & 4.0 \\
\hline $\begin{array}{l}\text { Fear of traveling to a new } \\
\text { country }\end{array}$ & 199 & 1.75 & 49.7 & 28.1 & 19.1 & 3.0 \\
\hline $\begin{array}{l}\text { Fear of racism in other } \\
\text { countries }\end{array}$ & 199 & 1.57 & 58.8 & 28.6 & 9.5 & 3.0 \\
\hline Fear of safety in other countries & 199 & 1.97 & 37.2 & 33.2 & 25.1 & 4.5 \\
\hline $\begin{array}{l}\text { Fear of getting low grades while } \\
\text { abroad }\end{array}$ & 198 & 1.67 & 54.0 & 29.3 & 12.6 & 4.0 \\
\hline $\begin{array}{l}\text { Citizenship/passport } \\
\text { requirements }\end{array}$ & 197 & 1.65 & 54.8 & 29.4 & 11.7 & 4.1 \\
\hline $\begin{array}{l}\text { Restrictions on financial aid for } \\
\text { study abroad }\end{array}$ & 197 & 2.27 & 28.9 & 27.9 & 30.5 & 12.7 \\
\hline $\begin{array}{l}\text { Complications with grad school } \\
\text { entrance exam preparation such } \\
\text { as GRE, MCAT, etc }\end{array}$ & 199 & 1.44 & 65.8 & 27.1 & 4.5 & 2.5 \\
\hline
\end{tabular}


Data collected from the focus group and individual interviews were consistent with the survey, but offered additional barriers not previously examined in this study. Data collected supported the findings of the survey, including discussion of program costs being an obstacle. As Amy described, "Money was a huge factor. Um, I obviously don't come from the most wealthy parents, so they weren't able to help me." The sentiment was also shared by Leigh, Jane, and Alex. They all concluded that financial was their first barrier to overcome as it related to study abroad.

In addition to the program cost of studying abroad, concern of additional expenses arose from the data collected by participants. As Alex described:

Financial was definitely the first of my concerns, just because I feel like with trips like this is that supposedly everything's, like, included. So I was like, is that actually true or do you-does it include your flight and your bus route, but doesn't include dinner, this or that, or this or that.

These extraneous expenses were also a concern of other participants. Azalea reflected that while institutional funding and financial support from her TRiO program was certainly helpful in going abroad, financial concerns remained. As she described:

Um, another thing was um, though it was still very financially like doable, um, getting like, um, the cash or the money I should say, the money, um, for like spending-wise, like though, while we can have everything paid for where I am staying, my airfare, like the miscellaneous costs that was a, like, a big thing that I would worry about, where are we going to get this money for the food that is not covered by the trip. Or, my um, sojourners, like, that is one of the things that I was kind of worried about, but clearly we figured it out and I was able to go.

While cost was of particular concern, none of the interview or focus group participants raised concerns about restrictions on financial aid not covering the cost of study abroad. Furthermore, the participants mentioned utilizing institutional scholarships and financial 
aid to finance their study abroad experience. The participants also raised concerns about family support for being able to go abroad as evidenced in the narratives below.

While family support was discussed previously as a positive social influence for some survey respondents and research participants, this section presents data demonstrating that family support in regard to study abroad could be an obstacle that had to be overcome by participants. One way family seemed hesitant to embrace the concept of study abroad was the idea of the student being away from family. As Amy described,

My dad, and my grandparents, they — it was not that they weren't supportive, but they were just nervous about the fact of me going abroad for that long, which has to do with that I am originally from [research site]. So going all the way to Europe. To them that I had never been away from them. It was not that they weren't supportive but it was definitely a lot of push back.

This type of family push back was also shared by Leigh, who remembered how her parents were concerned about her going to Romania. Leigh described, "I mean, it's not your Western Europe, so I knew I had to have a solid base before I approached my parents about it." She further described that while her parents had concerns about Romania due to its former Communist government, it was more the fact that she would be away. As Leigh described, she would be "where my parents can't protect me; that was the problem."

Of the research participants, Kendall faced some of the harshest push back from her family concerning her decision to study abroad. Kendall's parents divorced when she was young, and the messages she received from her birth parents were different. Her mother was a positive factor and source of support in her decision to study abroad, while her father's side was quite the opposite. Kendall summarized the dynamic, "Yeah, basically my whole family didn't want me to go." As evidenced earlier in the results, 
Kendall did attribute a lot of family support from her mother; however, it was mostly her father's side of the family that served as a barrier.

The most negative of her family sources came from her stepmother. As Kendall described,

Like, specifically I told my stepmom that I wanted to study abroad and she... She told me. Um. She said, "Kendall, you don't have enough common sense. Like you really shouldn't. You wouldn't be able to survive in another country."

Her father also shared reservations about study abroad:

And my dad, he just kept bringing up finances. He was super, not mean about it, but was really discouraging. He was like, "you realize that is going to cost a lot. Who are you going to ask for money?"

Even Kendall's grandmother did not support the decision to study abroad. Kendall described her grandmother's reluctance:

She is a big Facebooker. She would always find these negative, um, Australian articles about poisonous animals, or like I don't even know, or about a death in Australia or something and post them to my wall. I was like "Grandma, that happens everywhere, it is not just Australia". But she was like looking for things to try and persuade me not to go. Because she was just so scared.

These family support issues were all barriers that Kendall had to overcome in order to solidify her decision to go abroad.

Another barrier or obstacle present in survey results and discussed by one research participant was foreign language. While the survey framed the discussion of foreign language as a "lack of knowledge," Azalea had knowledge but was hesitant about her proficiency. As she described,

So the barriers, um, one of them was kinda like my fear of, 'cause, um though I am Hispanic, my Spanish isn't all that great. I kind of lost it over the years, as the years went by. So that was kind of one of the things that kind of, while it is affordable, am I going to communicate like effectively with my host family or with other people that I am going to be in contact with? 
Other barriers shared by research participants included work/internship obligations, having difficulty fitting courses into their academic programs, fear of not graduating on time, and not wanting to be away from home as additional barriers. Participants who desired to work and do internships in the summer found it challenging to fit all these commitments and study abroad within their undergraduate study.

Jane, a business and journalism major, shared the difficulty she had fitting study abroad into her schedule. Jane described the challenges of choosing a study abroad program:

But in other situations, like the semester programs that I am saying the fact that I cannot fit it into my schedule. Maybe they have summer programs, but it's like, I want to be doing internships over the summer.

Jane eventually selected a week-long spring break study abroad program, due to the barriers presented by other programs.

Kendall also found it challenging to fit study abroad into her required courses and program of study. As Kendall described,

I met with my advisor to talk about like which classes I would have to complete before studying abroad, because you have to have certain classes done before you apply to physical therapy school.

Kendall went on to say that "there were just, like, so many steps that I had to take, like, with classes to make sure that I could study abroad. So, I remember that was complicated." Amy also found it difficult to plan study abroad into her academic program. As Amy reflected,

The biggest barrier and reason that I thought I wasn't going to be able to was, um I didn't think I would graduate on time. I thought that there were certain classes that I needed to take in the spring semester my junior year. 
Amy said that speaking to an academic advisor in her college helped her overcome this barrier to study abroad; however, she and other research participants additionally identified not wanting to be away from home as a barrier.

The concept of being away from home as a barrier to study abroad was identified by $19.1 \%$ of survey respondents, with focus group and individual interview participants providing further insight into what this meant for them. For Amy, a first-generation student and Pell grant recipient who attended college in the same town she had grown up in, being away from home presented her with quite a challenge. Combined with the negative support she received from her father about actually going abroad, it was something that she had to grapple with herself. As Amy described,

Um, I guess just I have never. I didn't even go away for college. So just a barrier as far as myself. It was like going away for college for the first time but just really far. So myself, I was a barrier to going to study abroad.

It was the interplay between positive social factors and perceived outcomes that eventually provided the encouragement for Amy to make the decision to go to Ireland.

The concept of not wanting to be away from home provided a different kind of obstacle for Kendall. For Kendall, who was in a long-term relationship, being away on a study abroad meant being away from her boyfriend. As she described,

'Cause that is like a hard thing for not seeing someone for five months who you love so much you know. We ended up. I mean, we stayed together while I was there but we broke up about a month ago. So that was probably definitely the hardest part, just like those concerns.

After Kendall made the decision to study abroad, the concept of not wanting to be away from home as a barrier to participating manifested into a challenging situation for her once she arrived in Australia. As Kendall described, 
I remember the first few days that I was there. I cried. I didn't like it. I was scared. You are in a new place and you know nothing. You know, so it was literally the hardest thing of my life. And at times I had the lowest self-esteem I have ever had. I didn't feel I was capable of anything.

Kendall went on to later describe the benefit study abroad afforded her by being able to work through this difficult situation in her life. She worked through the homesickness by connecting with her Malaysian roommates and other students from the research site on the same study abroad program who were working through similar situations. While these barriers presented challenges in making the decision to go, and to the initial experience while abroad, these barriers provided an opportunity for participants to overcome them. Therefore, students gained resiliency, independence, and enjoyed their study abroad experience.

A comparison of institutional, personal, and social factors. Table 13 demonstrates a comparison of factor influences for the 15 highest mean scores collected from the online survey. Survey items with the highest mean scores are listed, along with the factor that each survey item is associated. Only institutional and personal factors are represented, as none of the mean scores from social factors ranked within the top 15. Results in Table 13 indicated that the personal factor of desire to learn about another culture had the highest mean score (3.47) of all the survey items.

Results also indicate the importance of institutional factors in the decision of students to study abroad. The second and third highest mean scores were the institutional factors that study abroad was encouraged for TRiO-eligible students (3.46), and study abroad types and number of study abroad programs offered through the research site were good (3.41). The fourth highest mean was the personal factor of perceived outcome of 
increased independence (3.41), and fifth highest score was the personal characteristic factor of program costs (3.41). Institutional factors accounted for 9 of the 15 highest mean scores, with each institutional factor receiving a mean score above a 3.0 on a 4.0 scale.

Table 13

A Comparison of Mean Scores by Social, Institutional, and Personal Factors

\begin{tabular}{lllc}
\hline Survey Item & \multicolumn{1}{c}{ Factor } & N & Mean \\
\hline Learn about one more culture & Personal & 198 & 3.47 \\
Study Abroad encouraged for TRiO-eligible students & Institutional & 201 & 3.46 \\
$\begin{array}{l}\text { Study Abroad types and number offered though institution are } \\
\quad \text { good }\end{array}$ & Institutional & 202 & 3.41 \\
Increase independence & Personal & 199 & 3.41 \\
Program costs & Personal & 199 & 3.4 \\
Study Abroad information available & Institutional & 203 & 3.35 \\
Overall needs as a first-generation college student or Pell grant & & & \\
$\quad$ recipient were met & Institutional & 200 & 3.3 \\
Good funding available & Institutional & 202 & 3.29 \\
Help professionally in a globalized world & Personal & 199 & 3.27 \\
Comfortable speaking with academic advisor about Study & & & \\
$\quad$ Abroad & Institutional & 202 & 3.24 \\
Comfortable speaking with professor about Study Abroad & Institutional & 201 & 3.23 \\
Learn about myself & Personal & 199 & 3.22 \\
Comfortable speaking with Study Abroad advisor about Study & & & \\
$\quad$ Abroad & Institutional & 201 & 3.18 \\
Study Abroad eligibility not strict & Institutional & 199 & 3.16 \\
Marketable to future employers & Personal & 199 & 3.13 \\
\hline
\end{tabular}

Benefits obtained from participating in study abroad programs. Something not measured by the online survey, but very apparent in the narratives drawn from research participants in the focus group and individual interviews, were the benefits and outcomes participants gained from the study abroad experience. Research participants shared a variety of statements of what they interpreted as gains from the study abroad 
experience. All of the data captured on the digital recorders were transcribed verbatim and reviewed several times by the researcher to look for commonalities between the focus group transcript and each of the individual interview transcripts. Consistent with approaches by Merriam (2009), an inductive process was utilized to create a color coding scheme to review the qualitative data from the transcripts utilizing the highlight text feature within Microsoft Word. As Vogt, Vogt, Gardner, and Haeffele (2014) suggest, Excel can assist qualitative researchers with tracking notes and organizing data to make coding decisions. Utilizing the data filter feature in Excel, data were sorted to review references to benefits gained from the study abroad experience, and to further analyze and code such data. Through this process, themes emerged that could be grouped into the following areas: adaptability and flexibility, cultural knowledge and competence, problem solving, independence, learning about oneself and being outside the comfort zone, a feeling of an experience of a lifetime, and coursework content. The following section presents data and results based on these areas.

Adaptability and flexibility. The concept of adaptability was discussed broadly by all research participants in the focus group and individual interviews, with two of them providing insight into how the study abroad experience made them more adaptable. When discussing the impact of study abroad on her future career and how she would articulate the study abroad experience on her resume, Kendall described, "It would probably include things on adaptability." She further described what she had gained from a failed weekend excursion with some of her study abroad classmates. Kendall felt the experienced helped her gain the ability to be adaptable: "You just kind of had to like adapt and go with it. So lots of unexpected things happened and I feel like, in the 
professional world you cannot always plan things, and that is one thing I really took away from it." This sentiment was also shared by Alex, who felt the study abroad experience helped her become more adaptable.

Alex reflected on her time she spent living on an isolated goat farm in Romania. The farm was 20 kilometers from the nearest town, and their host family's home did not have indoor plumbing. She felt that her study abroad experience taught her,

So like, being able to work with what you have, and being able to adapt quickly to it, I feel like is something that's really, really valuable. Especially in, likeespecially in, like, any type of career, just because things can change with the blink of an eye. So being able to just be like, okay, this is what changed, this is what we have to do, the goal is still the same, but this is how we have to adapt to what changed. So being able to, like, do that right off the bat and do it quickly with these kinds of experiences, I think, would be really, really helpful to anybody.

Alex and others felt that learning to be adaptable helped inform future career potential and an overall way to live a less stressful life. As Kendall reflected, "I definitely got a lot more laid-back. I used to stress out about the future all the time. That is one thing that I really, really enjoyed that I took away from it." Another benefit gained from the study abroad experience discussed by research participants includes growth in cultural knowledge and competence.

Cultural knowledge and competence. The study abroad experience provided research participants an opportunity to learn about the local culture and cultural history from their respective study abroad locations of Spain, Australia, Romania, Ireland, and Taiwan. Interestingly, the research participants had more to say, not about what they learned about other cultures through study and travel while abroad, but the opportunity to engage individuals of cultural backgrounds different than their own. This section will 
discuss the growth of cultural competence experienced by the research participants and how it allowed them to handle different situations, work with others, and expand their network.

For Kendall, who studied abroad in Australia, her cultural and personal growth in study abroad came through the cultural experiences she had with the different students attending the University of Queensland. These opportunities to engage in-depth with individuals from different cultural backgrounds helped her to grow in her cultural competence. As she described,

I just feel really capable of doing things now. Not that I wasn't before, but kinda of. I feel like I have more common sense and people experience. Like, I lived with, um, ten Malaysians in Australia. So I, I don't know, I feel like I could get along with any type of person, which is really cool. Like, I could go to any country now and stay with somebody, like, I feel like I was really more diversified, which was really cool.

Kendall went on to share examples of how living with her Malaysian roommates allowed her to recognize cultural differences. Kendall gave examples of how they ate different foods, and had different approaches for balancing class work and social obligations.

Overall, Kendall believed she grew in her cultural awareness as she stated,

So I, I don't know, I feel like I could get along with any type of person which is really cool. Like I could go to any country now and stay with somebody like I feel like I was really more diversified and developed people skills.

Other students developed cultural competency skills such as improving communication with individuals of different cultural backgrounds while working on team projects.

Alex, who studied abroad in a remote area of Romania, felt that she grew in her ability to communicate with individuals from different cultural backgrounds than hers. Not only the Romanian students they interacted with, but also students from her home 
institution that had a different background than herself. As she described,

And it's just, working with different people like that, and learning how to, like, just accept other people, even if they're from the same culture, just, like, learning to accept, like, the different perspectives and the different views that everyone has was something that I, like, really, that really helped me with, like, throughout the trip.

Other students shared similar outcomes of the study abroad experience.

Amy, who studied in Ireland, said, "It has also made me more culturally aware.

So before when I was at [research site] I never noticed how many, um, like, study abroad students we had." Upon her return to the research site campus, Amy became more involved with students from other countries and went out of her way to help those individuals feel welcomed at her home institution.

Developing these cultural competency skills allowed study abroad participants the opportunity to make friends from other countries, aiding students professionally. As Jane, who participated in a business school-sponsored program on emerging Asian markets, described, "So it's being able to make those friendships that are, like, across borders. And I have them on Snapchat and things like that. So, you know, it's just, to have an international network." These skills of learning other cultures and building relationships with individuals from different cultural backgrounds aided in the development of problem solving skills.

Problem solving. All research participants shared a similar story of how they were faced with challenges traveling to their desired destination. These students utilized problem-solving skills to navigate these challenges to their travel itinerary and to navigate their new environments. As Azalea described, 
So we were put into situations where we had to figure out, okay, how can we get here? Or there was miscommunication. Or we got lost or like. We need to figure out how we can reach out for help from the locals to figure out where we were location-wise.

Beyond challenges to travel, research participants expressed how the overall study abroad experience improved problem-solving ability.

For Leigh, the study abroad experience in Romania involved service learning, and many group projects that allowed her to develop or utilize problem-solving skills.

Because of the experience I had over there and seen what teamwork could do for other people, um, I hope it made me a less selfish person. But it also made me aware of other, um, other aspects that you can apply, such as communication and group work and problem solving that you're gonna have to deal with in the real world anyway, and strengthen those, uh, aspects and characteristics of yourself.

As evidenced by her reflection, the study abroad experience helped Leigh assign a value that developing these problem-solving skills would have on her future. Others shared the same value as Leigh, as many recognized how the study abroad experience helped them to become more independent.

Independence. Many of the research participants discussed how the process of planning and participating in study abroad helped them to become more independent as an individual. Before participating in study abroad, several steps and tasks were required and needed completing. While some students felt these steps were cumbersome, some derived a benefit from completing them. As Kendall described, "I can manage my finances, organize a phone and insurance, and all this stuff. And I did. And it was really self-assuring that I can do that kind of stuff on my own." In addition to the tasks required ahead of time, the study abroad experience provided an opportunity for students to become independent. 
While studying abroad in Australia was exciting, being away from home presented a few challenges for Kendall. While these challenges were present in the discussion of barriers, in her reflection, Kendall realized the value of the experience. She described,

Things were new, and hard. And I was by myself, I couldn't go to my mom's house, or call my best friend, you know. I had to figure it out by myself and the other two [research site] people that were there. It was hard, but [it] was seriously the most rewarding thing ever because I went through it, and now I know that I can do things like that.

Another research participant, Amy, also realized the value that the study abroad experience had in developing a greater sense of independence. As Amy reflected,

Um, I would say it would definitely impact me by making me more independent. Um, since I hadn't gone away for college and I live in the same city as [research site]. Now, I feel more independent and able to know that if I got a job in a different state or even in a different country I would be up to it and know that I can do it since I was able to study abroad for five months.

For Amy and Kendall, the experience provided them an opportunity to do things on their own and to experience something different. Other research participants discussed this aspect in a similar way, but as an opportunity to learn about themselves and being outside their comfort zone as a benefit worth categorizing.

Learning about self and their comfort zone. Some research participants talked about the study abroad experience as one that provided an opportunity to push students to do something outside their comfort zone, allowing them to reflect or get to know more about themselves. Many times the phrases "learning about myself" and "being outside my comfort zone" could be discussed interchangeably, and with some sharing how the experience "changed" them as a person or made them a "better person." Much of this dynamic was evident in Azalea's reflection, 
Going to Spain it definitely changed me as a person. I was able to see, like, I know this is how other people live, this is how the Spaniards live their lives versus us Americans. Even speaking with my host family, I just found it amazing how different they do things in Spain compared how we do it in America. And by going to Spain I was also, I was put out of my comfort zone.

Being able to experience opportunities outside the norm and the comfort zone of

participants was also shared by Leigh. When discussing the conditions of her homestay

in Romania, Leigh reflected,

We had an outhouse. Like, they don't-they didn't have plumbing, they didn't have anything like that. And, you know, we were all fine with it, we were cool with it. All-there was a group of four of us together at this homestay, and we were just grateful that this family, who obviously didn't have very much, that they were willing to share with us. And it really puts perspective on what we have here and how lucky we all are.

This provided Leigh an opportunity to reflect and get to know more about herself, and in this case how lucky she was. Amy also used the study abroad experience to reflect and consider possibilities. As Amy shared, "I guess it just completely made me just a different person now. I want to be able to potentially work in a different country." While the outcome of what research participants decided to do once they had the opportunity to reflect on what they had learned about themselves, they all viewed this as a benefit gained from the study abroad experience. For many, they considered the study abroad experience as "an experience of a lifetime."

An experience of a lifetime. Many of the research participants discussed the concept of study abroad as an experience of a lifetime or something priceless. In the discussion of social factors early in this work, research subjects revealed that they had heard past study abroad participants describe their experience in these terms, and it fit much of the overall narrative on study abroad (Dolby, 2004). This sentiment about study 
abroad was shared by Alex, who described her overall study abroad experience in these ways,

I feel like that the experience is so much-it's worth so much more than, like-like, the money or, like, the worries or anything like that that you have. I just feel like this is the time. If you're ever gonna do it, I feel like this is the time to do it is right now. I feel like the experience is completely price-priceless when it comes to that, but it also comes with work.

The idea that the study abroad experience was priceless was something shared too by Azalea.

For Azalea, the study abroad experience was something that she truly valued and considered important for students who are first-generation and Pell grant recipients like herself. She appreciated the support she received from her TRiO program in making the study abroad experience a reality for her. As she described, "I would say just, like, just appreciating the opportunity that I was given. Cause, um. After going I realized how lucky I was to have the opportunity to study abroad." In addition, when asked what she would tell other first-generation students about the study abroad experience, Azalea had this to share:

So if I saw another first-generation student wanting to do study abroad I would tell them to go for it. It is the best experience that they'll ever get. It's, um, I remember one of my professors or staff members told me, he [was] like, "This is something that you will not be able to recreate. The moments that you live are something special that you will always hold dear". And he was right.

In addition to the overall study abroad experience, research participants discussed the benefits they derived from the content covered in their study abroad experience.

Course content. Of the research participants, Jane attended the shortest study abroad program; however, she had the most to say about what she learned from her courses while abroad than any other participant. Jane was enrolled in a course entitled 
Emerging Asian Markets and Cultures, as part of her short study abroad program of only

8 days. Among the things that Jane learned first-hand from this course and the study abroad experience was the differences between different Asian markets. As Jane described,

Because there [are], like, a lot of start-up companies that are happening in Taiwan. And it is, like, rapidly developing and trying to keep up with China and things like that. So it is interesting to see how they are trying to do that. Um, you know, it is not just going to historic sites and the like. It's really interesting to see like the social business aspects and like solar business that they have and stuff like that.

Jane further described what she learned from the Chinese culture section of her course, where the text of focus was the Art of War: "developing a mentality. It is not necessarily about war, you know, you can apply it to your relationships too and to your school and everything."

\section{Summary of Findings}

The factors explored by the survey and through the individual interviews and focus group that influenced the decision of participants to study abroad varied. In comparison of the grouped social, institutional, and personal factors in Table 13, it was the institutional factors that study abroad was encouraged for TRiO-eligible students, the study abroad program types and number of study abroad programs offered through the research site were good, study abroad information is available, overall the institution met the needs of TRiO-eligible students, and good funding for study abroad was available at the institution that revealed some of the highest mean scores, followed by the personal factors. This was consistent with the data gathered through the qualitative phase of the study, with individuals discussing a combination of personal and institutional factors that 
contributed to the decision of research participant to engage in a study abroad opportunity. For example, program cost was the highest reported obstacle according to data presented in Table 12, and it was a combination of institutional factors such as study abroad encouraged for TRiO-eligible students and good funding available that had some of the highest mean scores captured by the survey. This was consistent with the narratives drawn from the interviews and focus group.

TRiO-eligible students reported several challenges in the decision process of studying abroad. Throughout the course of this research study, participants overwhelmingly identified the program cost of study abroad as an obstacle that had to be overcome. Other challenges faced by students reported in the survey results included restrictions on financial aid for study abroad and a lack of foreign language knowledge. Narratives drawn from the focus group and interviews also highlighted a variety of challenges presented by the families of research participants.

For research participants participating in the individual interviews and focus group, the study abroad experience provided them with several benefits that they felt added value to their lives. These benefits ranged from teaching research participants to be more adaptable and flexible to aiding research participants in their cultural knowledge and competency. This allowed research subjects to work better with individuals from a variety of backgrounds in order to solve problems, which lead to a greater sense of independence. This independence, combined with situations while abroad that placed students outside their comfort zone allowed them to learn more about themselves, and ultimately experience an "opportunity of a lifetime." 


\section{CHAPTER V \\ SUMMARY, CONCLUSION, IMPLICATIONS, AND RECOMMENDATIONS \\ Summary}

The purpose of this study was to explore the factors that influence TRiOeligible students' decision to participate in a study abroad program. In addition, the study examined the challenges the students faced and the benefits they obtained from participating in study abroad programs. This chapter will provide a summary of the results section, conclusion, implications, and recommendations. The chapter will also include linkages of this study's findings to the findings from past research on underrepresented student populations and the study abroad experience in general, as well as a discussion on the limitations of the study, implications for practitioners, and directions for future research.

\section{Quantitative Findings}

It is important to note that $74.6 \%$ of survey respondents report having first considered study abroad prior to college or within the first year of college; only $8 \%$ of TRiO-eligible students considered the possibility after the second year in college. These percentages indicate that TRiO-eligible students who participate in study abroad consider the possibility of doing so early in their educational career. As noted earlier, students cannot make a decision about whether to study abroad or not if they do not first have the intention to study abroad. Research from Salisbury, Umbach, Paulsen, and Pascarella 
(2009) reveal that students coming from lower-income households are 11 percentage points less likely intent on studying abroad than students from higher income families and that parent's education level is positively related to the probability of a student planning to study abroad. Therefore it is important to expose TRiO-eligible students to information on study abroad early in their educational career. Possible ways this could be accomplished is through pre-college visits and during summer orientation programs. While exposing students to study abroad is important for the formation of study abroad consideration and intent, it is equally important to investigate the social, institutional, and personal factors that influence the decision of TRiO-eligible students to decide to participate when they are at the point in their educational career to apply to study abroad.

When asked about social, institutional, and personal factors that influenced their decision to study abroad, a number of important factors stood out. A review of the social factor items showed that most students found a friend/significant other to be very influential in their decision to study abroad, followed by the influence of a former study abroad participant, and then parent(s). Therefore institutions should consider peer outreach programs, workshops by former study abroad participants, and information for parents about study abroad programs.

When considering the institutional items, the highest percentage of students agreed that the types and number of study abroad programs offered (through the research site) are good. A high percentage of students also indicated that the information on study abroad programs and opportunities are readily available to students at the institution, and that the institution encourages international experiences such as study abroad for individuals such as TRiO-eligible students, first-generation students or Pell grant 
recipients. Overall, the students felt their needs and concerns were met, that the study abroad eligibility was not strict, and that the institution offered good sources of funding for students wanting to study abroad. While this is certainly important, institutions must also pay attention to the needs and concerns of TRiO-eligible students who do not participate in study abroad. While challenging, institutions should try to establish systems to identify TRiO-eligible students who express intent to study abroad but never end up going.

In addition to institutional factors, student responses to the personal factors also revealed that this factor had an influence on their decision to study abroad. Personal factors were composed of three subcategories: perceived outcomes, personal characteristics, and obstacles. On the issue of perceived outcomes, most students reported learning about another culture was most influential to their decision, followed by increased independence, and then becoming more professional in a globalized world. These finding are consistent with those of researchers such as Kasravi (2009), Carlson et al. (1990), Peterson (2003), and Guerrero (2006), who all found students were most influenced in their study abroad decision to live abroad and experience another culture. For instance, Kasravi (2009) concluded personal factors were the largest source of influence for students of color in their decision to study abroad, more than the social and institutional factors, with the personal factor of individuals assigning personal growth as the most important value to participation in study abroad.

On the issue of personal characteristics, most students said that program cost was important or very important in the decision to choose the specific study abroad program, followed by the duration of the program and their interest in the course work available. 
This is consistent with the findings of Bandyopadhyay and Bandyopadhyay (2015), who concluded that program cost and duration of study abroad programs, as well as demographic factors including race and gender play a role in the intent of individuals to participate in study abroad programs.

When considering obstacles, program cost, restrictions on financial aid, and lack of foreign language knowledge were the most acknowledged obstacles as reported by study participants. This is consistent with the findings of Carter (1991), Burkhart, Hexter, and Thompson (2001), and Booker (2001), who all cite the cost of study abroad programs and the limitation of financial aid as a detriment to the decision to study abroad. Further, Booker (2001) acknowledges that students who apply to participate in a study abroad program view foreign language programs as more desirable as a study abroad program than students who do not apply to a study abroad program.

A comparison of mean scores from personal, social, and institutional factors plainly demonstrated that institutional factors played a very important role in the decision of students to participate in study abroad compared to the personal and social factors. The key finding of this study is that most of the institutional items were scored on the highest scaling options. These findings on the influence of institutional factors differ from previous studies.

Kasravi (2009) investigated the factors influencing the decision of students of color to participate in study abroad programs and found that the personal factors carried more influence on the decision of students of color to participate in study abroad, more so than the institutional factors. One reason for this difference could be that much has happened in the 7 years since her study, with more attention being paid at the national 
level for internationalizing campuses through study abroad (Bandyopadhyay \& Bandyopadhyay, 2015). In addition, the research institution under study invested a great deal of funding and attention to study abroad, such as featuring the $400+$ study abroad opportunities in the marketing materials on their admissions website.

\section{Qualitative Findings}

The findings from the qualitative data analysis gathered from the research participants in the focus group and individual interviews are presented in relation to the themes generated from the data: social factors, institutional factors, personal factors, and benefits from participation in study abroad. The findings of the qualitative data were woven into the previous section; however, the qualitative process asked questions related to the outcomes of the study abroad experience that were not covered by the survey. These qualitative results are presented below.

As revealed in the previous section, social factors overall did not have as much influence on the decision of students to study abroad as the personal and institutional factors; however, social influence was still found to be important. The themes that emerged from the qualitative data as it related to social factors included influence from friends/peers and former study abroad participants who interacted with research participants in advance of the decision to study abroad. While some of these social interactions were sponsored or organized by various departments at the institution, these peer social interactions helped shape positive and realistic notions of study abroad among the research participants.

In addition to peer social influences, some research participants shared both supportive and non-supportive stories about the influence of family members on the 
decision to study abroad, with there being mixed messages within families. Despite these differences, families were supportive both financially and emotionally to these students who had participated in study abroad. In fact, some of the research participants became emotional when describing the verbal support they received from their mothers during the process, with the mothers articulating that they wanted their daughters to seize upon opportunities that never existed for them. Other social factors identified by the research participants included the influence of professors and campus staff who provided influence on the decision to study abroad. Research participants had established relationships with professors and advisors who recommended study abroad participation, carrying influence on the decision of these TRiO-eligible students to be influenced into making the decision to study abroad.

Institutional factors were shared in different terms and context than the discussion of professors and campus staff. Institutional factors identified in the qualitative data included support specifically from the Study Abroad Office, an increased awareness and visibility of study abroad on campus through intentional programs and classes, and institutional funding for study abroad. The research participants shared that these types of institutional based factors for study abroad helped them be aware of opportunities and to know that support through information seeking and funding was available to help them finalize their decision to study abroad.

Personal factors discussed in the focus group and individual interviews included three subcategories: personal characteristics, perceived outcomes, and obstacles/barriers. The personal characteristics included program costs such as program cost, duration of study abroad, and the opportunity to do service learning, perceived outcomes such as 
helping students in a globalized world and to be more marketable to future employers, and obstacles/barriers faced included programs costs, extraneous expenses, and family attitudes to study abroad. Qualitative data revealed participants were concerned about program cost and that played a very important role in their decision to choose a specific study abroad program. Additionally, the duration of the study abroad program and the opportunity to do service learning were also mentioned.

The personal factors of perceived outcomes included what research participants in the focus group and individual interviews shared as desirable outcomes to the study abroad experience that carried influence on their decision to study abroad. The perceived outcomes represented in the qualitative data included the idea that study abroad would assist students professionally by helping them work in a globalized context and be more marketable to future employers. This is an interesting finding considering the perceived outcome of being more marketable to future employers scored lower on survey results. These were all discussed in the context of influencing the decision for the participants to choose to study abroad, while later in this section some of the perceived outcomes measured by the survey are presented as benefits and outcomes of the study abroad experience. Lastly, the perceived outcome of meeting new people was also shared as influencing the decision of students to go abroad. Another interesting finding is while the personal factor of learning another culture was discovered to have the highest mean score of the survey, no mention of learning about another culture as a perceived outcome was mentioned in the interviews.

The last personal factor, obstacles/barriers in the decision to study abroad was also captured in the interviews and focus group. Like the survey results, research 
participants shared program costs as a major obstacle to the decision to study abroad. Something not covered by the survey, but something that surfaced in the qualitative data collection included the additional expenses not calculated in the program costs such as money for travel and souvenirs. While family was discussed previously as a positive influence on the decision, several students shared that negative family attitudes toward study abroad were an obstacle/barrier that had to be overcome. Other obstacles/barriers, such as lack of foreign language knowledge and not wanting to be away from home, emerged as additional themes to obstacles/barriers that had to be overcome.

Something not covered by the survey in the quantitative phase of the study included the benefits obtained from the study abroad experience. Research participants in the focus group and the individual interviews shared a variety of statements about what they interpreted as benefits from the study abroad experience. Themes emerged that could be grouped into the following areas: adaptability and flexibility, cultural knowledge and competence, problem solving, independence, learning about oneself and being outside the comfort zone, a feeling of an experience of a lifetime, and coursework content. A brief synopsis of each theme is discussed in this section.

Some research participants talked broadly of how the study abroad experience provided them with unexpected situations, forcing them to adapt to these unexpected situations or to a new environment with different cultural norms. Participants internalized that this growth in adaptability made them grow in their career potential and how to live life in a less stressful way.

Cultural knowledge and competence emerged as a theme due to the ability of participants to learn about the cultural history and local customs of their study abroad 
location. Most of the research participants attributed their growth in cultural knowledge and competence to the interactions they had with people of different backgrounds. Some of these interactions were gained from living arrangements or from service projects that involved students from many different cultural backgrounds. The research participants all described this growth in terms of improving the ability to work better with others, expand one's network, and handle situations better. This related to the other theme of problem-solving that emerged.

Research participants discussed navigating unexpected situations or working through problems with groups of people from different cultural backgrounds in the context of problem-solving. They felt that they had grown in their ability to solve problems, and this allowed them to grow and have a positive impact on their future. This also contributed to the theme of independence because these problem-solving skills were gained as a result of being on their own and having to make decisions based on reflection and not on utilizing their usual network.

Independence was discussed in both leading up to study abroad and the actual experience of going. Students had to take ownership of all the tasks and requirements that needed to be completed ahead of time independently, especially as some family members were not as supportive of participating in study abroad. This growth in independence allowed the research participants to push themselves to grow in their ability to live outside their comfort zone.

Actually participating in study abroad and living outside their comfort zone allowed them to view study abroad as "an opportunity of a lifetime". While much of the marketing materials and discussion of study abroad is that it is a once in a lifetime 
opportunity; the research participants internalized this message mentioning further that due to the fact that they were first-generation or from households of limited income, it was truly an accomplishment and lifetime experience.

\section{Importance of Institutional Factors in the Decision of TRiO-Eligible Students to Study Abroad}

The most significant finding of this study was the degree of influence that the three types of factors and especially institutional factors had in the decision of TRiOeligible students to study abroad. It is important to note that TRiO-eligible students acknowledged that the institution offered quality study abroad options and provided information and funding to students. The TRiO-eligible students felt that their needs were supported by the institution in their efforts of study abroad. Professionals in the field of international education have advocated that institutions need to do a better job of encouraging underrepresented student groups in the study abroad process (Andriano, 2010; Booker, 2001; Butler, 2016; Carter, 1991; Kasravi, 2009; Norfles, 2006), and results from this study indicate that this research site could serve as an example.

As identified by the review of literature and applicable studies, financial constraints and program costs contribute to the low participation of first-generation, lowincome, and other underrepresented groups from participating in study abroad (Amani, 2011; Andriano, 2010; Booker, 2001; Butler, 2016; Carter, 1991; Kasravi, 2009; Norfles, 2006; Salisbury, Umbach, Paulsen, and Pascarella (2009). While the institution offered good sources of funding for students wanting to study abroad, it is important to note that $76.8 \%$ of survey responders agreed or strongly agreed that program costs were an obstacle to TRiO-eligible students' participation in study abroad. These disparities in 
findings are consistent with the literature (Carter, 1991; Burkhart, Hexter, \& Thompson, 2001; Norfles, 2006) and demonstrate that more needs to be done in order to support TRiO-eligible students in their quest to study abroad.

\section{Discussion of the Findings}

The Institute for Study Abroad, Butler University (IFSA-Butler) is a non-profit organization affiliated with Butler University, although a separate organization, that is focused on providing study abroad opportunities and support to undergraduate students who desire to earn academic credit through study abroad (IFSA-Butler, 2016). The organization also provides educational materials and scholarships specifically for firstgeneration college students to study abroad. According to IFSA-Butler, some of the lowest participation rates among U.S. students in study abroad are first-generation college students (IFSA-Butler, 2016).

In their application of the integrated college choice model to the choice to study abroad, Salisbury, Umbach, Paulsen, and Pascarella (2009) conclude that students who receive federal financial aid are 11 percentage points less likely to intend to study abroad than their peers who do not receive federal aid. Further, they conclude that few empirical studies exist that examine the factors influencing intent of individuals to study abroad. This disparity in participation and lack of empirical knowledge on factors influencing the decision of TRiO-eligible students to participate in study abroad created the basis for this current study.

One of the few empirical studies on first-generation students and study abroad is Bryan Andriao's 2010 study that utilized secondary data from the National Survey of Student Engagement College Student Report to investigate if a predictive relationship 
existed between four engagement factors: institutional support, quality of institutional relationships, faculty contact, and impact of diversity experiences and participation in study abroad for first-generation students. Andriano (2010) discovered that enrollment in foreign language coursework, living in campus-affiliated housing, and attendance at a private institution were all predictive effects on study abroad enrollment of firstgeneration students. Surprisingly, no relationship was found for a student's perceptions of institutional support, involvement with faculty, or quality of institutional relationships and participation in study abroad. Andriano's (2010) conclusions differ from the findings of this study, as the current study found institutional factors to be influential in the decision of TRiO-eligible students to study abroad.

Another population underrepresented in study abroad is community college students. In her (2011) study, Monija Amani investigated the decisions of community college students who studied abroad through individual interviews with 26 students and 6 study abroad faculty coordinators all from community colleges. Utilizing Hossler and Gallagher's College Choice Model (1987) and Ajzen and Fishbein's (1980) Theory of Reasoned Action, Amani's findings revealed the interplay between social, individual, and institutional factors that influenced the students' decision to participate in study abroad programs. The most significant factors promoting study abroad from Amani's study include: gaining international experiences, improving foreign language skills, enhancing career prospects, friends, family/significant other, foreign language requirements, and fulfilling degree requirements. These findings are similar to the current study in that the desire to learn another culture recorded the highest mean score on the survey, and that research participants viewed the study abroad experience as career 
enhancing as both a perceived outcome and benefit to study abroad participation. Improving language skills was not found to be as influential within the current study. Amani (2011) also noted that factors hindering study abroad included cost of studying abroad, misconceptions that study abroad will delay graduation, that foreign language skills are required to study abroad, fear of discrimination, commitments to family/significant others, lack of faculty involvement, program offerings, lack of institutional commitment to administrative infrastructure and resources, such as funding resources (Amani, 2011). These findings differ from that of the current study, as institutional factors, such as funding, support, and the type and numbers of study abroad programs, were found to be good by research participants, and as an influencing factor of the decision, not hindering study abroad participation. Congruence of her findings with this current study included that participants viewed study abroad as an opportunity of a lifetime and that family existed as both an influential factor and barrier to study abroad participation.

Booker's (2001) study on the difference between students who apply to study abroad and students who do not apply to study abroad found that understanding the factors could prove useful in shaping the practice at a national and institutional level to grow the study abroad population. While his study did not examine first-generation or socioeconomic status of participants, Andriano (2010) argues that Booker's framework "is the seminal study on the student choice process in study abroad" (Andriano, 2010, p. 16). While Booker's framework influenced the design of the survey instrument used in this study, differences exist between Booker's (2001) work and that of the current study as it relates to institutional factors as outlined below. 
Booker (2001) concluded that seven belief-based factors made significant independent contributions toward the difference between students who applied to a study abroad program and those students who did not apply to a study abroad program. In priority order: influence of academic relationships, potential delay of graduation, financial constraints, influence of family/friend, possibility of taking a travel break, learning more about the world and oneself, and possibility that study abroad would enhance career prospects. Applicants and non-applicants had significantly different perspectives of institutional support as it related to the institution's ability to provide study abroad opportunities and to support study abroad efforts. Overall results indicated applicants and non-applicants held moderate perceptions of institutional support for study abroad, with the highest scores for access to information and lowest of integration of study abroad into the curriculum. For the current study, institutional support and learning more about the world and oneself had higher influence on the decision to study abroad than they did in Booker's (2001) study. Another difference was the size of the sample, with Booker receiving complete results for 105 non-applicants, and 77 applicants to study abroad, while 208 survey responses from TRiO-eligible students who had studied abroad guided analysis for the current study.

Peterson's 2003 study investigated the decision process for students considering study abroad by utilizing and testing the Decision to Study Abroad Model. Peterson's work was influenced by the theoretical framework of Fishbein and Ajzen (1975). Peterson's (2003) study concluded that "study abroad would open my eyes to the world" (p. 102) as the most important reason for students' decision to study abroad. Participants in her study included 239 participants from a large research institution in the Midwest 
who had all participated in study abroad, and a sub set of 313 non-participants in study abroad. Comparison between the two groups revealed that study abroad program faculty leaders and former participants of study abroad were the most influential messengers from whom they received study abroad information. Former study abroad participants were found to be the second most influential messenger of study abroad information within the current study, while friend/significant other ranked as the most influential. Professors in the current study were discovered to be the fourth most influential, behind $\operatorname{parent}(\mathrm{s})$.

Influenced by both Booker (2001) and Peterson (2003), Kasravi (2009) developed the Adapted Model of the Decision to Study Abroad Model and utilized this framework to investigate the personal, social, and institutional factors influencing the decision to study abroad among students of color who did apply to a study abroad program and nonapplicants regardless of race. Consistent with the findings of this study, Kasravi (2009) concluded financial barriers to be the main obstacle to study abroad for applicants. Unlike the findings of this study that concluded institutional factors to be most important, Kasravi found the personal and social factors as the primary factors influencing the student's decision to apply to a study abroad program.

\section{Limitations}

There were a number of limitations for this study. First, this study was focused on just one institution located in the Midwest region of the United States, so the results of the study may not be generalizable to other institutions across the United States or outside the United States. Another limitation was this study focused solely on first-generation and Pell grant recipients, and not on other students who studied abroad through the 
research site. This limited the ability of the study to compare results from TRiO-eligible and non-TRiO-eligible populations that could have resulted in a richer and deeper investigation of the factors influencing the decision of students to participate in a study abroad program.

Further, only investigating those students who went abroad and not students who expressed interest in study abroad but did not follow through was another limitation of this study. The study was limited in its ability to compare factors influencing those TRiO-eligible students who went abroad and those who did not. This was attempted, but it was not feasible to do this through the research site, as they did not accurately collect data on those students expressing interest in study abroad, only those that did go abroad. Another limitation was that the survey instrument only provided options for male and female and was not inclusive of transgender students. Effort was made to make the survey consistent with data collection available through the Open Doors survey and through the institutional research office at the research site; neither collects nor reports information on transgender participation in study abroad.

\section{Implications for Future Practice}

The research site was chosen for a variety of reasons, but one of them was the fact that this institution had a federal TRiO program, and that TRiO program sponsored a short-term summer study abroad program for its participants. Despite the well-established collaboration between the study abroad office and the TRiO program, neither side knew the institutional participation rate of first-generation and/or Pell recipients within the institution's study abroad population. In fact, it was the first time that either side was asked the question. From the study abroad office perspective, it was not information they 
collected or were required to report on the annual Open Doors Report survey, the main data source for all U.S. study abroad activity that is administered by the Institute for International Education. From the TRiO-program perspective, they were very knowledgeable about the individual students participating in study abroad through their specific TRiO sponsored study abroad program, but were not fully aware of all situations where TRiO/Student Support Services students participated in a study abroad program outside of their annual summer trip. Hence, the first implication is the need for better data collection focused on first-generation and Pell grant recipients in study abroad programs.

If the Institute of International Education (IIE) included the fields of firstgeneration and Pell grant recipient to their student demographic data collection survey, this would be one way to start better data collection at a national level. Another suggestion is for the U.S. Department of Education to add study abroad activity as a required field to the Annual Performance Report for TRiO programs. In doing so, TRiO programs would be required to better track and report this information. At the campus level, making these requirements would force professionals working either in study abroad or with underrepresented students to better collaborate to identify this population. This type of identification at the campus level could lead to better marketing, outreach, and collaboration for creating study abroad programs that are attractive and supportive to TRiO-eligible students.

The case has been made clear by the Lincoln Commission, IIE's Generation Study Abroad campaign and the Benjamin A. Gillman Scholarship Program funded by the U.S. Department of State and administered by IIE that a need exists to diversify the 
U.S. student body participating in study abroad. Improving data collection for the participation of first-generation students and Pell grant recipients in study abroad would better help these organizations advocate the need for funding of these initiatives and better gauge the impact of their efforts on diversifying the study abroad population. It would also create opportunities for larger samples and more possibility of creating random sampling of first-generation and Pell grant recipients from which to draw richer information.

Results from this study demonstrate that investment in institutional support is effective for influencing the decision of first-generation students and Pell recipients to participate in study abroad. According to survey data, friend/significant others and former study abroad participants have a high degree of influence on the study abroad decision. As a result, institutions can benefit from employing undergraduate students to promote study abroad to TRiO-eligible students during the study abroad decision making process. For example, Amy was a research participant who also was employed in the Financial Aid Office at the research site. She was responsible for serving as a study abroad peer ambassador for students who came into the office to talk about how they could finance a study abroad experience. As Amy suggests for institutions:

So maybe even you can create a program. Or, um something where you can have students that have done it in the past. That have had those same feelings or those same thoughts just like me. And you know when you get that from a student to student it is going to be a lot more effective than when you get that from a staff member!

Creating these types of intentional interactions and supports for TRiO-eligible students could potentially better influence more students to decide to study abroad. 


\section{Recommendations for Future Research}

In addition to practical implications for collecting better data, better research focused on the needs of first-generation and Pell grant recipients in the study abroad process is needed. A recommendation would be to collaborate with other scholars at the national level to identify institutions that report the participation of TRiO-eligible students and utilize these sites for study. Another recommendation would be to reinitiate collaboration with the Institute for International Education and the Council for Opportunity in Education to conduct a more national study of TRiO students who participate in study abroad programs.

While previous research (Salsibury, Umbach, \& Pascarella, 2009) indicates community college students are less likely to intend to study abroad compared to students who attend other institutions, community colleges would be worth targeting, since these institutions have higher proportions of first-generation and Pell grant recipients. Research should also investigate if differences exist for TRiO-eligible students who attend different types of institutions.

While challenging, future research should also examine TRiO-eligible students who express interest in study abroad, but who ultimately do not participate. Many study abroad offices host study abroad information sessions and record those who participate. Adding fields such as first-generation and Pell grant status to these attendance records from study abroad information sessions would be a start to better identification of these students. Future research should compare results from TRiO-eligible students who express intent but decide not to study abroad, and those TRiO-eligible students who do decide to participate in study abroad. 
Another potential research opportunity would be to conduct a document analysis of student essays that are submitted as part of a scholarship application to the Benjamin A. Gilman Scholarship Program. These scholarships are submitted by students who qualify based on their verification of receiving a federal Pell grant, so these types of essays could provide rich data to researchers interested in studying what motivates them to participate in study abroad.

Results from the qualitative phase of this study demonstrate that TRiO-eligible students felt they benefited from the study abroad experience. Particularly, TRiO-eligible students felt that they grew in their knowledge of other cultures, as well as cultural competence. Participants viewed this as a skill that would make them more marketable to future employers compared to students who do not participate in study abroad. This deserves more attention from the research community from a critical lens. Limited research focuses on the negative aspects of the study abroad experience, particularly in qualitative research with participants. Much of what is written and shared is positive. This could be attributed to choice-supportive memory distortion, where individuals attribute more positive features to the option that they chose compared to other alternatives (Mather, Shafir, \& Johnson, 2000). Essentially, study abroad participants would speak highly about their experiences because they made the choice to study abroad and they assume it must have been the best choice.

Qualitative researchers investigating the study abroad experience should consider the influence of choice-supportive memory distortion on the narratives drawn from research participants. Future research should explore the assertion by the TRiO-eligible research participants in this study that the study abroad experience makes them more 
marketable to future employers. This could be accomplished through a future study focused on former study abroad participants who were TRiO-eligible, and who are a few years removed from the study abroad experience. Such a study should explore the neoliberal assumptions and messages that are used to promote study abroad.

\section{Conclusion}

Internationalizing the campus experience through study abroad has seen a growth in recent years through many different initiatives such as Generation Study Abroad, U.S. Department of State Benjamin A. Gilman International Scholarship, and the U.S. National Security Education Program at the national, state, and institutional level. The call to action from the Institute of International Education to almost double the U.S. study abroad population to 600,000 by the end of the decade and to diversify the population going has drawn considerable attention in higher education (IIE, 2015). The only way IIE will be successful in its campaign is to reach students from diverse backgrounds, including first-generation students, community college students, and Pell grant recipients to join in study abroad. If this study has done nothing else, it has drawn attention to the need for institutions to better track and collect the participation of first-generation and Pell grant recipients in the study abroad process. Further, this study provides guidance and suggestions for institutions to adjust practices to meet the needs of TRiO-eligible students.

This study provides evidence to institutions that institutional factors are more important in the decision making process for TRiO-eligible students than originally thought by previous research on this population. This study demonstrates that institutional investment into institutional factors, such as funding, awareness, and support 
of first-generation students, can be a worthy and effective investment to answer the call to diversify the study abroad population, particularly among first-generation and Pell grant recipients. 


\section{REFERENCES}

Amani, M. (2011). Study abroad decision and participation at community colleges: Influential factors and challenges from the voices of students and coordinators (Doctoral dissertation). Retrieved from ProQuest. (Order No. 3438831)

Andriano, B. R. (2010). Study abroad participation and engagement practices of firstgeneration undergraduate students coordinators (Doctoral dissertation). Retrieved from ProQuest (Order No. 3417953).

Bandyopadhyay, S., \& Bandyopadhyay, K. (2015). Factors Influencing Student Participation in College Study Abroad Programs. Journal of International Education Research, 11(2), 87-94.

Bellstrom, K. (2007). Back to school-abroad. Smart Money, 16(9), 123.

Booker, R. W. (2001). Differences between applicants and non-applicants relevant to the decision to apply to study abroad. Columbia, MO: University of Missouri.

Brustein, W. I. (2007). The global campus: Challenges and opportunities for higher education in North America. Journal of Studies in International Education, 11(34), 382 .

Bu, L. (2003). Making the world like us: Education, cultural expansion, and the American century. Westport, CT: Praeger.

Burkart, B., Hexter, H., \& Thompson, D. (2001). Why TRIO students need to study abroad. Washington, DC: Pell Institute.

Carter, H. M. (1991). Minority access to international education. In Black students and overseas programs: Broadening the base of participation (pp. 6-13). New York, NY: Council on International Educational Exchange.

College News. (2005): Bipartisan commission calls for sending one million college students abroad annually by 2017 . Retrieved from http: http://collegenews.org/news/2005/bipartisan-commission-calls-for-sending-onemillion-college-students-abroad-annually-by-2017.html

Commission on the Abraham Lincoln Study Abroad Fellowship Program. (2005, November). Global competence \& national needs: One million Americans studying abroad. Retrieved from https://www.nafsa.org/uploadedFiles/ NAFSA_Home/Resource_Library_Assets/CCB/Lincoln_commission_ report.pdf 
Comp, D. (2010). Germany as a study abroad destination of U.S. Students in the science, technology, engineering and mathematics (STEM) fields. Frontiers: The Interdisciplinary Journal of Study Abroad, 19, 191-203.

Cook-Anderson, G., \& Greenbaum, J. (2013, May). Proven approaches to handholding when advising first-generation study abroad students. Conference presentation at the NAFSA: Association of International Educators annual conference, St. Louis, MO. Retrieved from http://www.nafsa.org/Find_Resources/Supporting_Study_ Abroad/Proven_Approaches_to_Handholding_When_Advising_FirstGeneration_Study_Abroad_Students/

Council for Opportunity in Education (2010). What is TRIO? Retrieved from http://www.coenet.us/ecm/AM/Template.cfm?

Section=What_is_TRIO\&Template=/CM/HTMLDisplay.cfm\&ContentID $=7992$

Creswell, J. W. (2003). Research design: Qualitative, quantitative, and mixed methods approaches $\left(3^{\text {rd }} \mathrm{ed}\right)$. Thousand Oaks, CA: Sage.

Deardorff, D. K. (2004, Spring). Internationalization: In search of intercultural competence. International Educator, 13-15. Retrieved from: http://www.nafsa.org/_/file/_/in_search_of_intercultural.pdf

Department of Education. (2010). Federal TRIO Programs: 2009 annual low income levels. Retrieved from http://www2.ed.gov/about/offices/list/ope/trio/incomelevels.html

Dolby, N. (2004). Encountering an American self: Study abroad and national identity. Comparative Education Review, 48(2), 150.

Drexler, D. S. (2006). Student perceptions on self-development variables in selected community college study abroad programs: A quantitative study using Chickering's theory of student development. (Doctoral dissertation). Available from ProQuest Dissertations and Theses Database. (AAT 3248967).

Durbin, R. J. (2006, January-February). The Lincoln Commission and the future of study abroad. International Educator, 1, 4-6. Retrieved from http://www.nafsa.org/_/File/_/InternationalEducator/FrontlinesJanFeb.pdf

Engle, J., Bermeo, A., \& O'Brien, C. (2006, December). Straight from the Source: What works for first-generation college students. Washington, DC: The Pell Institute for the Study of Opportunity in Higher Education. Retrieved from http://www. Pellinstitute.org/downloads/publications_Straight_from_the_Source.pdf

Engle, J., Tinto, V., \& Pell Institute for the Study of Opportunity in Higher, E. (2008). Moving Beyond Access: College Success for Low-Income, First-Generation Students. Pell Institute for the Study of Opportunity in Higher Education. (Federal Student Aid, 2015). 
Fields, C. D. (2001, August 2). Go abroad, and save the excuses. Black issues in Higher Education. Retrieved from http://www.findartcles.com/cf_)m0DXK/12_18/77398872/print.jhtml

Fischer. (2008, November 21). For American students, study-abroad numbers continue to climb, but financial obstacles loom. The Chronicle of Higher Education, 55(13), A24.

Fischer. (2010). University of Minnesota integrates study abroad into the curriculum. The Chronicle of Higher Education, retrieved: March 28, 2010. http://chronicle.com.proxy.lib.ilstu.edu/article/U-of-Minnesota-Integrates-/64859/

Fishbein, M., \& Ajzen, I. (1975). Belief, attitude, intention, and behavior: An introduction to theory and research. Reading, MA: Addison-wesley Publishing.

Geiger, R. L. (2000). The American College in the Nineteenth Century. Vanderbilt Issues in Higher Education. Nashville, TN; Vanderbilt University Press.

Giroux, H. A. (2009). Neoliberalism, youth, and the leasing of higher education. In D. hill \& R. Kumar (Eds.), global neoliberalism and education and its consequences (pp. 30-53). New York, NY: Routledge.

Giroux, H. A. (2002). Neoliberalism, corporate culture, and the promise of higher education: Theuniversity as a democratic public sphere. Harvard Educational Review, 72(4), 425-464.

Gregor, K. (2009). The design of a study abroad model to improve student understanding of different cultures. (Doctoral dissertation). Available from ProQuest Dissertations and Theses Database. (AAT 3360228).

Goucher College. (2015). Study Abroad. http://www.goucher.edu/study-abroad

Harvey, D. (2007). A brief history of neoliberalism. New York: Oxford University Press.

Hatton. (1995). Internationalizing the community college. Community College Journal of Research and Practice, 19(5), 453.

Heilbron, J. L. (2003). The Oxford companion to the history of modern science. Oxford: Oxford University Press.

IFSA-Butler First Generation College Student Program. (n.d.). Retrieved March 21, 2016, from http://www.ifsa-butler.org/first-generation-scholar-program.html

Institute for Study Abroad, Butler University. (n.d.) Bibliography: Selected readings on engaging first generation college students in study abroad. Retrieved from http://www.nafsa.org/uploadedFiles/Chez_NAFSA/Find_Resources/Supporting_ Education_Abroad/IFSABibliography.pdf 
Institute of International Education. (1957). Open Doors 1957. New York: Institute of International Education. Retrieved from http://www.library.ohiou.edu/hosted/opendoors/pdfs/007/0004.pdf

Institute of International Education. (2012) Open Doors 2012 "Fast Facts". Retrieved from http://www.iie.org/Research-and-Publications/Open-Doors/Data/Fast-Facts

Institute of International Education. (2013) Open Doors 2013 "Fast Facts". Retrieved from http://www.iie.org/Research-and-Publications/Open-Doors/Data/Fast-Facts

Institute of International Education. (2015). Generation Study Abroad: About the initiative. Retrieved June 12, 2015 from http://www.iie.org/Programs/GenerationStudy-Abroad/About

Indiana University. (2011) Overseas study programs by major. Retrieved from http://www.indiana.edu/ overseas/programs/majors/index.shtml

International Student Exchange Program. (2015) Our Story. Retrieved from http://www.isep.org/About_ISEP/who_we_are.asp.

Jackson, M. (2006). Traveling shoes: Study abroad experience of African American students participating in California State University international programs. Unpublished doctoral dissertation, University of San Francisco, San Francisco.

Kasravi, J. (2009). Factors influencing the decision to study abroad for students of color: Moving beyond the barriers. Unpublished doctoral dissertation, University of Minnesota, St. Paul, MN.

Kotz, D. M. (2015). The rise and fall of neoliberalism capitalism. Cambridge, MA: Harvard University Press.

Lindsey, E. W. (2005). Study abroad and values development in social work students. Journal of Social Work Education, 41(2), 229-249.

Llanes, A. \& Munoz, C. (2009). A short stay abroad: Does it make a difference? System, 37(3), 353-365.

Mather, M., Shafir, E., \& Johnson, M. K. (2000). Misrememberance of options past: Source monitoring and choice (PDF). Psychological Science, 11(2), 132-138. doi:10.1111/1467-

Martinez, M. D., Ranjeet, B., \& Marx, H. A. (2009). Creating study abroad opportunities for first-generation college students. In R. Lewin (Ed.), The Handbook of Practice and Research in Study Abroad: Higher Education and the Quest for Global Citizenship (pp. 527-542). New York, NY: Routledge.

Merriam, S. (2009). Qualitative Research: A guide to design and implementation (rev.). San Francisco, CA: Jossey-Bass. 
NAFSA: Association of International Educators. (2006). Facts \& figures:

Underrepresented Students Abroad. Retrieved from

http://www.nafsa.org/resourcelibrary/default.aspx?id=8355

NAFSA: Association of International Educators. (2011). Internationalizing the campus 2011: Profiles of success at colleges and universities. Author. Retrieved from http://www.nafsa.org/_/File/_/itc2011.pdf

NAFSA: Association of International Educators. (n.d.). Resources for supporting diversity in education abroad. Retrieved from http://www.nafsa.org/Find_Resources/Supporting_ Study_Abroad/Resources_for_Supporting_Diversity_in_Education_Abroad/

National Center of Education Statistics. (2012). http://nces.ed.gov/collegenavigator

National Center of Education Statistics. (2013). https://nces.ed.gov/programs/digest/d14/tables/dt14_306.10.asp

National Survey of Student Engagement. (2007). Experiences that matter: Enhancing student learning and success, annual report 2007. Retrieved from http://nsse.indiana.edu/NSSE_2007_Annual_Report/docs/withhold/NSSE_2007_ Annual_Report.pdf

Niser, J. (2010). Study abroad education in New England higher education: A pilot survey. International Journal of Educational Management, 24(1) 48.

Norfles, N. (2007, May). What we know about diversity in education abroad: Obstacles and opportunities. In C. A. Herrin, S. Dadzie, \& S.A. MacDonald (Eds.), The Proceedings for the Colloquium on Diversity in Education Abroad: How to Change the Picture (pp. 54-59). Washington, DC: Academy for Educational Development.

Office of Postsecondary Education, U.S. Department of Education. (2015a).

Office of Postsecondary Education, U.S. Department of Education. (2015b).

Opper, S., Teichler, U., \& Carlson, J. (1990). Impacts of study abroad programmes on students and graduates (Vol. 2). London: Jessica Kingsley Publishers.

Pascarella, E. T., Pierson, C. T., Wolniak, G. C., \& Terenzini, P. T. (2004). First generation college students. Journal of Higher Education, 75(3), 249-284.

Pappano, L. (2007, November 4). The Foreign Legions. The New York Times. Retrieved from http://www.nytimes.com/2007/11/04/education/edlife/studyabroad.html?pagewan ted=all\&_r $=0$ 
Peterson, D. L. (2003). The decision to study abroad: Contributing factors and implications for communication strategies. (Doctoral dissertation). Available from ProQuest Dissertations and Theses Database. (AAT 3092192).

Rockefeller Foundation. http://www.rockefellerfoundation.org/uploads/files/56d00f7ed624-4375-a84e-e913f38ccdf9-1962.pdf

Saenz, V.B., Hurtado, S., Barrera, D., Wolf, D., \& Yeung, F. (2007) First in my family: A profile of first-generation college students at four-year institutions since 1971. Los Angeles: Higher Education Research Institute, UCLA Graduate School of Education \& Information Studies.

Schlor, W. (2006). Access in international education: A study on minority participation. In C. A. Herrin, S. Dadzie, \& S. A. MacDonald (Eds.), The Proceedings for the Colloquium on Diversity in Education Abroad: How to Change the Picture (pp. 60-65). Washington, DC: Academy for Educational Development.

Schroth, M., \& McCormack, W. A. (2000). Sensation seeking and need for achievement among study-abroad students. Journal of Social Psychology, 140(4), 533-535.

Shirley, S. W. (2006). The gender gap in post-secondary study abroad: Understanding and marketing to male students. (Doctoral dissertation). Available from ProQuest Dissertations and Theses Database. (AAT 3233968).

Stuart, R. (2007). Stepping up to study abroad. Diverse Issues in Higher Education, 24(19), 16.

Syed \& Tolan. (2013). Engaging first-generation college students in study abroad. Retrieved from http://world.utexas.edu/io/forms/abroad/globalaccess/session-2first-generation.pdf

Teague, J. T. (2007). Democratizing access to study abroad. Community College Journal, 77(4), 26-29.

Tillman, M. (2010). Diversity in international education-A hands-on workshop: Summary report and data from the workshop held on September 21, 2010. Stamford, CT: American Institute for Foreign Study (AIFS). Retrieved from http://www.aifsabroad.com/advisors/pdf/diversity_workshop_summary.pdf

Thomas, C. (2001). Study abroad for minorities: African American, Hispanic, Asian, and Native American students return from overseas with glowing tales. Retrieved from http://www.petersons.com/stdyabrd/abroad7.html

Twombly, S. B., Salisbury, M. H., Tumanut, S. D., \& Klute, P. (2012). Study abroad in a new global century: Renewing the promise, refining the purpose. Hoboken, NJ: Wiley Periodicals, Inc. 
TRiO Legislation and Regulations. (2011).

Walker, S., Bukenya, J. O., \& Thomas, T. (2010, February). Examining students' perceptions of globalization and study abroad programs at HBCUs. Paper presented at the Southern Agricultural Economics Association Annual Meeting, Orlando, FL.

Wynkoop, M. A. (2002). Dissent in the heartland: The sixties at Indiana University. Bloomington, IN: Indiana University Press.

Vogt, W. Paul. (2007) Quantitative research methods for professionals. Boston, MA: Pearson.

Vogt, P. W., Vogt, E. R., Gardner, D.C., \& Haeffele, L. M. (2014). Selecting the right analyses for your data: Quantitative, qualitative, and mixed methods. New York: McMillan. 


\section{APPENDIX A}

\section{ONLINE SURVEY}

RESEARCH PARTICIPANT CONSENT FORM for Online Survey TRiO-Eligible Students \& Study Abroad: Influential Factors, Barriers, and Benefits IRB Protocol \#1504016024

Principal Investigator: Dr. Programs/Director of Study Abroad University

Co-Principal Investigator: Mike Minton/PhD. Student Illinois State University

What is the purpose of this study?

The purpose of this research project is to gain a better understanding of the personal, social, and institutional factors that influence students in their decision to study abroad. Additionally, barriers and benefits of participation of study abroad are examined.

What will I do if I choose to be in this study?

You will complete an online survey containing 32 questions that explore the social, personal, and institutional factors that influence the choice of students to participate in study abroad programs.

How long will I be in the study?

The online survey will take $\mathbf{1 0 - 1 5}$ minutes to complete.

What are the possible risks or discomforts?

The risks associated with this research study are minimal. The only foreseeable risk would be tying the identity of the research participant with their responses. To minimize this, the survey results will be collected in an anonymous manner in which responses are not traceable to people completing the survey.

Are there any potential benefits?

This research has the potential to enhance study abroad programs at your university. Ultimately, the research may help encouraging first-generation and Pell Grant recipients to participate in study abroad. You may also benefit from answering the questions forcing you to reflect on the study abroad experience.

Will I receive payment or other incentive?

Individuals who choose to take the online survey wlll have the opportunity to register to enter their name into a drawing for 1 of 4 Jimmy John's Gift Cards valued at $\$ 25$ each. The drawing will occur after the conclusion of data collection for the online survey. Winners will be notified via email and individuals who register for the drawing will receive an email invitation to participate in a focus group.

\section{Conflict of Interest Disclosure}

Principal Investigator

and Associate Dean of Students not be able to associate you with your survey responses. The following disclosure is made

to give you an opportunity to decide if this relationship will affect your willingness to participate in the research study.

Will information about me and my participation be kept confidential? The project's research records may be reviewed by departments at Purdue University responsible for regulatory and research oversight. Your survey responses will not be traceable to you and will only reported in aggregate form. The only record this study will maintain that could be tied to your identity is your email address that will be entered at the end of the survey. This information will be kept on a flash drive that will be stored in a locked desk drawer within the locked office of the CO-Prineipal Investigator. 
What are my rights if $\mathbf{I}$ take part in this study?

Your participation in this study is voluntary. You may choose not to participate or, if you agree to participate, you can withdraw your participation at any time without penalty or loss of benefits to which you are otherwise entitled.

Who can I contact if I have questions about the study?

If you have questions, comments or concerns about this research project, you can talk to one of the researchers. Please first contact the CO-Principal Investigator Mike Minton or the Principal Investigator Dr.

If you have questions about your rights while taking part in the study or have concerns about the treatment of research participants, please call the Human Research Protection Program at mail (irb@ write to: Human Research Protection Program

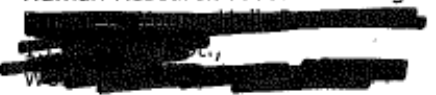

Documentation of Informed Consent

I have had the opportunity to read this consent form and have the research study explained. I have had the opportunity to ask questions about the research study, and my questions have been answered. I am prepared to participate in the research study described above. I acknowledge that I am 18 years of age or older and legally have the ability to offer my consent.

Clicking on NEXT button $(>>)$ below will indicate that you understand this information and the conditions of the research and have voluntarily agreed to participate in this survey.

Page 2

\section{Have you ever received a Federal Pell Grant to pay for your education at \\ Ores ONo}

2. Are you a first-generation college student? (Meaning neither of your natural or adoptive parents graduated with a baccalaureate (4-year) college degree?) ${ }^{+}$

ONO = Not a first-generation student one or more parents HAVE a 4-year degree

OYes $=$ first-generation student neither parents have a 4-year degree

3. Have you ever participated in a study abroad program? *

OYes

ONo

4. What is your biological or adoptive mother's highest level of education? -- None --

5. What is your biological or adoptive father's highest level of education? - None $\checkmark$

6. What is your gender?

OFemale

OMale 
7. What is your ethnic background?

O Not Hispanic or Latino

OHispanic or Latino

8. Please indicate your racial identity by selecting all that apply regardless of ethnicity status selected above.

OAmerican Indlan or Alaska Native

OAsian

OBlack or African American

ONative Hawalian or Other Pacific Islander

OWhite

OTwo or more races

9. Please indicate your citizenship status

OU.S. citizen

O Naturalized U.S. citizen

OPermanent resident

ONot a U.S. citizen

10. Have you previously traveled to another country before participating in study abroad?

OYes

ONo

11. Have you lived in another country before participating in study abroad?

Ores

ONo

12. How do you currently pay for school? (Please select all that apply)

$\square$ Scholarships

$\square$ Federal loans

$\square$ Private loans

$\square$ Federal grants (Pell Grant)

$\square$ state Grants

$\square$ Private grants

$\square$ Personal funds

$\square$ Working while going to school

$\square$ Family support 
What type of funding did you use to fund your study abroad program? (Please select all that apply)

$\square$ Scholarships offered by

$\square$ Federal loans

$\square$ Private loans

$\square$ Federal grants (Pell Grant)

$\square$ State Grants

$\square$ Private grants

$\square$ Personal funds

$\square$ Family support

14. What is your annual family income?

-- None - $\quad \checkmark$

15. Which of the thirteen University colleges are you enrolled in? - None -. $\checkmark$

16. What is your current year in college?

OFreshman

OSophomore

OJunior

OSenior

ORecent graduate of

17. What is your current major(s)? (No text limit)

18. What is your current overall GPA?

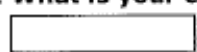

19. Please select your appropriate age range 18-24

20. Where did you participate in study abroad? (Please fill in city and country. If more than one, please list them all)

City

Country

21. How long was your study abroad program? - None - . 


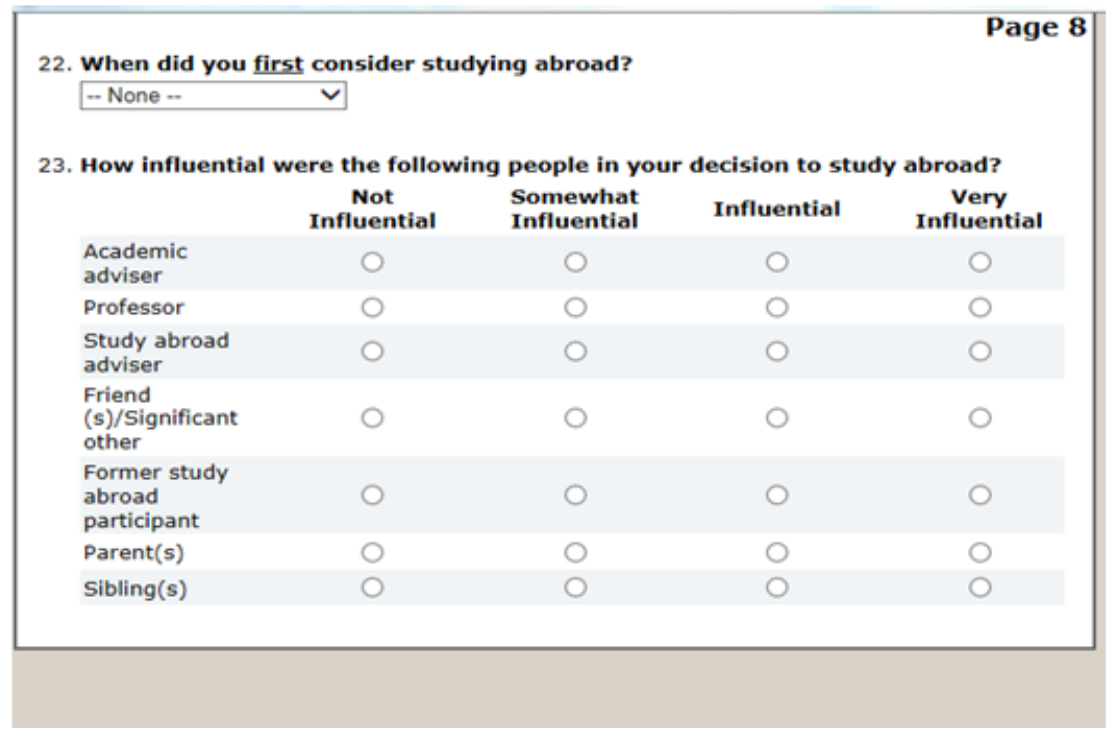

24. How did you first hear about the specific study abroad program that you participated in?

(Please select all that apply)

$\square$ Academic adviser

Student Support Services, or other programs for first-generation students and Pell Grant recipients

$\square$ Study abroad adviser

$\square$ Professor

$\square$ Study abroad fair

$\square$ Former student who went abroad

$\square$ Family member

$\square$ Emall

$\square$ Printed poster or flier

$\square$ study abroad website

$\square$ Study abroad information table

$\square$ Classroom presentation

$\square$ Friend/Significant other

25. Do you actively participate in any of the following programs at University?

(Please select all that apply)

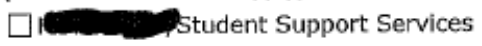

$\square$ The Purdue Promise Program

$\square$ Emerging Urban Leaders

$\square$ Purdue Opportunity Award Scholars

$\square$ Science Bound

$\square$ I do NOT actively participate in any of the above programs 
26. To what extent do you agree or disagree with the following statements?

Information on study abroad programs

Strongly

Disagree

Disagree Agree

Strongly

and opportunities is readily available to

students

The types and number of study abroad programs offered through are good

Eligibility requirements for the study abroad programs are not strict

offers good sources of funding for students wanting to study abroad ancourages international experiences such as study abroad for students such as myself

I felt comfortable talking to the study abroad adviser about my study abroad options, concerns, and needs

I felt comfortable talking to my academic adviser about my study abroad options, concerns, and needs I felt comfortable talking to my professors about my study abroad options, concerns, and needs

Overall, as a first-generation college student or Pell grant recipient, I felt that my needs and concerns were met in discussion of study abroad.

$\begin{array}{cccc}0 & 0 & 0 & 0 \\ 0 & 0 & 0 & 0 \\ 0 & 0 & 0 & 0 \\ 0 & 0 & 0 & 0 \\ 0 & 0 & 0 & 0 \\ 0 & 0 & 0 & 0 \\ 0 & 0 & 0 & 0 \\ 0 & 0 & 0 & 0 \\ 0 & 0 & 0 & 0\end{array}$


27. How important were the following factors in your decision to choose your specific study abroad program?

\begin{tabular}{|c|c|c|c|c|}
\hline & $\begin{array}{c}\text { Not } \\
\text { Important }\end{array}$ & $\begin{array}{l}\text { Slightly } \\
\text { Important }\end{array}$ & Important & $\begin{array}{c}\text { Very } \\
\text { Important }\end{array}$ \\
\hline Program cost & 0 & 0 & 0 & 0 \\
\hline Duration of the program & $\bigcirc$ & $\mathrm{O}$ & $\mathrm{O}$ & 0 \\
\hline Language of study & 0 & 0 & 0 & 0 \\
\hline Size of city/town & $\mathrm{O}$ & $\mathrm{O}$ & 0 & O \\
\hline Country of program & $\mathrm{O}$ & 0 & 0 & 0 \\
\hline Parent(s)/family influence & $\bigcirc$ & $\bigcirc$ & $\bigcirc$ & $\bigcirc$ \\
\hline Transferability of credits & $\mathrm{O}$ & 0 & 0 & 0 \\
\hline $\begin{array}{l}\text { Interest in course work } \\
\text { available }\end{array}$ & O & O & $\bigcirc$ & O \\
\hline $\begin{array}{l}\text { Exploring my own } \\
\text { heritage/cultural roots }\end{array}$ & $\mathrm{O}$ & O & O & $\mathrm{O}$ \\
\hline $\begin{array}{l}\text { Internship/volunteer work } \\
\text { options with program }\end{array}$ & O & $\bigcirc$ & $\bigcirc$ & 0 \\
\hline Living with a host family & $\mathrm{O}$ & $\mathrm{O}$ & $\mathrm{O}$ & $\mathrm{O}$ \\
\hline Living in an apartment & O & 0 & 0 & $\mathrm{O}$ \\
\hline $\begin{array}{l}\text { Taking classes at host } \\
\text { university }\end{array}$ & $\mathrm{O}$ & 0 & O & $\mathrm{O}$ \\
\hline $\begin{array}{l}\text { Level of integration into host } \\
\text { culture }\end{array}$ & $\bigcirc$ & $\bigcirc$ & O & 0 \\
\hline
\end{tabular}

28. Reflecting back on your decision to study abroad, how influential were the following perceived outcomes in making that decision?

Not Somewhat Influential Influential

Influential $\begin{gathered}\text { Very } \\ \text { Influential }\end{gathered}$

Fulfill elective

requirements

$\begin{array}{ll}0 & 0 \\ 0 & 0 \\ 0 & 0\end{array}$

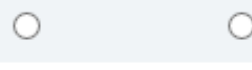

Fulfill major requirements

Learn/improve a foreign

language

Learn about my own

cultural roots

Learn about myself

Make friends from other countries tries

Learn about another culture

Make me more

marketable to future employers

Increase my critical

thinking skills

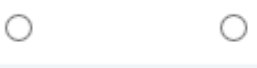

O

Help me professionally in a globalized world

Increase my

independence

$\begin{array}{ll}\mathrm{O} & 0 \\ \mathrm{O} & \mathrm{O}\end{array}$

O

O
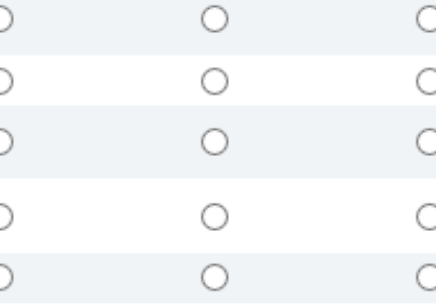
29. To what extent do you agree or disagree with the following statements?

Strongly Disagree Agree $\begin{gathered}\text { Strongly } \\ \text { Agree }\end{gathered}$
Disagree

I did NOT have a difficult time meeting the eligibility requirements for admission to

$\bigcirc$

I did NOT have a difficult time adjusting to the academic rigor of courses on the campus

Overall, I did NOT have a difficult time adjusting academically to being at a four-year institution

Overall, i did NOT have a difficult time adjusting socially to being at a fouryear institution

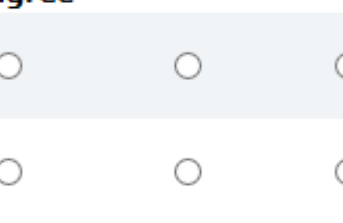

$\mathrm{O}$

○
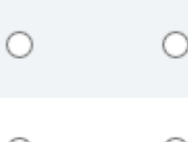

(1)

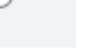

(2)

(1)

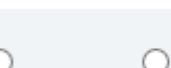

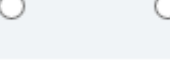

(1) 


\section{APPENDIX B \\ FOCUS GROUP PROTOCOL AND INTERVIEW QUESTIONS}

Recruitment: Those individuals who registered for the drawing will receive an email from the CO-PI Minton, inviting them to participate in a focus group consisting of 8-15 individuals. Interested individuals will contact the CO-PI Minton for details on focus group location and time. The recruitment email will also offer compensation of $\$ 10$ in cash for their participation in the focus group.

Selection: The first 15 students who respond to the recruitment email, and can confirm their ability to make the focus group time and location will be selected for the focus group.

\section{Protocol:}

- Students who decide to participate in the focus group will be asked a variety of questions related to the factors that influenced their decision to study abroad, barriers that almost affected their participation in a study abroad program, and how they benefited from the study abroad experience. The questions and protocol follow those outlined in Kasravi's (2009) study for students of color in study abroad. Kasravi has granted permission to CO-PI Minton to utilize this format.

- This focus group will take approximately 45-60 minutes.

\section{Introductions and Informed Consent Process}

- Participants will be provided with an informed consent document highlighting the voluntary nature of the study, and asking for their permission to be audio taped before the focus group begins.

- Participants will create a pseudonym and write it on a sticky name tag to be worn during the focus group. Participants will be referred to by their pseudonym before an ice breaker activity and before audio taping begins.

- Participants take part in an icebreaker activity called name tag switch. Participants will be asked to say their pseudonym, the country they studied abroad in, and their favorite food they had while abroad. After sharing this information, participants give their name tag to someone else, and try to repeat the information to the next person.

\section{Reasons for Study Abroad}

- Participants will be asked to think of the top three reasons why they chose to participate in a study abroad program and to jot those down on paper provided to them.

- CO-PI: Let's go around the room and share with each other who you wrote down. I will write your responses on the flip chart. Please keep in mind we will revisit this information later. 


\section{Institutional Factors}

- CO-PI: I want you all to think about the sources of information and support at Midwest University about studying abroad. Please think about some of the steps you took in getting information about study abroad.

- Where did you primarily receive this information from? The study abroad office? Academic advisors? Faculty members? The study abroad office? Somewhere else at Midwest U?

- Were the study abroad staff, university advisors, or faculty members helpful talking about your concerns regarding study abroad?

- Do you think Midwest $U$ provides adequate information about study abroad?

- Do you think Midwest $U$ offers adequate financial support and funding for studying abroad?

- How did you hear about funding opportunities for study abroad at Midwest U?

\section{Barriers}

- Please reflect on the moment you first thought about doing study abroad. Please jot down three barriers or apprehensions that you had about deciding whether or not go abroad.

- Thank you, now let's go around the room and share what you wrote. I will write down the responses on the flip chart.

- Please look at the flip chart, which barrier stands out the most and is the most significant in describing what you were experiencing during the time you first considered going abroad..

- Why did you choose this barrier? How did you overcome this to study abroad?

- Research is not clear on the number of first-generation and Pell Grant recipients that study abroad. If it is consistent with students of color, participation remains low. If also consistent, the cost of going abroad is a major barrier. Did you experience this barrier, and if yes, why did you decide to participate despite the price tag of going abroad?

- How did your family react to your decision to study abroad? Were they supportive, helpful, or doubtful?

\section{Summary of Influencing Factors}

- Now think back to the main reasons of why you chose to participate in study abroad, and all that we have discussed in this session. Are there any other main reasons, or factors that come to mind about what INFLUENCED you in your decision to study abroad?

- Is there anything you would like to add, or anything that you think I should have asked? 


\section{APPENDIX C INDIVIDUAL INTERVIEW QUESTIONS}

1. Did either of your parents earn a bachelor's degree?

2. Did/do you receive a Federal Pell Grant?

3. Where did you study abroad?

4. What factors influenced your decision to study abroad?

5. Were there any individuals that motivated you to study abroad?

6. How supportive was your family of your decision to study abroad?

7. What barriers existed to your decision to study abroad?

8. Can you think of any other barriers that existed for you?

9. How did the study abroad experience impact you?

10. What would you tell other individuals about the decision to study abroad?

11. What would you want staff at colleges and universities to know about the decision process of students who desire to study abroad? 